\title{
Sleep and vital exhaustion : their relationship with cardiovascular disease
}

Citation for published version (APA):

van Diest, R. (1993). Sleep and vital exhaustion : their relationship with cardiovascular disease. [Doctoral Thesis, Maastricht University]. Rijksuniversiteit Limburg. https://doi.org/10.26481/dis.19930923rd

Document status and date:

Published: 01/01/1993

DOI:

10.26481/dis.19930923rd

Document Version:

Publisher's PDF, also known as Version of record

\section{Please check the document version of this publication:}

- A submitted manuscript is the version of the article upon submission and before peer-review. There can be important differences between the submitted version and the official published version of record.

People interested in the research are advised to contact the author for the final version of the publication, or visit the DOI to the publisher's website.

- The final author version and the galley proof are versions of the publication after peer review.

- The final published version features the final layout of the paper including the volume, issue and page numbers.

Link to publication

\footnotetext{
General rights rights.

- You may freely distribute the URL identifying the publication in the public portal. please follow below link for the End User Agreement:

www.umlib.nl/taverne-license

Take down policy

If you believe that this document breaches copyright please contact us at:

repository@maastrichtuniversity.nl

providing details and we will investigate your claim.
}

Copyright and moral rights for the publications made accessible in the public portal are retained by the authors and/or other copyright owners and it is a condition of accessing publications that users recognise and abide by the legal requirements associated with these

- Users may download and print one copy of any publication from the public portal for the purpose of private study or research.

- You may not further distribute the material or use it for any profit-making activity or commercial gain

If the publication is distributed under the terms of Article $25 \mathrm{fa}$ of the Dutch Copyright Act, indicated by the "Taverne" license above, 


\section{SLEEP AND VITAL EXHAUSTION}

Their relationship with cardiovascular disease 


\title{
SLEEP AND VITAL EXHAUSTION
}

\author{
Their relationship with cardiovascular disease
}

PROEFSCHRIFT

ter verkrijging van de graad van doctor

aan de Rijksuniversiteit Limburg te Maastricht, op gezag van de Rector Magnificus, Prof. Mr. M.J. Cohen, volgens het besluit van het College van Dekanen, in het openbaar te verdedigen op donderdag, 23 september 1993 om 16.00 uur

door

Robert van Diest

geboren op 1 januari 1951 te Haarlem 


\section{Promotores:}

Prof. dr. A.P.W.M. Appels

Prof. dr. M.M.W. Richartz

\section{Beoordelingscommissie:}

Prof. dr. M.A. van den Hout (voorzitter)

Dr. A.C. Declerck (Epilepsiecentrum 'Kempenhaeghe')

Dr. A.P.M. Gorgels

Prof. dr. E.C. Klip (Rijksuniversiteit Groningen)

Prof. dr. M.W. de Vries

\section{CIP-DATA KONINKLIJKE BIBLIOTHEEK, DEN HAAG}

Diest, Rob van

Sleep and vital exhaustion: their relationship with cardiovascular disease /

Rob van Diest. -Maastricht: [ill. by the author].

Thesis Maastricht. -With ref. -With summary in Dutch.

ISBN 90-9006293-9

NUGI 745

Subject headings: sleep / psychological risk factors /

cardiovascular disorders

Financial support by the Netherlands Heart Foundation for the publication of this thesis is gratefully acknowlegded. 


\section{CONTENTS}

Summary

Samenvatting

9

Chapter 1 General Introduction

Chapter 2 The Sleep-Wake Experience List

Chapter 3 Subjective Sleep Characteristics as Coronary Risk Factors, their association with Type A Behaviour and Vital Exhaustion 35

Chapter 4 Vital Exhaustion and Depression: a Conceptual Study

Chapter 5 Vital Exhaustion and Perception of Sleep

Chapter 6 Sleep Physiological Characteristics of Exhausted Males

Chapter 7 General Discussion

Appendices

Dankwoord

Curriculum Vitae 


\section{SUMMARY}

This thesis explores two potential risk indicators for myocardial infarction (MI): disturbed sleep and a state of vital exhaustion (VE). In chapter 1, a general background is given for the studies to be presented in this thesis. In chapter 2, the development and validation is described of the Sleep-Wake Experience List (SWEL), a questionnaire for the detection of six distinct types of sleep complaints. The results showed that the quality of the SWEL as a screening instrument ranges from $52.3-90.3 \%$. The quality of this questionnaire as a diagnostic and prognostic instrument ranges from 51.1-78.0\%. In chapter 3, the question is raised whether an association of VE with these sleep complaints, habitual sleep durations, napping, and snoring is confounded by the Type A coronary prone behaviour pattern (TABP) and vice-versa. It appeared that exhausted subjects report sleep problems, a short habitual sleep, and frequent napping significantly more often than nonexhausted subjects. TABP did not confound these associations. This suggests that these various subjective sleep characteristics can be understood as risk indicators for MI by their association with VE. Some caution for this conclusion is required, however, because VE shares a number of symptoms with depression, a condition that is closely tied to a disturbed sleep. In chapter 4, therefore, a study is presented that explored whether VE is characterized by a depressed mood or by a loss of vigour and excess fatigue. The results indicated that depression is not a likely reason for exhausted subjects to complain about their sleep because the key symptom for depressive disorders, a depressed mood, is not among the major characteristics of VE. Chapter 5 focusses on a possible discrepancy in the perception of the habitual quality and current night quality of sleep. It appeared that exhausted subjects perceive both their habitual and their current sleep as more disturbed than non-exhausted subjects. The results further suggested that exhausted subjects do not base their sleep quality entirely upon time spent asleep or upon the length of nocturnal wake times. In chapter 6 , we hypothesized that the sleep of exhausted subjects is characterized by a relative absence of slow wave sleep (SWS). To test this hypothesis, all-night sleep recordings of exhausted and nonexhausted subjects were analyzed visually, by an automatic system, and by spectral analysis. It appeared that EEG-derived awake times of exhausted subjects were not significantly different from those of non-exhausted subjects. However, both visual and spectral analysis of sleep converged to the conclusion that the sleep of exhausted subjects is characterized by a reduced SWS. Chapter 7 concludes the thesis by presenting a review of the findings and a discussion of their implications for the study of sleep, vital exhaustion and future MI. 



\section{SAMENVATTING}

Dit proefschrift beschrijft een onderzoek naar twee potentiële risico indicatoren voor een myocard infarct (MI): gestoorde slaap en een toestand van vitale uitputting (VU). In hoofdstuk 1 wordt een algemene achtergrond gegeven voor de te beschrijven studies. Hoofdstuk 2 beschrijft de ontwikkeling en validering van de Slaap-Waak Ervaring Lijst (SWEL) ter meting van zes typen slaapklachten. Het bleek dat de kwaliteit van de SWEL als screening instrument varieerde tussen 52.390.3\%. De kwaliteit van deze lijst met betrekking tot diagnostiek en prognose varieerde tussen 51.1-78.0\%. In hoofdstuk 3 wordt onderzocht of het Type A gedrag (TABP) een confounder is voor een associatie tussen VU en deze slaapklachten, habituele slaapduur, dutjes en snurken en vice-versa. Uitgeputten bleken significant vaker slaapproblemen, een korte habituele slaapduur en dutjes te rapporteren dan niet-uitgeputten. TABP bleek geen confounder voor deze samenhangen te zijn. Dit suggereert dat deze subjectieve slaapkenmerken begrepen kunnen worden als risico indicatoren voor MI vanwege hun samenhang met VU. Enige terughoudendheid aangaande deze conclusie is echter geboden, daar VU een aantal symptomen gemeen heeft met depressie, een conditie welke nauw samenhangt met gestoorde slaap. In hoofdstuk 4 wordt derhalve onderzocht of VU gekenmerkt is door een gedeprimeerde stemming of door een verlies aan levenslust en overmatige vermoeidheid. Depressie bleek niet aannemelijk te zijn als reden voor uitgeputten om over hun slaap te klagen daar het kernsymptoom voor een depressieve stoornis, een gedeprimeerde stemming, niet tot de belangrijke kenmerken van VU behoort. Hoofdstuk 5 richt zich op de mogelijke discrepantie in de waarneming van de habituele en huidige nacht slaapkwaliteit. Het bleek dat uitgeputte subjecten zowel hun habituele als hun huidige nacht slaap als meer gestoord ervaren dan niet-uitgeputten. De resultaten suggereerden tevens dat uitgeputte subjecten hun slaapkwaliteit niet uitsluitend baseren op de tijd die geslapen is of op de dur van nachtelijke waaktijden. In hoofdstuk 6 wordt de hypothese getoetst dat de slaap van uitgeputten gekenmerkt wordt door een relatieve afwezigheid van "slow wave sleep (SWS)". Hiertoe zijn nachtelijke slaapregistraties van uitgeputte- en niet uitgeputte subjecten visueel, met behulp van een geautomatiseerd systeem en via spectraal analyse onderzocht. De op het EEG gebaseerde waaktijden van uitgeputten bleken niet significant te verschillen van die van niet-uitgeputten. Echter, visuele- en spectraal analyse lieten zien dat de slaap van uitgeputte subjecten gekarakteriseerd wordt door een relatieve afwezigheid van SWS. In hoofdstuk 7 , tenslotte, wordt een overzicht gegeven van de huidige bevindingen alsmede een discussie met betrekking tot hun implicaties voor het onderzoek naar slaap, vitale uitputting en toekomstige MI. 


\section{VA7 THWYATHE?}

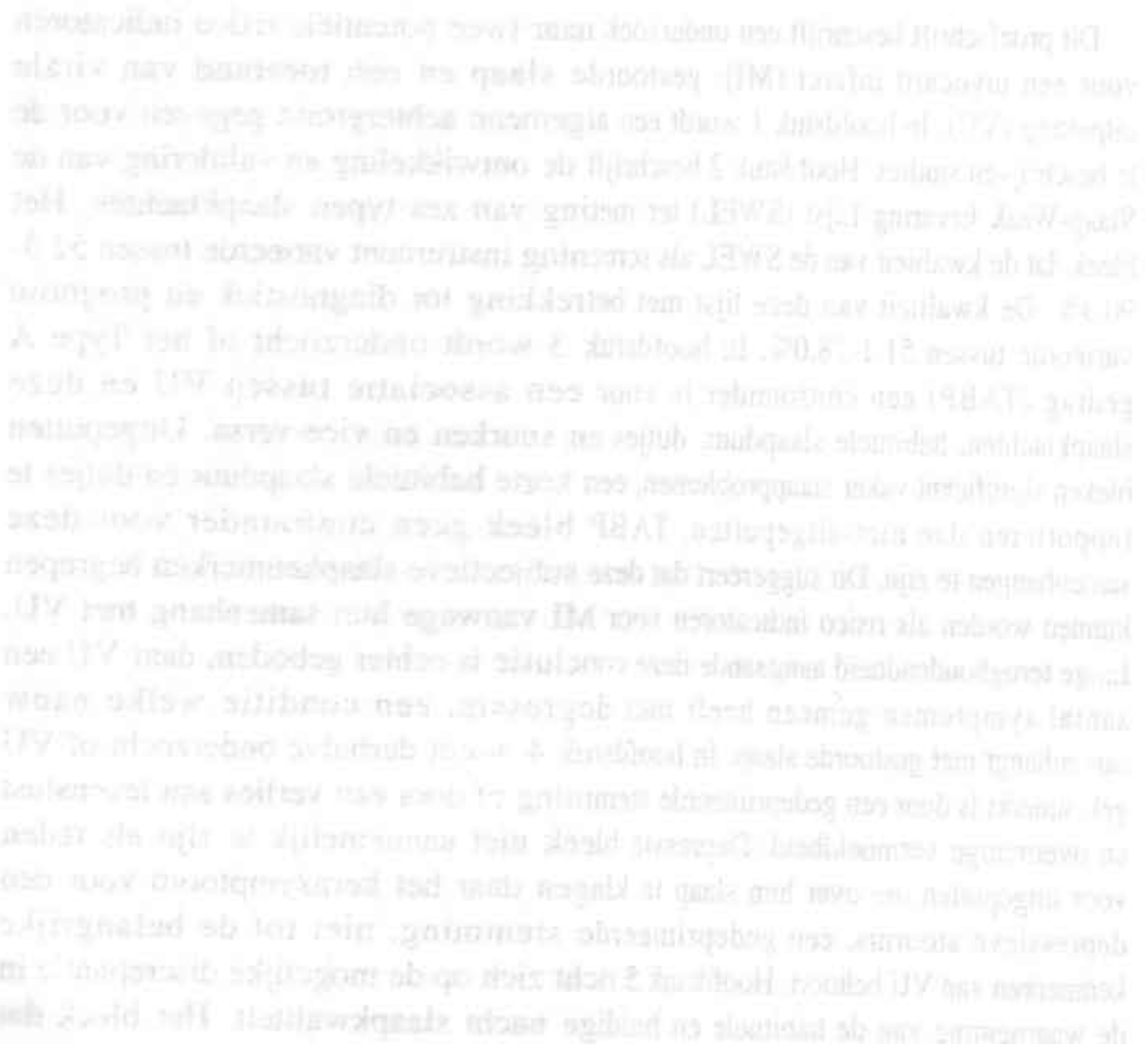




\section{GENERAL INTRODUCTION}

This thesis explores two phenomena that have been described as risk indicators of myocardial infarction: disturbed sleep and a state of vital exhaustion.

\section{Sleep}

Various studies have provided evidence that sleep complaints (difficulty falling asleep, frequent nocturnal awakenings, early morning awakenings, fatigue on final waking), heavy snoring, sleep durations that deviate from the usual $7-8 \mathrm{~h}$ of sleep, and daytime naps are potential risk indicators for future myocardial infarction (MI) [1-12]. These studies do not, however, indicate what the mechanisms are that link subjective sleep characteristics to future MI. For this, a sleep physiological study is needed. Yet, such a study is difficult to carry out since an exact comparison of the results of these prior studies is difficult to draw. One of the reasons is that only a few of these sleep characteristics were included in each of the studies. Moreover, almost all of the studies lacked information regarding the transient or chronic nature of these sleep characteristics. They also differed in the phrasing of their items to assess these problems. Finally, all of these studies employed retrospective, self-assessment procedures for the measurement of these sleep characteristics. Some caution for such procedures is required, however, as became clear from studies in which insomniacs describe their habitual sleep, but not their current sleep, as different from that of controls [13,14].

Notwithstanding these criticisms, some interesting suggestions have been made as to why disturbed sleep may be predictive for MI. One came from a study that explored the prevalence of insomnia and depression in subjects with a recent MI [10]. The results suggest that difficulty falling asleep, frequent nocturnal awakenings, and early morning awakenings are frequently reported by these subjects as part of a major depressive episode they suffered from in the weeks prior to their MI. Another suggestion came from a prospective study (average follow-up: 4.2 years) among middle-aged males $[7,11]$. The results of that study suggest that problems falling asleep and, in particular, feeling exhausted upon waking up in the morning are predictive for a first, non-fatal MI because they are elements of a state of "vital exhaustion". 
The concept "vital exhaustion" was derived from interviews with coronary patients. These patients often indicated that they had suffered from excess fatigue, increased irritability, and feelings of demoralization in the months prior to their MI. Most, if not all, of these feelings, however, are also characteristic of subjects suffering from a depressive disorder. One of the first reports of an association between depression and $\mathrm{MI}$ came from a prospective study of mental precursors for MI [15]. The results of that study indicated that subjects destined for MI are characterized by depression, in particular sadness, loss of libido, and exhaustion. Although additional evidence (reviewed in [16]) has been presented that depression is a reliable predictor of coronary heart disease (CHD), this association has been seriously questioned in a recent meta-analytic study on the role of psychological predictors of CHD [17]. The controversy with respect to depression as a predictor of CHD is important for the present thesis as it calls attention to the possibility that exhausted subjects in fact suffer from depression, a condition that is closely tied to a disturbed sleep. Coronary patients, however, rarely report guilt or lowered selfesteem, two other symptoms associated with depression, but rather emphasize their excess fatigue and increased irritability in the months prior to their MI. To fit their descriptions as closely as possible, our working hypothesis was that these feelings reflect a state of vital exhaustion (VE) at which subjects arrive when their resources for adapting to stress have broken down. The retrospective nature of these interviews, however, called for a prospective study to test the predictive validity of this state for future MI. Such a study was conducted in 3877 subjects who were followed up for an average period of 4.2 years after initial screening of cardiovascular risk factors. During screening, an item pool was used to assess different manifestations of VE. Included in this pool were three items to assess difficulty falling asleep, nocturnal awakenings, and feeling exhausted upon waking up in the morning. The results of that study revealed that exhausted subjects had a significantly elevated risk ( 2.28 times the normal risk) for non-fatal MI at followup [18], thus providing evidence that a state of vital exhaustion constitutes a risk indicator for future MI. Using this same data base, it also became clear that problems falling asleep and, in particular, feeling exhausted upon waking up in the morning are predictive for a first, non-fatal MI because they are elements of VE
$[7,11]$. 
Based upon this evidence, the assumption was made that vital exhaustion may be the unifying concept that relates sleep complaints, heavy snoring, unusual sleep durations, and daytime naps to future MI. If this conjecture were true, the search for underlying mechanisms linking these subjective sleep characteristics to MI would be served by a sleep physiological study in exhausted subjects. Therefore, at the outset of the current thesis, a study was called for that explored whether VE was associated with these various sleep characteristics. It was also felt that the Type A coronary-prone behaviour pattern (TABP) should be included in this study, the reasons being the observed positive association between this behaviour pattern and VE $[19,20]$ and the substantial influence that TABP may exert upon the duration of sleep and the occurrence of sleep problems [21,22]. However, a study that explores an association between VE and these various sleep characteristics requires an instrument that systematically assesses sleep complaints and that is suited, for instance, for the screening of the prevalence of sleep complaints in the general population. Such an instrument was not available at the outset of the current thesis.

In sum, complaints about sleep, heavy snoring, unusual sleep durations, and daytime naps are considered as potential risk indicators for future MI. However, the mechanisms that link these various sleep characteristics to future MI are unknown. A state of vital exhaustion is also considered as a potential risk indicator for future MI. Of particular interest for the current thesis is the observation that problems falling asleep and feeling exhausted upon waking up in the morning were found to be predictive for a first, non-fatal MI because they are elements of this state of vital exhaustion. The basic assumption made in this thesis is that this state may be the unifying concept that relates these various sleep characteristics to future MI. If this is a valid assumption, the search for underlying mechanisms would be served by a sleep physiological study in exhausted subjects. However, a number of problems have emerged from these studies that first need to be addressed.

The first problem involves the fact that these sleep characteristics have not been systematically explored as risk indicators for future MI. Vital exhaustion and the Type A coronary-prone behaviour pattern, as risk indicators for future MI, have not been explored in most of these studies either. 
The second problem involves the fact that retrospective, self-assessment procedures were used for the measurement of these sleep characteristics. The fact that insomniacs describe their habitual sleep, but not their current sleep, as different from that of controls, indicates that the results of these procedures should be interpreted with some caution.

The third problem involves the question of whether exhausted subjects suffer from depression. It may just be that exhausted subjects complain about their sleep because they suffer from depression, a condition that is closely tied to a disturbed sleep.

The fourth problem involves the fact that no instrument was available that systematically assesses sleep complaints and that is suited, for instance, for the screening of the prevalence of sleep complaints in the general population.

\section{Plan of the thesis}

In chapter 1, a general background is given for the studies to be presented in this thesis.

In chapter 2, a study is presented that describes the development and validation of an instrument -the Sleep-Wake Experience List- for the detection of problems that are related to initiating sleep, maintaining sleep, early morning awakening, difficulty waking up, tiredness upon waking up, and daytime sleepiness.

In chapter 3, a study is described that explores the association of these sleep complaints with VE and a possible confounding of this association by TABP in a sample of 451 middle-aged, male subjects. Additional questions presented to these subjects were related to their habitual snoring, taking of naps, and habitual sleep duration. Manifestations of exhaustion were assessed with Form $B$ of the Maastricht Questionnaire (MQ). The first version of the MQ (Form A) was developed in a 10-month prospective study among middle-aged subjects [23]. These subjects had all gone to a general practitioner about complaints of possible cardiac origin. All subjects filled out Form $A$ at the beginning of the follow-up. That study revealed that the 37 subjects who suffered a new coronary event within this 10-month period had a significantly higher mean score on this questionnaire than the remaining 405 subjects. The same set of items, in another study, also discriminated between these cases and a group of healthy controls [24]. After these 
two studies, Form A was revised. Nondiscriminating items were dropped and new items, derived from interviews with coronary patients, were added. This second version of the MQ was tested in the group of 3877 subjects, described previously [18]. An item analysis at the end of the study showed that 21 items from this pool were predictive for future MI. These items make up Form B of the MQ [25].

In chapter 4, the similarity in symptomatology between depressive disorders and vital exhaustion is explored. Two approaches were used to assess depression. In the first approach, depressed mood, fatigue, and vigour were self-monitored. In the second approach, a retrospective assessment of depression was made. The question to be explored was whether a state of exhaustion is characterized by a depressed mood or by a loss of vigour and excess fatigue.

The procedure used to select participants for this study deserves some particular attention because it comprised two stages. In the first stage, a random sample of 1500 male subjects, aged 45-65 year, were invited by letter to participate in a study on sleep problems. A stamped reply card was included. Affirmative responses were obtained from 566 subjects who then received two questionnaires and the MQ. Of the 471 questionnaires that were returned, 20 had to be discarded because of incomplete answers. The final sample, therefore, consisted of 451 subjects. Manifestations of exhaustion in this sample were assessed with the MQ. Higher scores on this questionnaire (range 0-42) indicate more exhaustion. To increase the likelihood of selecting "true-positives" or "true-negatives" as participants, subjects with scores in the upper tertile (range 18-42) of the MQ distribution were designated as "exhausted" and subjects with scores in the lower tertile (range 0-7) as "non-exhausted". Subjects in the intermediate tertile were excluded. To validate complaints of exhaustion, the second stage comprised an interview with subjects from these subsamples. Interviews were held by a psychiatrist 3-4 weeks after the questionnaires were returned, and were stored on videotape. The psychiatrist was unaware of all details of this selection procedure, including the subjects' answers on the MQ. All 21 items of the MQ were reassessed during this interview, and possible causes were explored. Using the video recordings, subjects were classified by two independent experts (blind to the subjects' group assignment) as either truepositive (exhausted) or true-negative (non-exhausted). Subjects were classified as true-positives if their complaints reflected a breakdown in adaptation to stress and if they were present for a relatively short duration.

In chapter 5 , a study is presented that focussed on a possible discrepancy in the retrospective and current night self-assessment of sleep. 
To explore this issue in exhausted subjects, both their habitual sleep for the past 3 months and their self-monitored sleep over 21 days were studied.

In chapter 6 , the results of these previous studies are integrated and the hypothesis is made that the sleep of exhausted subjects is characterized by a relative absence of slow wave sleep. To test this hypothesis, the sleep of exhausted and non-exhausted subjects was polygraphically monitored for four consecutive nights. The participants in these last two studies were the same as those in the study described in chapter 4 .

Chapter 7 concludes the thesis by presenting a review of the findings and a discussion of their implications for the study of sleep, vital exhaustion, and future MI.

\section{REFERENCES}

1. Thiel H, Parker D, Bruce T. Stress factors and the risk of myocardial infarction. J Psychosom Res 1973; 17: 43-45.

2. Kuller L. Prodomata of sudden death and myocardial infarction. Adv Cardiol 1978; 25: 61-72.

3. Kripke DF, Simons RN, Garfinkel L; Hammond EC. Short and long sleep and sleeping pills: Is increased mortality associated? Arch Gen Psychiatry 1979; 36: 103116.

4. Partinen M, Putkonen PT, Kaprio J, Koskenvuo M, Hilakivi I. Sleep disorders in relation to coronary heart disease. Acta Med Scand (Suppl) 1982; 660: 69-83.

5. Wingard DL, Berkman LF. Mortality risk associated with sleeping patterns among adults. Sleep 1983; 6: 102-107.

6. Koskenvuo M, Kaprio J, Partinen M, Langinvainio H, Sarna S, Rita H, Heikkilä K. Poor sleep quality, emotional stress and morbidity: a six year follow-up of 10778 persons aged 35-59 years. In Stress and Psychosomatics (Edited by Achte K, Pakaslahti A), pp. 115-120. Helsinki: Psychiat Fennica (Suppl), 1986.

7. Appels A, de Vos Y, van Diest R, Höppener P, Mulder P, de Groen J. Are sleep complaints predictive of future myocardial infarction? Act Nerv Sup (Praha), 1987; 29: 147-151.

8. Siegrist J. Impaired quality of life as a risk factor in cardiovascular disease. J Chronic Dis 1987; 40: 571-578.

9. Falger PRJ, Schouten EGW, Appels AWPM, de Vos YCM. Sleep complaints, behavioral characteristics and vital exhaustion in myocardial infarction cases. Psychology and Health 1988; 2: 231-258.

10. Carney RM, Freedland KE, Jaffe AS. Insomnia and depression prior to myocardial infarction. Psychosom Med 1990; 52: 603-609. 
11. Appels A, Schouten E. Waking up exhausted as risk indicator of myocardial infarction. American J Cardiol 1991; 68: 395-398.

12. Freedland KE, Carney RM, Lustman PJ, Rich MW, Jaffe AS. Major depression in coronary artery disease patients with vs. without a prior history of depression. Psychosom Med 1992; 54: 416-421.

13. Mendelson WB, Garnett D, Gillin JC, Weingartner H. The experience of insomnia and daytime and nighttime functioning. Psychiatry Res 1984; 12: 235-250.

14. Mendelson WB, James SP, Garnett D, Sack DA, Rosenthal NE. A psychophysiological study of insomnia. Psychiatry Res 1986; 19: 267-284.

15. Crisp AH, Queenan M, d'Souza M. Myocardial infarction and the emotional climate. Lancet 1984; i: 616-619.

16. Booth-Kewley S, Friedman H. Psychological predictors of heart-disease: a quantitative review. Psychol Bull 1987; 101: 343-362.

17. Matthews K. Coronary heart disease and type A behaviors: Update on and alternative to the Booth-Kewley and Friedman (1987) quantitative review. Psychol Bull 1988; 104: 373-380.

18. Appels A, Mulder P. Excess fatigue as a precursor of myocardial infarction. Eur Heart J 1988; 9: 758-764.

19. Falger PRJ. Vital exhaustion and depression and Type A behavior in myocardial infarction cases. Eur Heart J 1986; 7: Abstract Suppl 1, 5.

20. Doornen LJP. Physiological Stress Reactivity. PhD Thesis, Free University of Amsterdam, The Netherlands, 1988.

21. Hicks RA, Pellegrini RJ. Sleep problems and Type A-B behavior in college students. Psychol Rep 1982; 51: 196.

22. Koskenvuo M, Kaprio J, Langinvainio H, Romo M, Sarna S. Psychosocial and environmental correlates of coronary-prone behavior in Finland. J Chronic Dis 1981; 34: 331-340.

23. Appels A. Psychological prodromata of myocardial infarction and sudden cardiac death. Psychother Psychosom 1980; 34: 187-195.

24. Verhagen F, Nass C, Appels A, van Bastelaer A, Winnubst J. Cross-validation of the A/B Typology in the Netherlands. Psychother Psychosom 1980; 34: 178-186.

25. Appels A, Höppener P, Mulder P. A questionnaire to assess premonitory symptoms of myocardial infarction. Int J Cardiol 1987; 17: 15-24. 
$-18$ 


\title{
THE SLEEP-WAKE EXPERIENCE LIST a
}

\author{
R. van Diest ${ }^{1}$, H. Milius ${ }^{2}$, R. Markusse ${ }^{3}$ and J. Snel ${ }^{4}$
}

1,2 Department of Clinical Psychiatry, Limburg University, Maastricht, The Netherlands. 3,4 Department of Psychology (section Psychonomy), University of Amsterdam, The Netherlands.

\begin{abstract}
In order to study the prevalence and incidence of chronic sleep complaints, an instrument is needed. In this paper, a questionnaire - the Sleep-Wake Experience List (SWEL) - is presented for the detection of chronic sleep complaints. The questionnaire comprises 15 items that cover six categories of sleep complaints. The qualities of the SWEL as a screening, diagnostic, and prognostic instrument for these complaints were investigated in a sample of 42 males aged 45-65 year. The results show that the SWEL is a moderate to good screening instrument. It is also moderate with respect to diagnosis and prognosis.
\end{abstract}

\section{INTRODUCTION}

Disturbed sleep is a highly prevalent problem that presents itself in most of the afflicted cases as insomnia or, to a lesser extent, as hypersomnia.

\section{SLEEP COMPLAINTS}

\section{Prevalence}

Various health surveys have indicated a high prevalence of insomnia. In the U.S., it has been estimated as ranging from 14-35\% [1-5]. Sleep complaints also appear to be prevalent in Holland. In a Dutch family practice survey [6], it was observed that approximately $25 \%$ of the patients described themselves as moderate to poor sleepers, a finding that is reasonably consistent with the results of a nationwide American family practice survey [7]. The prevalence of excessive daytime sleepiness is estimated to range from $0.3-4.9 \%$ [3,5,8-10]. Lavie [9], however, also reported that approximately $15 \%$ of the industrial workers in his study frequently suffered from daytime sleepiness. This finding suggests a higher prevalence of daytime sleepiness than previously estimated.

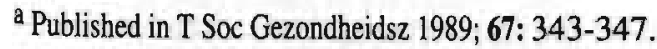




\section{Sleep and health}

It has been suggested that insufficient sleep may be a risk factor for one's general health. Males who slept for more than $9 \mathrm{~h}$ or less than $6 \mathrm{~h}$ per night were found to be 1.7 times more likely to die within a period of 9 years than those who slept 7-8 $\mathrm{h}$ [11]. Women and men who reported sleeping less than $4 \mathrm{~h}$ per night were 1.5-2.8 times more likely to die within 6 years than those who slept 7-8 $\mathrm{h}$ [12]. These authors reported similar results for long sleep durations. Both men and women who reported sleeping more than $10 \mathrm{~h}$ were 1.8 times more likely to die within 6 years than those who slept $7-8 \mathrm{~h}$.

\section{Shortcomings in the assessment of sleep complaints}

Both the prevalence of insomnia and of hypersomnia and the association of sleep duration with the risk of dying indicate that disturbed sleep is an important problem. There are, however, shortcomings in the assessment of sleep complaints. First, sleep complaints are not assessed systematically [13,14]. Second, frequently no distinction is made between transient sleep complaints (i.e., less than three weeks) and chronic ones (i.e., more than three weeks) $[15,16]$. With respect to the first point, in a systematic assessment, the entire $24-\mathrm{h}$ period has to be considered. Within a 24-h period, complaints about sleep can be distinguished as problems that are related to: initiating sleep, maintaining sleep, early morning awakening, difficulty waking up, tiredness upon waking up, and sleepiness during the day (Fig. 1).

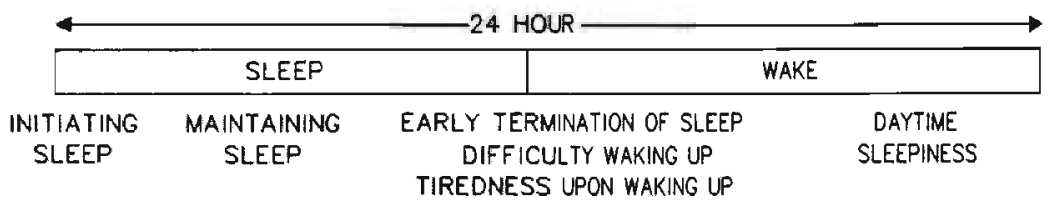

Fig. 1. The occurrence of sleep complaints in a 24-h period

As for the second shortcoming, transient complaints about sleep are often associated with a temporary, stressful event. Usually, the complaints subside when the consequences of the stressful event are effectively addressed [17]. Chronic sleep complaints, however, are often associated with a moderate to poor physical and/or mental health $[14,18]$. To establish the presence of chronic sleep complaints, 
three dimensions of these complaints need to be known: (1) the severity of the complaint, (2) the period during which the complaint is present, and (3) the occurrence of the complaint within this period. In Holland, no list is available that systematically assesses sleep complaints and that is suited, for instance, for the screening of the prevalence of sleep complaints in the general population. In this paper, the development and validation of a simple questionnaire is described that should make possible epidemiological research about the prevalence and incidence of chronic sleep complaints in the general population as well as selection of subjects suffering from chronic sleep complaints for psychophysiological or pharmacological sleep research.

\section{METHOD}

\section{The items}

Mostly non-Dutch questionnaires were used for the development and selection of items. The questionnaires were either short and geared towards specific situations $[4,19-24]$ or they were very lengthy $[9,25]$. Furthermore, items have been developed on the basis of a classification system [26] in which four major groups of sleep disorders are described in order to clarify the pathophysiology and etiology of these sleep disorders. In the present study, it was decided a priori not to include any question related to the fourth group, one which includes either rarely occurring problems, such as sleep-related asthma, or problems that occur mainly during childhood, such as sleep-related enuresis or sleepwalking.

\section{The pilot studies}

The first version of our questionnaire contained nine items about sleep complaints. The contents and phrasing of the items were verbally commented upon by 66 males (i.e., myocardial infarction (MI) patients, hospital referents, and neighborhood referents of the MI patients, all of whom were between 35-70 years of age). These subjects were also questioned about sleep complaints that were not covered by these items [27]. Based upon the responses of these subjects, a second version was devised, consisting of 15 items. This version was commented upon in writing by 60 males and females who were between 16 and 90 years of age. These subjects included three narcoleptics, 37 individuals who were known by their general practitioners to suffer from longstanding sleep complaints, and 20 individuals from homes of the elderly. They were also explicitly questioned about any lack of clarity in the phrasing of the items and about sleep complaints that were 
not covered by the items [28]. The combined results of these two pilot studies formed the basis of the Sleep-Wake Experience List.

\section{The Sleep-Wake Experience List (SWEL)}

The final questionnaire consists of 15 items. All items are to be answered on a five-point adjective rating scale. The 15 items cover six types of complaints, as they occur within a 24-hour sleep-wake cycle (Fig. 1). Except for daytime sleepiness, there are items that assess the severity (Table IA) and items that assess the occurrence of the complaint (Table IB) within a period specified in the instructions. For daytime sleepiness, items only assess the occurrence of the complaint.

Table IA+IB.-The 15 items of the Sleep-Wake Experience List

IA Items that assess the severity of sleep complaints within a period specified in the instructions. The possible answers are: not at all; a little; rather severe; severe; very severe.

01 Is it a problem for you to fall asleep?

02 Is it a problem for you when you wake up at night?

03 If you wake up at night, is it a problem for you to fall asleep again?

04 Is it a problem for you when you wake up too early in the morning?

05 Do you have problems with waking up easily in the moming?

06 Are you tired on final waking, even if you have slept enough?

IB Items that assess the occurrence of sleep complaints within a period specified in the instructions. The possible answers are: never; seldom; sometimes; often; always.

07

08

09

10

11

12

13

14

15
If you wanted to go to sleep, did you fall asleep quickly?

Did you usually fall asleep quickly again, if you woke up from your sleep?

How often did you wake up earlier than you wanted?

If you woke up too early, did you usually fall asleep quickly again?

How often was it difficult for you to wake up?

How often were you too tired to rise?

Did you regularly fall asleep during the daytime without wanting this?

How often were you troubled by sleepiness during your daily activities?

How often was it difficult for you to stay awake during your daily activities? 


\section{The sample}

The SWEL was developed and validated in order to explore characteristics of disturbed sleep in males who are at increased risk for myocardial infarction. In order to conduct this sleep physiological study, a random sample of 1500 males was drawn from the population registry of the city of Maastricht. Because sleep complaints are more prevalent after the age of $45[4,6,8]$, the age range included ages 45-65. Subjects were invited by letter to participate in a study on the associations between sleep and the functioning of the heart. A stamped reply card was included. Those who accepted the invitation received the SWEL, together with two additional questionnaires. These were the Maastricht Questionnaire (MQ), to assess increased risk for myocardial infarction [29], and the Jenkins Activity Survey (JAS), to assess Type A behaviour [30]. A full set of questionnaires was returned by 471 subjects (31.4\%). After removing incomplete or incomprehensible answers, 451 questionnaires $(30.1 \%)$ remained to be included in the analysis.

\section{The instructions}

Because the SWEL is intended to assess chronic sleep complaints, subjects were instructed as follows: "In the following list you will find questions about your sleep for the past three months and about your daytime functioning for the past three months. In the case of irregular work schedules, what is meant by 'during the day' is the time that you work or are awake, and what is meant by 'at night' is the time that you are asleep".

\section{The coding of the answers to the SWEL}

With the exception of daytime sleepiness, a sleep complaint was labeled "chronic" if the complaint was described both as 'rather severe' to "very severe' and as 'often present' or 'always present' for a period of three months.

\section{The combinations of items on the SWEL}

In order for a sleep complaint to qualify as chronic, the items were combined as follows (the numbers refer to Tables IA and IB):

Initiating sleep. (01) 'Is it a problem for you to fall asleep?'; and (07) 'If you wanted to go to sleep, did you fall asleep quickly?'

Maintaining sleep. (02) 'Is it a problem for you when you wake up at night?'; 
or (03) 'If you wake up at night, is it a problem for you to fall asleep again?'; and (08) 'Did you usually fall asleep quickly again, if you woke up from your sleep?'

Early morning awakening. (04) 'Is it a problem for you when you wake up too early in the morning?'; and (09) 'How often did you wake up earlier than you wanted?'; and (10) 'If you woke up too early, did you usually fall asleep quickly again?'

Difficulty waking up. (05) 'Do you have problems with waking up easily in the morning?'; and (11) 'How often was it difficult for you to wake up?'

Tiredness upon waking up. (06) 'Are you tired on final waking, even if you have slept enough?'; and (12) 'How often were you too tired to rise?'

Daytime sleepiness was labeled as chronic if one or more of the following three items was answered with 'often' or 'always': (13) 'Did you regularly fall asleep during the daytime without wanting this?; or (14) 'How often were you troubled by sleepiness during your daily activities?'; or (15) 'How often was it difficult for you to stay awake during your daily activities?'

\section{The associations between sleep complaints}

The intercorrelations between the six types of sleep complaints in this sample of 451 adult subjects are shown in Table II.

Table II.-Correlations between the six types of sleep complaints

\begin{tabular}{lllllll}
\hline Types of complaints & (1) & (2) & (3) & (4) & (5) & (6) \\
& & & & & & \\
1 Initiating sleep & - & $0.42^{*}$ & $0.28^{*}$ & 0.04 & $0.15^{*}$ & 0.01 \\
2 Maintaining sleep & & - & $0.29^{*}$ & 0.04 & 0.05 & 0.09 \\
3 Early morning awakening & & & - & 0.05 & $0.19^{*}$ & 0.04 \\
4 Difficulty waking up & & & & - & $0.25^{*}$ & 0.06 \\
5 Tiredness upon waking up & & & & & - & $0.12^{*}$ \\
6 Daytime sleepiness & & & & & & - \\
\hline
\end{tabular}

$* \mathrm{p}<0.01$.

It appears that the intercorrelations are rather low. The highest correlation that is observed is between problems initiating sleep and problems maintaining sleep $(r=0.42)$. These low associations justify investigating these sleep complaints as distinct entities. 
The prevalence of sleep complaints

The items and the codings of the answers have been used to estimate the prevalence of individual sleep complaints (Table III).

Table III.-Prevalence of sleep complaints in the sample of 451 subjects

\begin{tabular}{llr}
\hline Types of complaints & N & $\%$ \\
& & \\
1 Initiating sleep & 57 & 12.6 \\
2 Maintaining sleep & 46 & 10.2 \\
3 Early morning awakening & 26 & 5.8 \\
4 Difficulty waking up & 18 & 4.0 \\
5 Tiredness upon waking up & 32 & 7.1 \\
6 Daytime sleepiness & 59 & 13.1 \\
\hline
\end{tabular}

Of the 451 subjects studied, $301(66.7 \%)$ reported no complaints. The remaining 150 subjects $(33.3 \%)$ reported one or more complaints. Of this latter group, $87(58.0 \%)$ reported one complaint, 42 (28.0\%) two complaints, 18 (12.0\%) three complaints, and $3(2.0 \%)$ four complaints or more.

\section{VALIDITY OF THE SWEL}

To what extent is it possible to trace subjects with chronic sleep complaints on the basis of these combined items and codings of the answers? In order to answer this question, an interview was developed to determine the presence or absence of sleep complaints.

\section{The selection of subjects to participate in the interview}

Based upon the answers given on the SWEL, two groups were formed. The first group consisted of subjects who, according to the SWEL, suffered from sleep complaints $(\mathrm{N}=150)$, and the other group consisted of those subjects $(\mathrm{N}=301)$ who, according to the SWEL, did not. Samples from both groups were randomly invited by telephone to participate in the interview. To increase the likelihood of a sufficient representation of each of the six types of sleep complaints in the sample in which the validity of the SWEL was to be explored, more subjects with sleep complaints were approached. From the group "with complaints", a total of 24 
subjects participated. Their mean age was 54.2 year (SD 3.4). From the group "without complaints", 18 subjects participated. Their mean age was 55.2 year (SD $5.5)$. The groups did not differ significantly with respect to age $(\mathrm{t}=0.75 ; \mathrm{df}=40)$.

\section{The occurrence of sleep complaints}

Based upon the answers given on the SWEL, the occurrence of sleep complaints in the first group was as follows: initiating sleep, $N=13$; maintaining sleep, $\mathrm{N}=13$; early morning awakening, $\mathrm{N}=10$; difficulty waking up, $\mathrm{N}=2$; tiredness upon waking up, $\mathrm{N}=6$; daytime sleepiness, $\mathrm{N}=7$. There were more sleep complaints reported $(\mathrm{N}=51)$ than there were subjects in this group, indicating that, in any case, subjects had been selected who were suffering from multiple sleep complaints. This was, however, not known to the interviewer.

Due to the selection procedure, there were only two subjects who, according to the SWEL, suffered from difficulty waking up. This was not known to the interviewer either. Because of its low occurrence, this complaint will be disregarded in the statistical analyses.

\section{The interview}

The interview was held 3-4 weeks after the questionnaires were returned. The interviewer was unaware of the answers given on the questionnaires and of the selection procedure. The interviewees were instructed to base their answers to the questions on the past three months. With these instructions, the period that was covered by the SWEL was included in the interview. The interviews were stored on videotape. After obtaining informed consent, all individual complaints, as depicted in Fig. 1, were reassessed and possible causes were explored. The questions that were posed during the interview are shown in Table IV.

\section{The diagnosis}

On the basis of the videotapes, the presence or absence of sleep complaints was diagnosed independently by the interviewer and by a second judge, who was also unaware of the answers given on the SWEL. For this purpose, a standardized ratingform was developed on which the presence or absence of each complaint could be indicated. Furthermore, in case of the presence of a complaint, the raters could indicate on a scale (ranging from 0-100\%) the confidence they had in their own diagnosis. The results of this procedure were used to establish the test quality of the SWEL. Because the raters did not always agree in their diagnosis, the 
following rule was used to establish the presence of a complaint: "A complaint was considered 'present' if both raters thought the complaint to be present and were reasonably confident about their diagnosis (a score of $40 \%$ or more on the scale of 0-1.00\%). In all other cases, the complaint was regarded as 'absent'".

Table IV.-Questions posed during the interview to establish the presence or absence of sleep complaints

01 Does it often happen that you cannot fall asleep?

Yes, is falling asleep a problem for you?

02 Does it often happen that you wake up during your sleep?

Yes, is staying asleep a problem for you?

03 Does it often happen that you wake up too early in the morning?

Yes, is waking up early in the morning a problem for you?

04 Is it often difficult for you to wake up in the morning?

Yes, is difficulty waking up in the morning a problem for you?

05 Does it often happen that you feel tired when you wake up in the morning?

Yes, is tiredness when you wake up a problem for you?

06 During the daytime, do you have an irresistible need to sleep?

\section{Data analysis}

The most important measures of the qualities of a test are sensitivity, specificity, and efficiency. Sensitivity is the probability that a patient with a positive diagnosis will have a positive test result. Specificity is the probability that a patient with a negative diagnosis will have a negative test result. Efficiency is the probability that test and diagnosis agree.

\section{Chance agreement}

It is well known, however, that efficiency may take on a high value purely by chance agreement. Therefore, in 1960, a chance-corrected measure of efficiency was proposed, the Kappa coefficient [31].

\section{The importance of "false-positives" and "false-negatives"}

In order to establish the quality of a test, it is important to weigh the number of "false-positives" and "false-negatives" of that test. To that end, "weighted" Kappas have been developed [32]. 
For a screening instrument, it is important to weigh the number of "falsenegatives" of the test (Kappa ${ }_{<\text {screening }}$ ). For a test to serve as a diagnostic instrument, it is important to weigh the number of "false-positives" of the test (Kappa $\left._{<\text {diagnosis }>}\right)$. As a prognostic test, there is equal concern for "false-positives" and "false-negatives" (Kappa ${ }_{<\text {prognosis }>}$ ).

\section{Kappa coefficient}

The Kappa coefficient ranges from negative values through 0 to 1 . With negative values, the observed agreement is less than might be expected from chance agreement. With a value of 0 , the agreement is entirely explained by chance; with positive values, the agreement is higher than chance [33]. In the calculations, the "level" of the test is needed. This level is the probability that a randomly selected subject will have a positive test. The level of the test is chosen to be reflected in the estimated prevalences of sleep complaints as they were found in this study (Table II).

\section{Test quality and diagnosis}

These test measures seldom reach a value of $1(100 \%)$. This is so because their upper limits are determined by the quality of the diagnostic procedure. The diagnostic procedure used in the present study was derived from the sleep diagnostic procedure described by Kales [34]. In the current study, the quality of this diagnostic procedure was explored by calculating the chance-corrected agreement between the two independent raters.

\section{RESULTS}

\section{Agreement between the two raters}

The results of the chance-corrected agreement [33] between the two raters are shown in Table IV. In this calculation, the non-agreement cells are equally important, which makes this calculation equal to Kappa ${ }_{\text {<prognosis> }}$.

The agreement between the two raters with respect to sleep complaints ranges from average to high. 
Table V.-Agreement between the two raters for complaints about sleep

Types of complaints $\quad$ Kappa $a_{\text {<prognosis }>} \quad 95 \%$ confidence

$\begin{array}{lcc}1 \text { Initiating sleep } & .95 & .90-.99 \\ \text { 2 Maintaining sleep } & .71 & .50-.92 \\ \text { 3 Early morning awakening } & .84 & .66-.99 \\ \text { 4 Difficulty waking up } & - & - \\ \text { 5 Tiredness upon waking up } & .71 & .50-.93 \\ \text { 6 Daytime sleepiness } & .73 & .44-.99\end{array}$

\section{Agreement between test and diagnosis}

The chance-corrected measures Kappa $\mathbf{< s c r e e n i n g ~}>, \mathrm{Kappa}_{<\text {diagnosis }>\text {, and }}$ $\mathrm{Kappa}_{<\text {prognosis> }}$ are shown in Table VI for all sleep complaints, with the exception of "difficulty waking up". The quality of the SWEL as a screening instrument ranges from average to high with respect to the detection of sleep complaints. The quality of this questionnaire as a diagnostic and prognostic instrument is average.

Table VI.-Agreement between diagnosis and SWEL for sleep complaints. Chance corrected Kappa ${ }_{<s c r e e n i n g>}, K_{\text {appa }}$ <iagnosis>, and Kappa $<$ prognosis> are shown

\begin{tabular}{lccc}
\hline Types of complaints & $\begin{array}{c}\text { Kappa } \\
\text { <screening> }\end{array}$ & $\begin{array}{c}\text { Kappa } \\
\text { <diagnosis> }\end{array}$ & $\begin{array}{c}\text { Kappa } \\
\text { <prognosis> }\end{array}$ \\
1 Initiating sleep & $74.1 \%$ & $57.2 \%$ & $64.6 \%$ \\
2 Maintaining sleep & $52.3 \%$ & $52.8 \%$ & $52.5 \%$ \\
3 Early morning awakening & $70.5 \%$ & $74.4 \%$ & $72.5 \%$ \\
4 Difficulty waking up & - & - & - \\
5 Tiredness upon waking up & $81.9 \%$ & $74.5 \%$ & $78.0 \%$ \\
6 Daytime sleepiness & $90.3 \%$ & $51.1 \%$ & $65.3 \%$ \\
\hline
\end{tabular}

\section{DISCUSSION}

The results of the present study show that the quality of the SWEL as a screening instrument ranges from average to high for the detection of sleep complaints. The quality of this questionnaire as a diagnostic and prognostic instrument is average. As argued previously, the upper limits of the test measures 
are determined by the quality of the diagnostic procedure. This quality was average to high. The presence or absence of complaints, however, could not always be unequivocally established in all subjects, as might be expected. It was striking that the absence of agreement was observed only in those cases in which one rater thought a complaint to be present but showed little confidence in his diagnosis (less than $40 \%$ on a scale of $0-100 \%$ ), while the other rater thought this particular complaint to be absent. Disagreement varied with the type of complaint under consideration and was highest with complaints of maintaining sleep and of tiredness upon waking up; it was lowest with the complaint of initiating sleep. The rule, used in this study, to regard a complaint as present only if both raters were reasonably confident about their diagnosis increases the likelihood of the occurrence of "false-positives". Because of this, the quality of the SWEL as a screening instrument may be underestimated.

The sample that was used to validate the SWEL was comprised of males with either a high or a low ranking on the MQ. The sensitivity, specificity, and efficiency of this questionnaire with respect to sleep complaints are unknown. It is, therefore, as yet impossible to determine how this selection has affected the validity of the SWEL.

Only $31.4 \%$ of the entire sample of 1500 subjects was willing to participate. The low response rate and the selection procedure that was used in the present study may indicate that the sample used to validate the SWEL is not representative for the entire population. This, however, will not so much have obscured the diagnosis of sleep complaints during the interview as it will have obscured the representativeness of the validity of the SWEL for the general population.

The questionnaire, developed and validated in the present study, represents a method for the systematic assessment of chronic sleep complaints. Due to the small number of items, the questionnaire is suited for epidemiological research. Finally, the SWEL may also serve as a suitable instrument for the selection of subjects for sleep physiological research.

\section{REFERENCES}

1. Hammond EC. Some preliminary findings on physical complaints from a prospective study of 1.064.004 men and women. Am J Public Health 1964; 54: 11-23.

2. Balter MB, Bauer ML. Patterns of prescribing and use of hypnotic drugs in the United States. In Sleep disturbances and hypnotic drug dependence (Edited by Clift AD), pp. 261-294. New York: Excerpta Medica, 1974. 
3. Karacan I, Thornby JI, Anch M, Holzer CE, Warheit GJ, Schwab JJ, Williams RL. Prevalence of sleep disturbance in a primarily urban Florida county. Soc Sci \& Med 1976; 10: 239-244.

4. Bixler E0, Kales A, Soldatos CR, Kales JD, Healy S. Prevalence of sleep disorders in the Los Angeles metropolitan area. Am J Psychiat 1979; 136: 1257-1262.

5. Coleman RM, Zarcone VP, Redington D, Miles LE, Dole KV, Perkins WG, Gananian M, Moore BJ, Stringer J, Dement WC. Sleep-wake disorders in a family practice clinic. In Sleep Research 9 (Edited by Chase MH, Kripke DJ, Walter PL), p. 192. Los Angeles: UCLA BIS/BRI, 1980.

6. de Graaf W, Pluymen J. Sleep disturbance in a general practice. In Sleep, Normal and Deranged Function (Edited by Kamphuizen HAC, Bruyn GW, Visser P), pp. 57 66. Leiden: Mefar, 1981.

7. Bixler EO, Kales A, Soldatos CR. Sleep disorders encountered in medical practice: a national survey of physicians. Behav Med 1979; 6: 1-6.

8. Bixler EO, Kales JD, Scharf MB, Kales A, Leo LA. Incidence of sleep disorders in medical practice: a physician survey. In Sleep Research 5 (Edited by Chase MH, Mitler M, Walter PL), p. 160, Los Angeles: UCLA BIS/BRI, 1976.

9. Lavie P. Sleep habits and sleep disturbances in industrial workers in Israel: main findings and some characteristics of workers complaining of excessive daytime sleepiness. Sleep 1981; 4: 147-158.

10. Hetta J, Almqvist H, Agren G, Hambert B, Liljenberg B, Roos BE. Prevalence of sleep disturbances and related symptoms in a middle-aged Swedish population. In Sleep '84 (Edited by Koella WP, Rüther E, Schulz H), pp. 373-376. Stuttgart: Gustav Fischer, 1985.

11. Wingard DL, Berkman LF. Mortality risk associated with sleeping patterns among adults. Sleep 1983; 6: 102-107.

12. Kripke DF, Simons RN, Garfinkel L, Hammond EC. Short and long sleep and sleeping pills: Is increased mortality associated. Arch Gen Psychiatry 1979; 36: 103116.

13. Kales A, Kales JD, Bixler EO, Martin E. Common short-comings in the evaluation and treatment of insomnia. In Hypnotics: Methods of development and evaluation (Edited by Kagan F, Harwood T, Rickels K, Rudzik A, Sorer H), pp. 29-40. New York; Spectrum Publications, 1975.

14. Kales A, Kales JD. Evaluation and treatment of insomnia. New York; Oxford University Press, 1984.

15. Coleman RM. Diagnosis, treatment and follow-up of about 8000 sleep/wake disorder patients. In Sleep/wake disorders. Natural History, Epidemiology and Long-Term Evolution. (Edited by Guilleminault CH, Lugaresi E), pp. 87-97. New York; Raven Press, 1983.

16. Parkes JD. Sleep and its Disorders (Major Problems in Neurology; V.14). London; WB Saunders Company, 1985. 
17. Kales A, Soldatos CR, Kales JD. Diagnosis and treatment of sleep disorders. In Treatment of Mental Disorders (Edited by Greist JH, Jefferson JW, Spitzer RL), pp. 473-500. New York; Oxford University Press, 1982.

18. Kales JD, Kales A, Bixler EO, Soldatos CR, Cadieux RJ, Kashurba GJ, Vela-Bueno A. Biopsychobehavioral correlates of insomnia, V: clinical characteristics and behavioral correlates. Am J Psychiatry 1984; 141: 1371-1376.

19. Thomas CB, Greenstreet RL. Psychobiological characteristics in youth as predictors of five disease states: suicide, mental illness, hypertension, coronary heart disease and tumor. John Hopkins Med J 1973; 132: 16-43.

20. de Diana IPF. Two stochastic sleep quality scales for self-rating of subjects' sleep. Sleep Rev 1976; 5: 101.

21. Hauri P. The Sleep Disorders: A Scope Publication. Michigan; The Upjohn Company, 1977.

22. Parrot AC, Hindmarch I. Factor analysis of a sleep evaluation questionnaire. Psychol Med 1978; 8: 325-329.

23. White L, Hahn PM, Mittler MM. Sleep questionnaire in adolescents. Sleep Res 1980; 9: 108.

24. Zomer J, Peled R, Rubin AH, Lavie P. Mini Sleep Questionnaire (MSQ) for screening large populations for EDS complaints. In Sleep " 84 (Edited by Koella WP, Rüther E, Schulz H), pp. 467-470. Stuttgart: Gustav Fischer, 1985.

25. Miles L. Sleep Questionnaire and Assessment of Wakefulness (SQAW). In Sleeping and Waking Disorders: Indications and Techniques (Edited by Guilleminault $\mathrm{CH}$ ), pp. 383-413. Menlo Park: Addison-Wesley Publ Co, 1982.

26. Association of Sleep Disorders Centers. The diagnostic classification of sleep and arousal disorders. Sleep 1979; 2: 1-137.

27. de Vos YC. Slaapklachten in de periode voor het hartinfarct. Internal report: Dept Medical Psychology, University of Limburg; The Netherlands, 1985.

28. Markusse $\mathbf{R}$, Stauder H. De ontwikkeling van een slaapklachten vragenlijst. Internal report: Dept Psychology (section: Psychonomy), University of Amsterdam; The Netherlands, 1985.

29. Appels A, Höppener P, Mulder P. A questionnaire to assess premonitory symptoms of myocardial infarction. Int J Cardiol 1987; 17: 15-24.

30. Appels A. Handleiding bij de Nederlandse bewerking van de Jenkins Activity Survey. Lisse; Swets \& Zetlinger, 1985.

31. Cohen J. A coefficient of agreement for nominal scales. Educ Psychol Measurement 1960; 20: 37-46.

32. Cohen J. Weighted Kappa: Nominal scale agreement with provision for scaled disagreement or partial credit. Psychol Bull 1968; 70: 213-220.

33. Kraemer HC. The methodological and statistical evaluation of medical tests: The dexamethasone suppression test in psychiatry. Psychoneuroendocrinology 1987; 12: 411-427. 
Sleep-Wake Experience List

34. Kales A, Soldatos CR, Kales JD. Taking a sleep history. Am Fam Physician 1980; 10: 101-108. 



\title{
SUBJECTIVE SLEEP CHARACTERISTICS AS CORONARY RISK FACTORS, THEIR ASSOCIATION WITH TYPE A BEHAVIOUR AND VITAL EXHAUSTION b
}

\author{
R. van Diest
}

Department of Clinical Psychiatry, Limburg University, Maastricht, The Netherlands.

\begin{abstract}
A deviant habitual sleep duration, sleep complaints, frequent napping and snoring have all been suggested as potential risk factors for future coronary heart disease. It has not been studied thoroughly, however, whether the association of these phenomena with coronary heart disease is confounded by Type A behaviour or by a state of vital exhaustion. The aim of the present study was to explore the association of the above sleep characteristics with the coronary risk factors, "Type A behaviour" and "vital exhaustion" systematically. The results indicated that Type A behaviour was not associated with any of these sleep characteristics, except with frequent waking. Exhausted subjects, however, reported chronic sleep complaints, a short sleep duration and frequent napping significantly more often than vital subjects. Type A behaviour did not confound these associations. The data support the assumption that these sleep characteristics can be considered as potential risk factors for coronary heart disease because of their association with vital exhaustion.
\end{abstract}

\section{INTRODUCTION}

Various studies have suggested that an unusual sleep duration, sleep complaints, frequent napping and snoring are potential risk factors for coronary heart disease (CHD).

\section{Sleep duration}

In a six-year follow-up study of over a million subjects [1], Kripke et al. showed that men and women who usually slept less than $4 \mathrm{~h}$ or more than $10 \mathrm{~h}$ per night were at least 1.5 times as likely to die from CHD, a stroke, cancer or by suicide as those who slept 7-8 h per night. Wingard \& Berkman [2] obtained similar results in

b Published in J Psychosom Res 1990; 34: 415-426. 
a nine-year follow-up study of almost 5000 subjects. They found that men and women who slept less than $6 \mathrm{~h}$ or more than $9 \mathrm{~h}$ per night were at least 1.6 times as likely to die from CHD, a stroke or cancer as those who slept 7-8 h. In a crosssectional study of over 5400 men, Partinen et al. [3] found that subjects who slept more than $9 \mathrm{~h}$ per night had the highest prevalence of diagnosed myocardial infarction (MI), while those who slept less than $6 \mathrm{~h}$ especially had pain complaints from possible MI and from angina pectoris. In the study by Kripke et al. increased mortality remained associated with a deviant sleep duration after controlling for insomnia, use of sleeping pills, age, sex and history of diabetes, heart disease, stroke or high blood pressure. Increased mortality also remained associated with a deviant sleep duration in Wingard and Berkmans' study after controlling for age, sex, smoking, alcohol consumption, physical activity, state of physical health and involvement in social networks.

\section{Sleep complaints}

In the study of Kripke et al. [1], subjects were asked to indicate the severity of "insomnia" as either 'no', 'seldom', 'fairly often' or 'often'. After controlling for reported number of hours of sleep, use of sleeping pills, age, sex and reported history of four major illnesses, Kripke and colleagues showed that the complaint of insomnia was associated with increased mortality, including CHD, only in the subjects who reported that they 'often' suffered from insomnia but who never used sleeping pills. Because insomnia was not associated with sleep duration in this study, the authors concluded that "a complaint of insomnia may not be a valid indication that a patient is at risk, unless it is accompanied by a usual sleep duration of less than 7 hours". Wingard \& Berkman [2] assessed sleep complaints by asking subjects; 'Do you have trouble sleeping?' The possible answers were; 'often', 'sometimes' or 'never'. These authors also reported that, independent of trouble with sleep, men and women who slept 7 or $8 \mathrm{~h}$ per night had the lowest mortality rates, compared with those with long or short sleep duration. In Partinens' study [3], sleep complaints were assessed by asking; 'How do you sleep in general?' The possible answers ranged from 'well' to 'poorly'. In this study, poor sleep and age did account for the significant association between short sleep and angina pectoris. Poor sleep and age were also more significant determinants of pain from possible infarction than short sleep. Poor sleep did not account for the association between long sleep and MI. An association between sleep complaints and CHD also emerges from a six-year follow-up study of over 10,000 subjects [4]. The study revealed an age adjusted risk ratio of $2.04(\mathrm{p}<0.01)$ for $\mathrm{CHD}$ in poor versus good sleepers. This decreased to an insignificant 1.15 when non-healthy subjects were 
excluded. The study suggests that somatic conditions are involved in the association between poor sleep and CHD. Sleep complaints also predicted future CHD in a 4.2-year follow-up study of 3269 subjects, initially free from CHD [5]. In this particular study, subjects were asked about their sleep by the following questions; 'Do you often have trouble falling asleep?', Do you wake up repeatedly during the night?' and 'Do you ever wake up with a feeling of exhaustion and fatigue?'. The questions could be answered as 'yes', '?', or 'no'. After controlling for age, smoking, blood pressure and cholesterol, it could be shown that subjects who reported difficulty in falling asleep and tiredness on final waking were at least 1.6 times as likely to develop CHD. The association of these sleep complaints with CHD disappeared after controlling for vital exhaustion, a state associated with near future MI [6]. In a three-year follow-up study of 416 men, initially free from CHD, Siegrist [7] showed that subjects who reported 'waking up during the night' frequently or very frequently and/or suffered from 'early morning waking' frequently or very frequently ran a greater risk of having a first MI within 2 years than subjects without such sleep problems.

\section{Napping}

In a case-control study, Falger et al. [8] investigated whether often taking naps during the day and, in addition, having difficulty in falling asleep, frequent waking, getting out of bed often, feelings of tiredness on final waking and feelings of not being refreshed on final waking were more prevalent in a period of six months before a first MI. After controlling for age, coffee consumption, smoking, Type A behaviour and vital exhaustion, 'often taking naps during the day' and the complaints of 'waking up feeling tired' still retained a significant association with MI.

\section{Snoring}

A cross-sectional study of over 7500 subjects [9] revealed a significant association between angina pectoris and snoring in men. This association remained significant after controlling for age, hypertension and Body Mass Index (BMI). The same study also showed a significant association between snoring and hypertension, even after adjusting for age and BMI. A three-year follow-up study of 4388 men [10] indicated that, after controlling for age, BMI, smoking, alcohol consumption and history of hypertension, the relative risk of CHD between habitual frequent snorers and non-snorers was 1.7. 
All aforementioned studies present evidence for considering an unusual sleep duration, sleep complaints, frequent napping and snoring as potential risk factors for CHD. An exact comparison of the results is difficult to draw, however, because the studies differ in their phrasing of the questions. Secondly, none of the studies explored nocturnal sleep complaints systematically or considered daytime sleepiness as a potential risk factor for CHD. Furthermore, it is difficult to deduce from most of the studies whether a distinction was made between transient (less than three weeks) and chronic (more than three weeks) sleep complaints. Finally, it has not been studied thoroughly whether the associations that are found are confounded by Type A behaviour or by vital exhaustion.

\section{Vital exhaustion}

The risk factor "vital exhaustion" was derived from interviews with coronary patients. These patients often report an increased fatigue, lack of energy, listlessness, loss of libido and increased irritability prior to their MI [11]. These feelings have been labelled "vital exhaustion" (VE). The predictive power of these feelings of vital exhaustion for future MI has been tested in a prospective study over an average period of 4.2 years among 3877 middle-aged subjects [6]. The study showed that "exhausted" subjects have a twofold increased risk for future MI. These results correspond with findings by Crisp et al. [12] who observed that a state of sadness, coupled with a loss of libido and exhaustion characterized those destined for MI.

\section{Type A coronary prone behaviour pattern}

Hicks \& Pellegrini [13] showed that Type A subjects complain more about sleep than Type B subjects. Koskenvuo et al. [14], however, did not find any difference in subjective sleep quality in "Type A coronary prone behaviour pattern" (TABP), but reported that Type A subjects slept less than Type B subjects. Furthermore, VE and TABP are positively associated $[15,16]$. These findings raise the question whether an association of VE with sleep complaints or sleep duration is confounded by TABP and vice versa.

Therefore, the purpose of the present study is to explore the association of chronic sleep complaints and sleep duration with the coronary risk factors TABP and VE systematically. 


\section{METHOD}

\section{Subjects}

A random sample of 1500 male subjects, aged $45-65$ years, from the city of Maastricht was invited by letter to participate in a study on sleep problems. A stamped reply card, on which subjects could indicate their willingness to volunteer, was included. Those who accepted the invitation received three questionnaires: the SWEL, the JAS and the MQ.

\section{The Sleep-Wake Experience List (SWEL)}

The SWEL consists of 15 items for assessing six distinct types of sleep complaints as they occur in a 24-h sleep/wake period [17]. The complaints are problems with: initiating sleep; maintaining sleep; early morning awakening; difficulty in waking up; tiredness on waking up; and sleepiness during the day. Both the severity and occurrence of the complaints are assessed, except for daytime sleepiness. "Sleepiness" items can only be answered by the frequency of their occurrence. The "severity" items can be answered as: 'not at all', 'a little', 'rather severe', 'severe' or 'very severe', the "occurrence" items as: 'never', 'seldom', 'sometimes', 'often' or 'always'. The answers are based on the past three months. The answers 'rather' to 'very' severe indicate that the complaint is severe, the answers 'always' or 'often' (or 'never' or 'seldom', depending on the phrasing of the item) that the complaint has been present for the past three months. To establish whether subjects suffered from a specific sleep complaint, a combination of "severity" and "occurrence" items was used. These combinations are ( $\mathrm{s}$ ' and ' $\mathrm{o}$ ' in parentheses refer to "severity" and "occurrence"): Initiating sleep. 'Is it a problem for you to fall asleep?' (s) and 'If you wanted to go to sleep, did you fall asleep quickly?' (0). Maintaining sleep. 'Is it a problem for you when you wake up at night?' (s) or 'If you wake up at night, is it a problem for you to fall asleep again?' (s) and 'Did you usually fall asleep quickly again, if you woke up from your sleep?' (o). Early morning awakening. 'Is it a problem for you when you wake up too early in the morning?' (s) and 'How often did you wake up earlier than you wanted?' (o) and 'If you woke up too early, did you usually fall asleep quickly again?' (o). Difficulty waking up. 'Do you have problems with waking up easily in the morning?' (s) and 'How often was it difficult for you to wake up?' (o). Tiredness upon waking up. 'Are you tired on final waking, even if you have slept enough?' (s) and 'How often were you too tired to rise?' (o). Daytime sleepiness. 
'Did you regularly fall asleep during the daytime without wanting this? (0) or 'How often were you troubled by sleepiness during your daily activities?' (0) or 'How often was it difficult for you to stay awake during your daily activities?' (0).

These combinations have been validated against a clinical diagnosis of chronic sleep complaints in a sample of 42 males [17]. The clinical diagnosis was arrived at by blind raters from videotaped interviews. Their chance-corrected agreement [18] ranged from $71-95 \%$ for the various sleep complaints. To determine the quality of the SWEL, a "weighted" chance-corrected measure (Kappa) [18] has been used. The quality of the SWEL as a screening instrument is from average to high with Kappa ranging from $52.3-90.3 \%$ for the various sleep complaints. The quality of the SWEL as a diagnostic and prognostic instrument is average with Kappa ranging
from $51.1-78.0 \%$. from $51.1-78.0 \%$.
The six types of sleep complaints have been used for clustering subjects into groups with distinct insomnia or hypersomnia complaints and a group with various sleep complaints. (a) Subjects were assigned to the insomnia group if they had complaints as to either sleep onset and/or sleep maintenance and/or early morning awakening. If any additional sleep complaint was present, subjects were assigned to the "mixed complaints" group (see below). (b) Subjects were assigned to the daytime sleepiness group if they suffered from the complaint of daytime sleepiness. In this case, too, subjects were assigned to the "mixed complaints" group if any additional sleep complaint was present. (c) Subjects were placed in the mixed complaints group, therefore, if they had various complaints, like insomnia and
daytime sleepiness.

Furthermore, subjects were questioned about their habitual snoring, taking naps and habitual sleep duration for the past 3 months. Snoring. Subjects were asked: 'Did you usually snore during your sleep?' Possible answers were 'Yes', 'No' or '?'. Snoring is regarded present if an affirmative answer is given and is absent with all other answers. Napping. Subjects were asked: 'How often did you have a nap?' Possible answers were 'less than once a month', '1-4 times a month', '1-4 times a week' and 'almost every day'. Napping is regarded frequent if a subject has a nap 1-4 times a week or more. Otherwise napping is infrequent. Sleep duration. Subjects were asked: 'How many hours of sleep did you usually get?' Possible answers were 'less than $5 \mathrm{~h}$ ', 'less than $6 \mathrm{~h}$ ', 'less than $7 \mathrm{~h}$ ', 'less than $8 \mathrm{~h}$ ', 'less than $9 \mathrm{~h}$ ' and 'more than $9 \mathrm{~h}$ ' a night. Less than $7 \mathrm{~h}$ of sleep makes a short sleep duration, more than $8 \mathrm{~h}$ a long sleep duration. Sleep duration is regarded normal if subjects indicated that they have slept $7-8 \mathrm{~h}$ a night. 


\section{The Maastricht Questionnaire (MQ)}

In this study, Form B of the MQ was used [19]. The scale is mainly formed by a reduction of Form A which was tested for its predictive validity for future MI in the Rotterdam Civil Servant Study (RCSS) [6]. Form B consists of 21 items (MQ21), which all load on a single factor. Cronbachs' alpha for these 21 items was 0.89 while the mean inter-item correlation was 0.31 . The $\mathrm{MQ}$ distribution in the RCSS was skewed to the right (skewness $=0.72$ ). To avoid a conceptual overlap in the association of VE with chronic sleep complaints, the three sleep items of the $\mathrm{MQ}$ have been omitted (MQ18). For these 18 items, the minimum score was 0 and the maximum score 36 .

\section{The Jenkins Activity Survey (JAS)}

The Dutch version of the JAS contains 24 items which all load on a single factor. Cronbachs' alpha for these 24 items was 0.84 , indicating good internal consistency. A comparison of the Dutch JAS with the structured interview for assessing TABP indicated that over $73 \%$ of subjects classified as either Type A or Type B by the interview were also classified as such by the JAS [20]. This indicates a good classification as to TABP by the Dutch JAS.

\section{Data analysis}

For computing the associations between sleep characteristics and TABP or VE, subjects were classified into three levels of TABP or VE. Normative cut-off scores were used for classifying subjects as Type A, B or X [20]. For VE, subjects with a score in the highest quartile of the MQ18 distribution (scores 16-36) were regarded "exhausted", those with a score in the lowest quartile (scores 0-3) "vital" and those with a score in the middle two quartiles (scores 4-15) "intermediate". The associations between the sleep characteristics and TABP or VE are expressed as age-adjusted standardized rate ratios (SRR). This allows an analysis of trend in the reporting of the sleep characteristics with increasing levels of TABP or VE. For the comparison of different levels of TABP or VE, a reference group was used. Type B was the reference group for TABP. For VE this was the group of vital subjects. Significance testing was accomplished by the Mantel-Haenszel extension test. To control for TABP in the association of sleep with VE, the data were stratified for TABP. To control for VE in the association of sleep with TABP, the data were stratified for VE. In these analyses, a heterogeneity chi-square $\left(\mathrm{Chi}^{2}<\right.$ het> $)$ was 
calculated to test whether the linear trend is uniform in the various strata. To adjust for age, age was categorized as: 45.0-49.9; 50.0-54.9; 55.0-59.9 and 60.0-65.0. All calculations were done with program 3 from Rothman and Boice [21]. The associations between VE, TABP and age were examined by inspecting whether the rank-ordered data were related (Spearmans' rho).

\section{RESULTS}

Affirmative responses were obtained from 566 men (37.7\%). Questionnaires were returned by 471 subjects. Due to incomplete or incomprehensible answers 451 questionnaires were finally available (30.1\%). No further attempts were made to increase the response rate, assuming that selection bias did not influence the associations under study. The issue of selection bias will be discussed below. The prevalence of sleep characteristics is shown in Table I.

Table I.-The prevalence of sleep complaints, snoring, napping and sleep duration

\begin{tabular}{llr}
\hline & $\mathrm{N}$ & $\%$ \\
& & \\
Initiating sleep & 57 & 12.6 \\
Maintaining sleep & 46 & 10.2 \\
Early morning awakening & 26 & 5.8 \\
Difficulty waking up & 18 & 4.0 \\
Tiredness upon waking up & 32 & 7.1 \\
Sleepy during daytime & 59 & 13.1 \\
Cluster 'Insomnia' & 60 & 13.3 \\
$\quad$ 'Daytime sleepiness' & 37 & 8.2 \\
$\quad$ 'Mixed complaints' & 53 & 11.8 \\
Snoring & 265 & 58.8 \\
Napping & 180 & 39.9 \\
$7-8$ h. sleep (normal) & 175 & 38.8 \\
< 7 h. sleep (short) & 114 & 25.3 \\
>8 h. sleep (long) & 162 & 35.9 \\
\hline
\end{tabular}

Insomnia and daytime sleepiness were reported by $13.3 \%$ and $8.2 \%$ of the subjects, respectively. Mixed complaints were reported by $11.8 \%$. Snoring was reported by almost $59 \%$ of the subjects and $39.9 \%$ had a nap at least once a week. A sleep duration of $7-8 \mathrm{~h}$ was reported by $38.8 \%$, shorter sleep duration by $25.3 \%$ and longer sleep duration by almost $36 \%$ of the subjects. 
The associations between VE, TABP and age are given in Table II.

Table II.-Association of VE, TABP and age

\begin{tabular}{lcl}
\hline & rho & critical ratio test \\
VE - TABP & 0.29 & $\mathrm{z}=6.15(\mathrm{p} \leq 0.001)$ \\
VE - age & 0.01 & $\mathrm{z}=0.21(\mathrm{NS})$ \\
TABP - age & -0.21 & $\mathrm{z}=-4.45(\mathrm{p} \leq 0.001)$ \\
\hline
\end{tabular}

VE and TABP are positively related. A similar observation has been reported by Falger [15] and van Doornen [16]. VE and age are not related. TABP and age are negatively related. This contrasts with an earlier study [20] in which TABP and age were unrelated.

\section{Sleep and TABP}

Age-adjusted associations of sleep complaints, clusters of complaints, snoring, napping and sleep duration with TABP are shown in Table III.

Table III.-Association of sleep complaints, clusters of sleep complaints, snoring, napping and sleep duration with TABP (adjusted for age)

\begin{tabular}{|c|c|c|c|c|c|c|c|}
\hline \multirow[b]{2}{*}{ Initiating sleep } & $\begin{array}{l}\text { B } \\
\text { SRR }\end{array}$ & $\begin{array}{c}X \\
\text { SRR }\end{array}$ & \multirow{2}{*}{$\begin{array}{c}\text { A } \\
\text { SRR }\end{array}$} & \multicolumn{2}{|c|}{$\mathrm{Chi}_{<\mathrm{ext}>}$} & \multicolumn{2}{|c|}{$\mathrm{Chi}^{2}<$ het> } \\
\hline & 1.0 & 1.0 & & 2.1 & $*$ & 6.4 & NS \\
\hline Maintaining sleep & 1.0 & 1.6 & 3.2 & 3.0 & $* *$ & 1.2 & NS \\
\hline Early morning awakening & 1.0 & 1.4 & 1.7 & 0.9 & NS & 0.7 & NS \\
\hline Difficulty waking up & 1.0 & 1.1 & 0.7 & -1.0 & NS & 2.2 & NS \\
\hline Tired upon waking up & 1.0 & 1.3 & 1.6 & 1.1 & NS & 0.1 & NS \\
\hline Sleepy during daytime & 1.0 & 1.0 & 1.6 & 1.5 & NS & 1.2 & NS \\
\hline 'Insomnia' & 1.0 & 1.0 & 3.4 & 2.9 & $* *$ & 5.6 & NS \\
\hline 'Daytime sleepiness' & 1.0 & 0.8 & 1.8 & 1.3 & NS & 5.1 & NS \\
\hline 'Mixed complaints' & 1.0 & 1.4 & 2.1 & 2.0 & $*$ & 0.2 & NS \\
\hline Snoring & 1.0 & 1.4 & 1.3 & 1.4 & NS & 3.1 & NS \\
\hline Napping & 1.0 & 0.6 & 0.9 & -0.8 & NS & 5.2 & NS \\
\hline Short sleep & 1.0 & 1.6 & 1.5 & 1.0 & NS & 7.0 & NS \\
\hline Long sleep & 1.0 & 1.1 & 0.9 & -0.6 & NS & 0.9 & NS \\
\hline
\end{tabular}

${ }^{*} \mathrm{p} \leq 0.05 ;{ }^{* *} \mathrm{p} \leq 0.01$. 
Complaints as to sleep onset and sleep maintenance are significantly associated with TABP. Type A subjects also reported the clusters insomnia and mixed complaints significantly more often than Type B subjects. None of the characteristics snoring, napping, short or long sleep is associated with TABP. These associations were further studied by controlling for VE. The non-significant associations from Table III remained non-significant after controlling for VE. The changes in the significant associations are reported in Table IV.

Table IV.-Association of sleep complaints with TABP controlling for VE (adjusted for age)

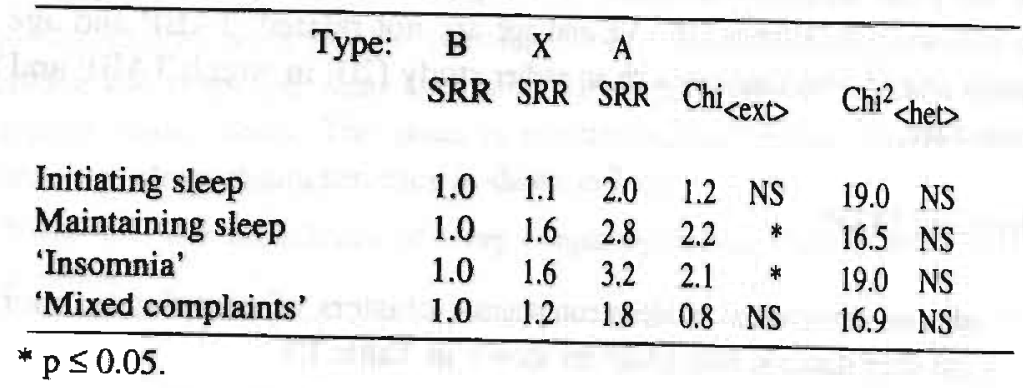

VE confounded the association of TABP with complaints as to sleep onset and with the cluster of mixed complaints. Vital exhaustion did not confound the more frequent reporting of difficulty in maintaining sleep or "insomnia" by Type A subjects. The heterogeneity chi-squares $\left(\mathrm{Chi}^{2}{ }_{<\text {het> }}\right)$ were not significant. This means that TABP is associated with the complaint of not being able to stay asleep and with the cluster of "insomnia", independent of VE.

\section{Sleep and VE}

Table V shows age-adjusted associations of sleep complaints, clusters of complaints, snoring, napping and sleep duration with VE. Sleep complaints are significantly associated with VE, except for "difficulty in waking up". Exhausted subjects complain of "insomnia", "daytime sleepiness" or "mixed complaints" significantly more often than vital subjects. A short sleep duration and frequent napping are significantly associated with VE, while a long sleep duration and snoring are not associated with VE. The associations were further examined by controlling for TABP (Table VI). The reporting of these subjective sleep characteristics was not confounded by TABP. The heterogeneity chi-squares never reached statistical significance. Consequently, VE is associated with sleep complaints, a short sleep and frequent napping, independent of TABP. 
Table V.-Association of sleep complaints, clusters of sleep complaints, snoring, napping and sleep duration with VE (adjusted for age)

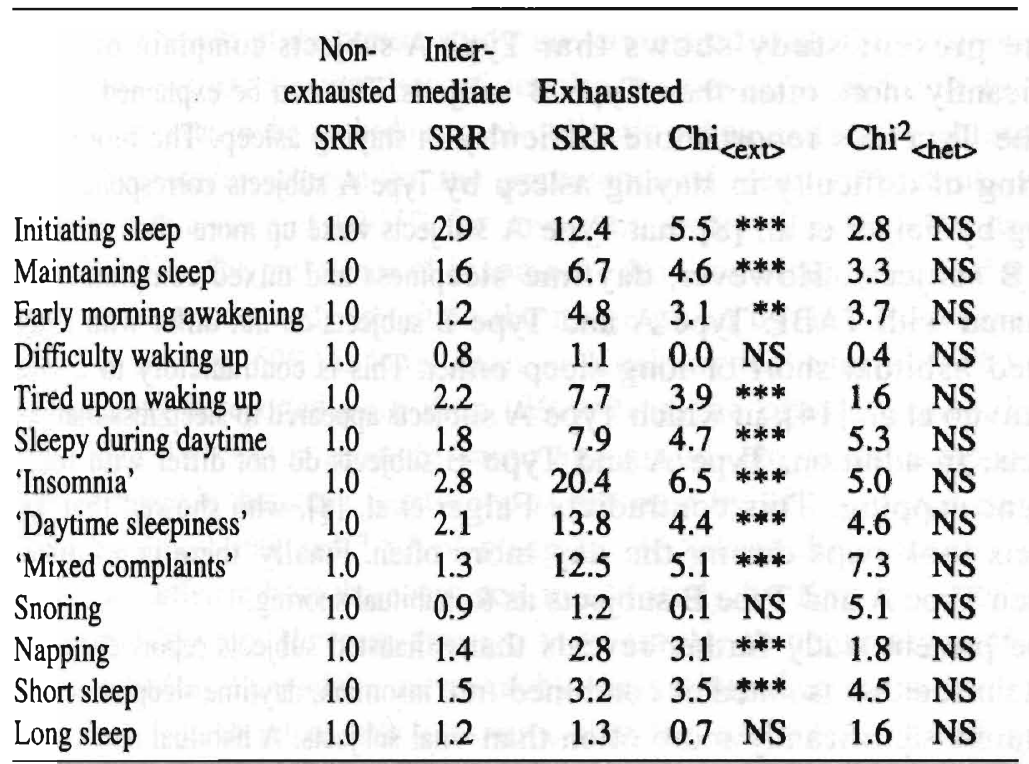

Table VI.-Association of sleep complaints, clusters of sleep complaints, snoring, napping and sleep duration with VE controlling for TABP (adjusted for age)

\begin{tabular}{|c|c|c|c|c|c|c|}
\hline \multirow[b]{3}{*}{ Initiating sleep } & \multicolumn{2}{|c|}{$\begin{array}{l}\text { Non- Inter- } \\
\text { exhausted mediate }\end{array}$} & \multicolumn{3}{|c|}{ Exhausted } & \multirow[b]{2}{*}{$\mathrm{Chi}^{2}<$ het $>$} \\
\hline & SRR & SRR & SRR & Chi< & ext> & \\
\hline & 1.0 & 3.4 & 15.9 & 5.3 & $* * *$ & $10.7 \mathrm{NS}$ \\
\hline Maintaining sleep & 1.0 & 1.6 & 7.0 & 4.1 & $* * *$ & $8.0 \mathrm{NS}$ \\
\hline Early morning awakening & $\lg 1.0$ & 0.9 & 4.4 & 2.7 & ** & $8.5 \mathrm{NS}$ \\
\hline Difficulty waking up & 1.0 & 0.8 & 1.4 & 0.0 & NS & $10.2 \mathrm{NS}$ \\
\hline Tired upon waking up & 1.0 & 2.3 & 7.5 & 3.8 & $* * *$ & $8.3 \mathrm{NS}$ \\
\hline Sleepy during daytime & 1.0 & 1.8 & 8.0 & 4.3 & $* * *$ & 13.6 NS \\
\hline 'Insomnia' & 1.0 & 3.3 & 25.7 & 6.1 & $* * *$ & $11.7 \mathrm{NS}$ \\
\hline 'Daytime sleepiness' & 1.0 & 2.1 & 16.1 & 4.2 & $* * *$ & $8.2 \mathrm{NS}$ \\
\hline 'Mixed complaints' & 1.0 & 2.1 & 19.0 & 5.2 & $* * *$ & $17.6 \mathrm{NS}$ \\
\hline Snoring & 1.0 & 0.9 & 1.4 & -0.4 & NS & $11.9 \mathrm{NS}$ \\
\hline Napping & 1.0 & 1.5 & 4.1 & 3.3 & $* * *$ & $16.7 \mathrm{NS}$ \\
\hline Short sleep & 1.0 & 2.1 & 3.0 & 3.3 & $* * *$ & 9.2 NS \\
\hline Long sleep & 1.0 & 1.6 & 1.5 & 0.8 & NS & 12.4 NS. \\
\hline
\end{tabular}

${ }^{* *} p \leq 0.01 * * * p \leq 0.001$. 


\section{DISCUSSION}

The present study shows that Type A subjects complain of insomnia significantly more often than Type B subjects. This can be explained by the fact that the Type A's report more difficulty in staying asleep. The more frequent reporting of difficulty in staying asleep by Type A subjects corresponds with the finding by Falger et al. [8] that Type A subjects wake up more often at night than Type B subjects. However, daytime sleepiness and mixed complaints are not associated with TABP. Type A and Type B subjects do not differ with respect to reported habitual short or long sleep either. This is contradictory to a study by Koskenvuo et al. [14], in which Type A subjects appeared to sleep less than Type B subjects. In addition, Type A and Type B subjects do not differ with respect to frequent napping. This contradicts Falger et al. [8], who showed that Type A subjects took naps during the day more often. Finally, there is no difference between Type A and Type B subjects as to habitual snoring.

The present study further reveals that exhausted subjects report chronic sleep complaints, either isolated or combined into insomnia, daytime sleepiness or mixed complaints significantly more often than vital subjects. A habitual short sleep and frequent napping are also more often reported by exhausted subjects. Type A behaviour did not confound the reporting of these complaints.

The results, therefore, suggest that it is unlikely that these sleep characteristics can be "explained" as risk factors for CHD because of an association with TABP, with the exception of frequent waking up during the night. The data indicate that a short habitual sleep duration, insomnia and frequent napping can be understood as risk factors for CHD by their association with VE. In addition, the data show that daytime sleepiness is an important characteristic of exhausted subjects.

At this point, an important question is whether it is likely that the low response has influenced the associations under study. Apart from age, however, no information was available from non-responding subjects. Therefore, to address this question, TABP, VE and the prevalence of sleep characteristics were compared with data from other studies. The mean age of the responders was not significantly different from the mean age of non-responders. Neither was the mean JAS value significantly different from that of a normgroup (response rate 81.8\%) [20]. The median VE value was slightly higher (1.6) than that found in the RCSS (response rate 100\%) [6]. There are, however, as yet no normative cut-off scores to classify subjects as either "vital" or "exhausted". In the present study, therefore, quartile cut-off points were used to assign subjects to increasing signs of exhaustion. These cut-off scores are almost similar to those derived from the RCSS. Application of the RCSS cut-off scores would have caused $4.0 \%$ of the subjects, who were 
assigned to the "intermediate" level, to have been assigned to the "exhausted" level of VE. For most of the sleep characteristics, no Dutch prevalence data are available, so the results of the present study are compared with those reported in foreign studies. An exact comparison of results, however, is difficult to draw because of differences in the methodology of collecting data and in the phrasing of questions. These studies indicate that the prevalence of sleep complaints varies considerably, with a range of $4.9-35 \%$ for insomnia and of $0.3-15 \%$ for daytime sleepiness [22-27]. The prevalence of insomnia, daytime sleepiness and mixed complaints in the present study are within the range given by health surveys. The prevalence of snoring (59\%) is lower than in Koskenvuos' study (89\%) [10]. Frequent napping is reported more often $(39.9 \%)$ in the present study than in Falgers' study [8] (7-9\%) in about the same age group. However, napping was assessed differently in that study. Short sleep is reported by $25.3 \%$ of the subjects, long sleep by almost $36 \%$ and $7-8 \mathrm{~h}$ of sleep by $38.8 \%$ of the subjects. These percentages are different from those reported in the study by Kripke [1] of males between 45 and 65 years. However, they are very similar to percentages of sleep durations reported by 1550 adults, surveyed by the Gallup Organization in 1979 (cited in: [28]). It is, therefore, safe to assume that the subjects, responding to a postal invitation to participate in a study on sleep problems, were not in particular people with complaints about their sleep. In addition, the sample was not biased as to age or the prevalence of TABP. The assignment of subjects to various levels of exhaustion by means of quartile cut-off scores, derived from the MQ18 distribution of either a referent group or from the sample of the present study, led to almost similar results. It is, therefore, unlikely that the slightly higher median value of VE, found in the present study, will have influenced the associations under study. Reported sleep durations are quite dissimilar in the various studies, which makes it rather difficult to estimate any bias of the present sample with respect to this particular sleep characteristic. The same difficulty applies to snoring and napping, which are quite dissimilar from those in other studies.

Stepanski et al. [29] studied daytime alertness in chronic insomniacs and found these people to be significantly more alert than controls. They interpreted their results in terms of a physiological hyperarousal. Because insomnia and VE are strongly associated, it would be highly interesting to study physiological hyperarousal in exhausted "insomniacs" as a possible mechanism for future MI.

Sleep apnoea is the diagnosis for excessive daytime sleepiness most frequently encountered $[30,31]$. The disorder may give rise to cardiovascular complications such as right heart failure or cardiac arrhythmia [30] and is implied as an important link between sleep complaints and CHD [32]. Because daytime sleepiness and VE are strongly associated, the present study suggests that sleep apnoea is a potential 
confounder in the association between VE and CHD.

Fatigue on final waking was implied as a determinant for MI because it is part of VE [5]. After controlling for several potential confounders, Falger et al. [8] still found that the complaint of "waking up feeling tired" retained a significant association with MI. However, the two studies differed as to the assessment of fatigue on final waking. The present study does not resolve this difference, but revealed that extreme fatigue on final waking is highly characteristic of VE. The complaint is indicative of both chronic insomnia [33] and excessive daytime sleepiness [22] and merits further attention in studies on the association betweenVE, sleep and CHD.

The present study also revealed that difficulty in waking up was not associated with VE or TABP. This particular sleep complaint represents trouble with "sleeping too deep". The absence of an association with VE and TABP supports the assumption that it is hyperarousal which causes the disruption of nocturnal sleep in VE and TABP. It is relevant to note that a long sleep duration was not associated with VE or TABP either. A long sleep duration has been shown to raise the risk of CHD. Difficulty in waking up has, however, not yet been studied. It is suggested, therefore, that a long sleep duration, and possibly difficulty in waking up, should be considered potential risk factors for future CHD independent of VE or TABP.

The present study revealed that short habitual sleep duration, insomnia and frequent napping can be considered potential risk factors for CHD because of their association with VE. In addition, it showed that daytime sleepiness is an important characteristic of exhausted subjects. So far, there is considerable uncertainty about the underlying pathophysiological mechanisms linking VE, a short habitual sleep duration, insomnia and frequent napping with future CHD. One possible link is based on the strong association between insomnia and VE. It is suggested that a physiological hyperarousal in exhausted insomniacs is a likely mechanism linking VE with future MI. Another possible link is based on the strong association of daytime sleepiness with VE. It is suggested that sleep apnoea is a potential confounding factor in the association between VE and CHD. The search for the neurohormonal and biochemical mechanisms which underlie the association between VE and MI, as well as the search for the physiological explanation of VE, its origins and its construct validity are in progress. 


\section{REFERENCES}

1. Kripke DF, Simons RN, Garfinkel L, Hammond EC. Short and long sleep and sleeping pills: Is increased mortality associated. Arch Gen Psychiatry 1979; 36: 103116.

2. Wingard DL, Berkman LF. Mortality risk associated with sleeping patterns among adults. Sleep 1983; 6: 102-107.

3. Partinen M, Putkonen PT, Kaprio J, Koskenvuo M, Hilakivi I. Sleep disorders in relation to coronary heart disease. Acta Med Scand (Suppl) 1982; 660: 69-83.

4. Koskenvuo M, Kaprio J, Partinen M, Langinvainio H, Sarna S, Rita H, Heikkilä K. Poor sleep quality, emotional stress and morbidity: a six-year follow-up of 10778 persons aged 35-59 years. In Stress and Psychosomatics (Edited by Achte K, Pakaslahti A), pp. 115-120. Helsinki: Psychiat Fennica (Suppl), 1986.

5. Appels A, de Vos $\mathbf{Y}$, van Diest R, Höppener P, Mulder P, de Groen J. Are sleep complaints predictive of future myocardial infarction? Act Nerv Sup (Praha), 1987; 29: $147-151$.

6. Appels A, Mulder P. Excess fatigue as a precursor of myocardial infarction. Eur Heart J 1988; 9: 758-764.

7. Siegrist J. Impaired quality of life as a risk factor in cardiovascular disease. J Chronic Dis 1987; 40: 571-578.

8. Falger PRJ, Schouten EGW, Appels AWPM, de Vos YCM. Sleep complaints, behavioral characteristics and vital exhaustion in myocardial infarction cases. Psychology and Health 1988; 2: 231-258.

9. Koskenvuo M, Partinen M, Sarna S, Kaprio J, Langinvainio H, Heikkilä K. Snoring as a risk factor for hypertension and angina pectoris. Lancet 1985; i: 893-895.

10. Koskenvuo M, Kaprio J, Telakivi T, Partinen M, Heikkilä K, Sarna S. Snoring as a risk factor for ischaemic heart disease and stroke in men. Br Med J 1987; 294: 1619.

11. Appels A, Mendes de Leon CF. The association between vital exhaustion, unstable angina and future myocardial infarction. In Predisposing Conditions for Acute Ischemic Syndromes (Edited by von Arnim TH, Maseri A), pp. 51-58. Darmstadt: Steinkopf, 1989.

12. Crisp AH, Queenan M, d'Souza M. Myocardial infarction and the emotional climate. Lancet 1984; i: 616-619.

13. Hicks RA, Pellegrini RJ. Sleep problems and Type A-B behavior in college students. Psychol Rep 1982; 51: 196.

14. Koskenvuo M, Kaprio J, Langinvainio H, Romo M, Sarna S. Psychosocial and environmental correlates of coronary-prone behavior in Finland. J Chronic Dis 1981; 34: 331-340.

15. Falger PRJ. Vital exhaustion and depression and Type A behavior in myocardial infarction cases. Eur Heart J 1986; 7: Abstract Suppl 1, 5. 
16. Doornen LJP. Physiological Stress Reactivity. PhD Thesis, Free University of Amsterdam, The Netherlands, 1988.

17. van Diest R, Milius H, Markusse R, Snel J. De Slaap-Waak Ervaring Lijst. T Soc Gezondheidsz 1989: 10: 343-347.

18. Cohen J. Weighted Kappa: Nominal scale agreement with provision for scaled disagreement or partial credit. Psychol Bull 1968; 70: 213-220.

19. Appels A, Höppener P, Mulder P. A questionnaire to assess premonitory symptoms of myocardial infarction. Int J Cardiol 1987; 17: 15-24.

20. Appels A, Jenkins CD, Rosenman R. Coronary-prone behavior in the Netherlands: A cross-cultural validation study. J Beh Med 1982; 5: 83-90.

21. Rothman KJ, Boice JD. Epidemiological analysis with a programmable calculator. Boston: Epidemiology Res Inc, 1982.

22. Lavie P. Sleep habits and sleep disturbances in industrial workers in Israel: main findings and some characteristics of workers complaining of excessive daytime sleepiness. Sleep 1981; 4: 147-158.

23. Bixler EO, Kales JD, Scharf MB, Kales A, Leo LA. Incidence of sleep disorders in medical practice: a physician survey. In Sleep Research 5 (Edited by Chase MH, Mitler M, Walter PL), p. 160, Los Angeles: UCLA BIS/BRI, 1976.

24. Karacan I, Thornby JI, Anch M, Holzer CE, Warheit GJ, Schwab JJ, Williams RL. Prevalence of sleep disturbance in a primarily urban Florida county. Soc Sci \& Med 1976; 10: 239-244.

25. Bixler EO, Kales A, Soldatos CR, Kales JD, Healy S. Prevalence of sleep disorders in the Los Angeles metropolitan area. Am J Psychiat 1979; 136: 1257-1262.

26. Hetta J, Almqvist H, Agren G, Hambert B, Liljenberg B, Roos BE. Prevalence of sleep disturbances and related symptoms in a middle-aged Swedish population. In Sleep ' 84 (Edited by Koella WP, Rüther E, Schulz H), pp. 373-376. Stuttgart: Gustav Fischer, 1985.

27. Partinen M, Eskelinen L, Tuomi K. Epidemiology of insomnia: environmental factors. In Sleep ' 84 (Edited by Koella WP, Rüther E, Schulz H), pp. 42-44. Stuttgart: Gustav Fischer, 1985.

28. Kales A, Kales JD. Evaluation and treatment of insomnia. New York; Oxford University Press, 1984.

29. Stepanski E, Zorick F, Roehrs T, Young D, Roth TH. Daytime alertness in patients with chronic insomnia compared with asymptomatic control subjects. Sleep 1988; 11: 54-60.

30. Coleman RM. Diagnosis, treatment and follow-up of about 8000 sleep/wake disorder patients. In Sleep/wake disorders. Natural History, Epidemiology and Long-Term Evolution. (Edited by Guilleminault CH, Lugaresi E), pp. 87-97. New York; Raven Press, 1983.

31. Guilleminault C, van den Hoed J, Mitler M. Clinical overview of the sleep apnoea syndrome. In Sleep Apnoea Syndromes (Edited by Guilleminault CH, Dement WC), pp. 1-12. New York: Alan R. Liss, 1978. 
32. Siegrist J. Sleep Disturbances and Cardiovascular Risk: A Biopsychosocial Approach. In Sleep related Disorders and Internal Diseases (Edited by Peter JH, Podszus T, von Wichert P), pp. 173-182. Berlin: Springer, 1987.

33. Kales JD, Kales A, Bixler E0, Soldatos CR, Cadieux RJ, Kashurba GJ, Vela-Bueno A. Biopsychobehavioral correlates of insomnia, V: clinical characteristics and behavioral correlates. Am J Psychiatry 1984; 141: 1371-1376. 
$-52-$ 


\title{
VITAL EXHAUSTION AND DEPRESSION: A CONCEPTUAL STUDY c
}

\author{
R. van Diest ${ }^{1}$ and A. Appels ${ }^{2}$
}

1 Department of Clinical Psychiatry, Limburg University, Maastricht, The Netherlands.

2 Department of Medical Psychology, Limburg University, Maastricht, The Netherlands.

Abstract-Excess fatigue, hopelessness, listlessness, loss of libido, increased irritability and problems with sleep have been found to increase the risk for a first non-fatal MI. These complaints are thought to reflect a state of "vital exhaustion". Most, if not all, of these feelings are also characteristic for subjects suffering from a depressive disorder. The aim of the present study was to explore whether a state of vital exhaustion is characterized more by depressed mood than by loss of vigour and excess fatigue. The Profile of Mood States was used to assess depressed mood, vigour and fatigue. Subjects monitored these factors themselves for a period of three weeks to circumvent retrospective recall bias and to investigate depressed mood, vigour and fatigue in a natural context. Current affective, cognitive, motivational and somatic symptoms of depression were further assessed retrospectively with the Beck Depression Inventory. The results with self-monitoring indicate that exhausted subjects suffer from loss of vigour and excess fatigue, while a depressed mood was almost absent. The retrospective assessment of symptoms of depression yielded similar results. It appeared that the most frequently reported symptoms were: "fatigability", "work inhibition", "sleep disturbance" and "loss of libido", while "depressed mood", the key symptom for depressive disorders, was hardly mentioned. Based upon these results, we suggest that what we term "vital exhaustion" is distinct from depression.

\section{INTRODUCTION}

Excess fatigue, hopelessness, listlessness, loss of libido, increased irritability and problems with sleep are complaints frequently reported by subjects in the months prior to their first myocardial infarction (MI) [1]. Despite the high prevalence of these complaints prior to MI (which were reported, using a 50\% cutoff reference from control groups, by $82 \%$ of MI patients [2]) their predictive validity for future MI lacked a prospective study. In the Rotterdam Civil Servant Study, the predictive validity was investigated in 3210 middle-aged males, initially free of coronary heart disease (CHD), over an average follow-up of 4.2 years [3].

c Published in Psychosom Res 1991; 35: 535-544. 
The study revealed that subjects who presented these complaints had a significant age-adjusted relative risk for non-fatal MI of 2.28 at follow-up, thus providing evidence that feelings such as excess fatigue, hopelessness, listlessness, loss of libido, irritability, and problems with sleep constitute a risk factor for future MI. Coronary patients emphasize the excess fatigue, in particular the fatigue they experience when waking up and at the end of the day, as their core feelings prior to MI. Because many of them attribute this excess fatigue to overwork or longstanding problems that could not be solved [2], we assume that these feelings reflect a state of exhaustion at which subjects arrive when their resources for adapting to stress are broken down [4]. Most, if not all, of these feelings, however, are also characteristic for subjects suffering from a depressive disorder as currently described in the DSM-III-R [5]. A state of exhaustion therefore appears to share common symptomatology with depressive disorders, although guilt or low selfesteem, two symptoms associated with depressive disorders, were not found to be predictive for future MI [6]. Evidence for an association between depression and CHD was given by Crisp et al. who observed that sadness, loss of libido and exhaustion discriminated most between subjects destined and those not destined for MI [7]. Booth-Kewley and Friedman, in a review of psychological predictors of CHD [8], also reported that depression is a reliable predictor of CHD. Matthews, however, found very limited support for this association [9], which made this author conclude that depression is not a significant predictor of CHD. The use of different assessment devices for depression may partly explain the controversy regarding the role of depression in CHD. Furthermore, the label "depression" itself may lead to some confusion [10] because it refers to a mood disturbance proper (a depressed mood or loss of interest in all, or almost all activities, DSM-III-R) and to a variety of depressive disorders that, according to the DSM-III-R, all have as their key feature the presence of a depressed mood or loss of interest. Depressive disorders are further characterized by various somatic, motivational, cognitive and behavioral symptoms, which do not all have to be present to lead to a diagnosis of depression [10]. In the retrospective assessment of depression, one has to take into account that recall bias frequently causes depressed subjects to overestimate their negative behaviours and underestimate their positive behaviours [11] and to emphasize somatic symptoms and underplay a depressed mood [12]. The assessment of depression is therefore complex and has led to the suggestion of using complementary approaches to assess depression [10]. The similarity in symptomatology of depressive disorders with that of "vital exhaustion" and the possible role of depression in CHD caused us to question whether subjects who are exhausted are suffering from depression. Following the suggestion of using complementary approaches in the assessment of depression, we opted to start with 
two exploratory approaches to investigate different manifestations of depression in exhausted subjects. The first approach consisted of the self-monitoring of depressed mood, fatigue and vigour over an extended period of 21 days [13,14] by means of the Profile of Mood States (POMS) [15]. These factors were chosen because they were assumed to cover relevant elements both of depressive disorders and of "vital exhaustion". They are known to be only moderately correlated $[15,16]$, which allows these factors to be studied relatively independently of one another. Although self-monitoring circumvents retrospective recall bias [17], it does give rise to a possible "reactivity" effect $[18,19]$ which causes subjects to change their reporting on depressed mood, fatigue and vigour because of selfmonitoring. As a second approach, a retrospective assessment of depression was made using the Beck Depression Inventory (BDI). The BDI was designed to include all symptoms integral to depressive disorders [20]. It provides for grading the intensity of each symptom and is not intended to establish a discrete psychiatric diagnosis [21]. Although developed to assess severity of depression in psychiatric patients, the BDI may not be suitable to detect severe depression [22] but has been described as appropriate for detecting mild depression in adults [23]. With these two approaches, the following question was investigated: "Is a state of exhaustion characterized by depressed mood or by a loss of vigour and excess fatigue?"

\section{METHOD}

\section{Subject selection}

Subjects were selected from 451 non-paid male volunteers (45-65 years) who participated in a study on the association between sleep characteristics, Type A behaviour and vital exhaustion [24]. A state of exhaustion was assessed by means of Form B of the Maastricht Questionnaire (MQ). Form B of this self-administered questionnaire consists of 21 items (range 0-42) which all load on one factor (Cronbachs' alpha: 0.89). The items of Form B were selected after the completion of the Rotterdam Civil Servant Study [3] because they were found to be predictive of future MI. A description of the construction of the MQ, including the 21 items, is given elsewhere [25]. To increase the likelihood of selecting "true-positives" and "true-negatives" for the present study, subjects with scores in the upper third (1842) were assigned to the "exhausted" group $(\mathrm{N}=158)$ and those in the lower third $(0-7)$ to the "non-exhausted" group ( $N=161)$. Subjects in the intermediate third were excluded. Random subsamples from the "exhausted" and "non-exhausted" 
group were approached by telephone and invited to participate in a sleep physiological study. Because that study required an oversampling of exhausted males, the subsamples consisted of 20 "exhausted" and 10 "non-exhausted" subjects. To further ensure that these subjects were "true-positives" or "truenegatives", they were interviewed (interviews were stored on videotape) by a psychiatrist prior to the start of the present study. Subjects were classified, using the video recordings, by two independent experts (blind to the assignment of subjects as to either the "exhausted" or "non-exhausted" group) as either truepositive (exhausted) or true-negative (non-exhausted). Subjects were classified as true-positives if their complaints reflected a breakdown in adaptation to stress and were present for a relative short duration. False-positives, which were excluded from the present study, may be caused by chronic psychiatric conditions or as a side effect of a somatic disease. After the interview, subjects were told that they had to fill out a diary six times a day for a period of 21 days. All participants started the diary study within 5 weeks after returning the MQ. Informed consent was obtained from all participants. Prior to starting with the diary they were visited at home to discuss the questions and instructions involved.

\section{Measurements}

Beck Depression Inventory. Symptoms of depression were assessed, in the fortnight prior to the start of the diary study, using the 21-item version of the Beck Depression Inventory (BDI) [20]. Subjects answered the BDI items according to the occurrence of symptoms during the past two weeks including the "present" day.

Profile of Mood States (POMS). Feelings of depressed mood, of vigour and of fatigue were assessed using three subscales of the Dutch version of the Profile of Mood States (POMS) [15]. Depressed mood is assessed as: Blue, Helpless, Sad, Lonely, Unhappy, Unworthy, Gloomy and Desperate (range 8-40: increased feelings of depressed mood result in a higher score). Vigour is assessed as: Active, Lively, Energetic, Cheerful and Clear-headed (range 5-25: more vigour results in a higher score) and fatigue is assessed as: Exhausted, Bushed, Fatigued, Listless, Worn out and Weary (range 6-30: more fatigue results in a higher score). All items are answered on a 5-point adjective rating scale ranging from 'not at all' to 'extremely'. 


\section{Self-monitoring}

Subjects were alerted when to fill in the diary with a "beeping" device (a Seiko $\mathrm{RC} 1000$ "wrist terminal"). The six beeps of each day were determined at random in six consecutive blocks of 150 minutes each, although beeps of consecutive blocks were at least 60 minutes apart. Beeps were calculated for each day of the week and were not given during the night $(22.30 \mathrm{pm}-07.30 \mathrm{am})$. The use of a wrist terminal is likely to cause some loss of data due to either malfunctioning of the terminal, noisy circumstances or because subjects were still asleep (or were having a nap) during a beep. The average loss was five beeps (range $0-10$ ) out of 126 . Subjects were instructed to answer the POMS items according to how they felt at the moment of the beep.

\section{Data analysis}

Beck Depression Inventory item scores were summed to arrive at a total severity score for each subject. This is the recommended use of the BDI because factor analytic studies with the BDI are not usually consistent with each other $[21,26]$. The Mann-Whitney U-test was used to test for significant differences in BDI scores between the exhausted and non-exhausted group.

Beep intervals were on average $2.5 \mathrm{hr}$ (SD: $0.5 \mathrm{hr}$ ) and will be treated as fixed.

Profile of Mood States item scores (excluding missing values) of each subject were used for two separate analyses. First, a reactivity effect to self-monitoring was explored. For each subject, the weekly averages of depressed mood, of vigour and of fatigue were calculated. These averages were analyzed in a 2 (exhausted vs nonexhausted) by 3 (weeks) MANOVA of repeated measures [27]. Secondly, the diurnal courses of depressed mood, of vigour and of fatigue were explored. For each subject, the diurnal courses of each of these factors were calculated by averaging the scores of beeps programmed at approximately the same time on separate days. The diurnal courses were analyzed in a 2 (exhausted vs nonexhausted) by 6 (diurnal course) MANOVA of repeated measures [27].

\section{RESULTS}

Based on their MQ scores, 20 "exhausted" and 10 "non-exhausted" subjects were invited to participate. The experts excluded five subjects who were all selected as "exhausted" by their MQ score. In the case of one man, the experts did not agree, two subjects were excluded because of somatic disease (cancer of the prostate and hypothyroidism) and two subjects were excluded because their 
complaints had been present over an extended period of years. One man, selected as "exhausted" by his MQ score, was classified as non-exhausted by the two experts. After the interview, three subjects (selected and classified as exhausted (two) or non-exhausted (one)), refused further participation. The participants, therefore, were 12 exhausted subjects (mean age $=54.6$ years; $S D=3.2$ ) and 10 nonexhausted subjects (mean age $=53.3$ years; $S D=4.1$ ).

\section{Symptoms of depression as assessed with the BDI}

Current symptoms of depression were present to a significantly greater extent in exhausted subjects (mean $\mathrm{BDI}=11.4 ; \mathrm{SD}=9.7$ ) than in non-exhausted subjects (mean $\mathrm{BDI}=1.0 ; \mathrm{SD}=1.1$ ) ( $\mathrm{U}=8.0 ; \mathrm{p}=.0007)$. The frequency with which symptoms were reported by exhausted subjects is shown in Table I.

Table I.-Number of exhausted subjects reporting BDI complaints

\begin{tabular}{llll}
\hline BDI symptom & N & BDI symptom & N \\
Fatigability & 9 & Pessimism & 4 \\
Work inhibition & 9 & $\begin{array}{l}\text { Guilty feelings } \\
\text { Crying spells }\end{array}$ & 4 \\
Sleep disturbance & 7 & Somatic preoccupation & 4 \\
Loss of libido & 6 & Sense of failure & 4 \\
& & Selfdislike & 4 \\
Indecisiveness & 5 & Depressed mood & 1 \\
Social withdrawal & 5 & Weight loss & - \\
Irritability & 5 & Loss of appetite & - \\
Lack of satisfaction & 5 & Distorted body image & - \\
& & Suicide wishes & - \\
& & Self-accusations & - \\
& & Sense of punishment & - \\
\hline
\end{tabular}

Symptoms reported most frequently were: "fatigability", "work inhibition", "sleep disturbance" and "loss of libido". Symptoms not reported at all were: "weight loss", "loss of appetite", "distorted body image", "suicide wishes", "selfaccusations" and "sense of punishment". It is important to note that "depressed mood", which is regarded as the key symptom for depression, was reported by only
one subject. 
Depressed mood, vigour and fatigue as assessed with the POMS

Reactivity to self-monitoring. The weekly averages of depressed mood, vigour and fatigue are shown in Fig. 1.
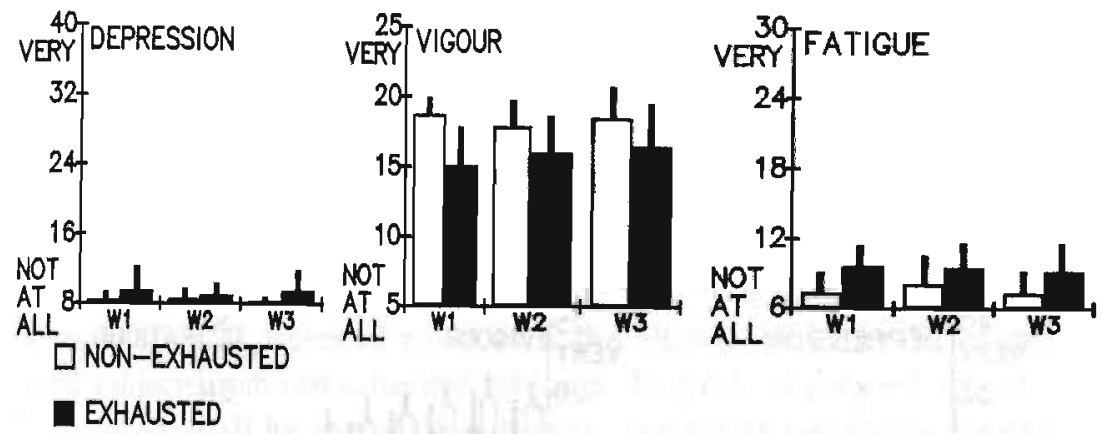

Fig. 1. Weekly averages (solid lines = SD) of depressed mood, of vigour, and of fatigue in exhausted and non-exhausted subjects.

A summary of a 2 (exhausted vs non-exhausted group) by 3 (weeks) MANOVA of repeated measures is shown in Table II.

Table II.-Summary of a 2 (group) by 3 (weeks) MANOVA of repeated measures

\begin{tabular}{|c|c|c|c|c|}
\hline \multirow[b]{2}{*}{ Depression } & \multirow{2}{*}{$\begin{array}{c}\text { Group * Week } \\
\text { Interaction } \\
\text { df } 2,19 \\
F=2,11 \quad p=0.15\end{array}$} & Week e & fect & \multirow{2}{*}{$\begin{array}{l}\text { Between Groups } \\
\text { df } 1,20 \\
F=2.66 \mathrm{p}=0.12\end{array}$} \\
\hline & & $\mathrm{F}=0.31$ & $p=0.74$ & \\
\hline Vigour & $F=2.00 p=0.16$ & $F=2.05$ & $p=0.16$ & $F=6.83 p=0.02$ \\
\hline Fatigue & $F=0.99 p=0.39$ & $\mathrm{~F}=1.98$ & $p=0.17$ & $F=5.07 \mathrm{p}=0.04$ \\
\hline
\end{tabular}

There is no significant group $\mathrm{x}$ week interaction for depressed mood, vigour or fatigue. Figure 1 shows that the weekly averages of these factors run almost parallel in both groups. Furthermore, there is no significant week effect. Inspection of Figure 1 shows that the weekly averages of either the exhausted or the nonexhausted group remain almost the same across the three weeks. Finally, exhausted 
and non-exhausted subjects differ significantly with respect to vigour and fatigue but not with respect to depressed mood. In fact, depressed mood is almost entirely absent in both groups. Figure 1 shows that exhausted subjects, on average, experience less vigour and more fatigue during the three weeks than non-exhausted subjects. These results do not support the assumption that a reactivity effect to selfmonitoring of depressed mood, vigour and fatigue was present in exhausted or nonexhausted subjects.

\section{Diurnal course}

The diurnal courses of depressed mood, vigour and fatigue are shown in Fig. 2.
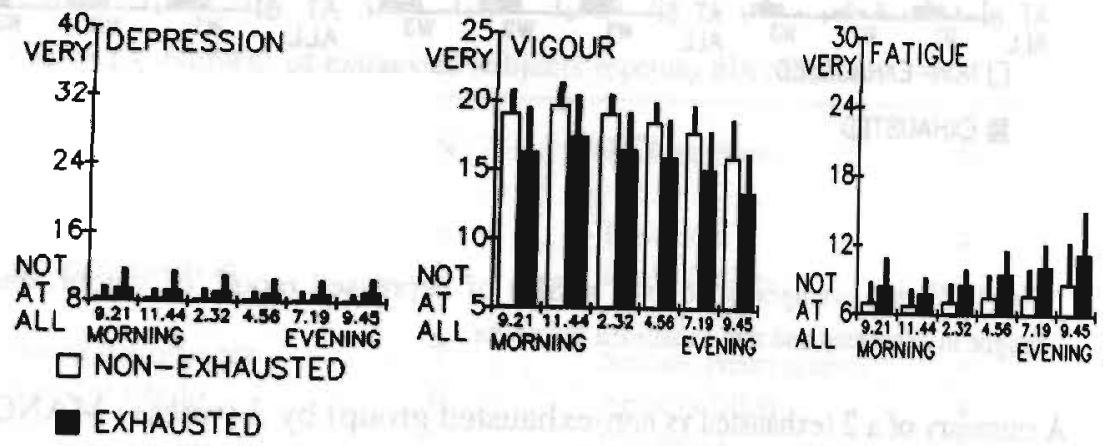

Fig. 2. Average diurnal course (solid lines = SD) of depressed mood, of vigour, and of fatigue in exhausted and non-exhausted subjects.

A summary of a 2 (exhausted vs non-exhausted group) by 6 (diurnal course) MANOVA of repeated measures is shown in Table III.

Table III.-Summary of a 2 (group) by 6 (diurnal course) MANOVA of repeated measures

\begin{tabular}{lccc}
\hline & $\begin{array}{c}\text { Group } \\
\text { df } 5,16\end{array}$ & $\begin{array}{c}\text { Diurnal Course } \\
\text { df } 5,16\end{array}$ & $\begin{array}{c}\text { Between Groups } \\
\text { df } 1,20\end{array}$ \\
Depression & $\mathrm{F}=0.69 \mathrm{p}=0.64$ & $\mathrm{~F}=0.84 \mathrm{p}=0.54$ & $\mathrm{~F}=2.71 \mathrm{p}=0.12$ \\
Vigour & $\mathrm{F}=0.18 \mathrm{p}=0.97$ & $\mathrm{~F}=12.8 \mathrm{p}=0.00$ & $\mathrm{~F}=7.11 \mathrm{p}=0.01$ \\
Fatigue & $\mathrm{F}=1.81 \mathrm{p}=0.17$ & $\mathrm{~F}=8.40 \mathrm{p}=0.00$ & $\mathrm{~F}=4.88 \mathrm{p}=0.03$ \\
\hline
\end{tabular}


There is no significant group $\mathrm{x}$ diurnal course interaction for depressed mood, vigour or fatigue. Inspection of Fig. 2 shows that the daily courses of these factors run almost parallel in both groups. There is a significant diurnal course effect for vigour and fatigue but not for depressed mood. Vigour decreases and fatigue increases during the day, while the daily course of depressed mood, in as far as present, is flat. Finally, Table III shows that exhausted and non-exhausted subjects differ significantly with respect to vigour and fatigue. Figure 2 shows that exhausted subjects, on average, experience less vigour and more fatigue during the entire day than non-exhausted subjects.

\section{DISCUSSION}

\section{Profile of Mood States}

Self-monitoring of depressed mood with the POMS did not differentiate exhausted subjects from non-exhausted subjects. In fact, depressed mood was hardly reported at all by any of the subjects during these three weeks of monitoring. Exhausted subjects, however, were significantly more tired and less vigorous than non-exhausted subjects during this entire period. This did not change across the three weeks, suggesting that elevated fatigue and diminished vigour are rather stable characteristics of a state of vital exhaustion. Furthermore, in both groups fatigue and vigour show a diurnal course with a significant increase in fatigue and a significant decrease in vigour as the day progresses. The diurnal courses of fatigue in exhausted and non-exhausted subjects are similar, however, as are the diurnal courses of vigour. Because the two groups differ significantly with respect to fatigue and vigour, the diurnal course results show that, on average, exhausted subjects start their day in a less vigorous and more fatigued state than non-exhausted subjects. This finding may be of diagnostic relevance because it corroborates, to some extent, the emphasis coronary patients give to their fatigue when waking up. The results obtained with the POMS therefore suggest that what we have termed "a state of vital exhaustion" is characterized more by excess fatigue and loss of vigour than by depressed mood.

\section{Beck Depression Inventory}

Despite these results, current affective, cognitive, motivational and somatic symptoms of depressive disorders, as reflected in the total severity score of the $\mathrm{BDI}$, were reported significantly more often by exhausted subjects. According to cut-off scores used by Beck and Beamesderfer [28], exhausted subjects can 
therefore be described as mildly depressed. Does this finding contradict the results obtained with the POMS. Tabulation of individual BDI items revealed that the symptoms reported most frequently were: "fatigability", "work inhibition", "sleep disturbance" and "loss of libido", while the key symptom for depressive disorders, "depressed mood", was reported by only one subject.

One can argue that the exclusion of subjects by the two experts (who were blind to the BDI results) or the refusals may have influenced the results of the present study, particularly because almost all non-participating subjects were exhausted subjects. The BDI total severity score of the group of exhausted non-participants (excluded and refusing subjects taken together) was, however, not significantly different from that of exhausted participants. This suggests that non-participation did not influence the results of the present study to a great extent. The results, obtained with the BDI and with the POMS, taken together therefore show that it is excess fatigue rather than depressed mood that is characteristic for "a state of vital exhaustion".

A major problem with respect to the concept of "vital exhaustion" concerns the possibility that what is being measured with the Maastricht Questionnaire are simply the physical sequelae of impaired myocardial functioning prior to MI. The essential finding of the prospective Rotterdam Civil Servant Study was, however, that what we have termed "vital exhaustion" precedes MI in males without complaints of chest pain or clinical manifestations of heart disease that are visible on a resting electrocardiogram [3]. In addition, the results of a recent study of 170 males referred for heart catheterization showed that feelings of exhaustion, as assessed with the $\mathrm{MQ}$, were related neither with severity of atherosclerosis of the coronary vessels nor with cardiac output as measured by the left ventricular ejection fraction [29]. Moreover, in a study of 175 patients, whose bloodflow needed to be restored by percutaneous translumenal coronary angioplasty (PTCA), it was observed that exhaustion, assessed with the MQ, had not significantly improved two weeks after PTCA [30]. These findings suggest that feelings of exhaustion are not predictive for future MI simply because they are the physical sequelae of manifest heart disease, severe atherosclerosis or left ventricular impairment. This, of course, does not exclude the possibility that "vital exhaustion" is a marker of subclinical heart disease, a hypothesis which merits attention in future research.

Illnesses with unexplained chronic fatigue have long been subsumed under the term "neurasthenia" and more currently under the term "chronic fatigue syndrome" (CFS). The reader interested in these concepts is referred to recent reviews of this topic [31-34]. Although a detailed answer to the question about the convergence and divergence between "neurasthenia/CFS" and "vital exhaustion" is beyond the 
scope of the present paper, a few remarks can be made. The draft of the tenth revision of the International Classification of Diseases (ICD) describes neurasthenia as persistent, distressing fatigability or bodily weakness after minimal effort, accompanied by unpleasant physical sensations like muscular aches and in absence of appreciable symptoms of anxiety or depression [35]. The main characteristics of illnesses subsumed under the term CFS are also severe physical and mental fatigue induced by physical or mental effort, myalgia, and absence of abnormalities on conventional medical investigations [33]. What we term "vital exhaustion" therefore shows both similarities and dissimilarities with neurasthenia and CFS. Most patients with CFS report length of illness ranging from 1.5 to 13 years and a rapid onset of symptoms which they ascribe to a physical cause [33]. We, however, consider someone "exhausted" if one or more stressful life events are indicated that "subjectively caused" the exhaustion, if the complaints cannot be attributed to a somatic disease and if the duration of "exhaustion" is relatively short (on average less than one year but not exceeding two years).

What has been attempted in the present study is to carefully select a small sample of subjects suffering from a set of symptoms predictive for future MI (the "exhausted" group) and a small sample of subjects not suffering from these symptoms (the "non-exhausted" group) to investigate whether a "state of vital exhaustion" is characterized more by feelings of depressed mood than by feelings of loss of vigour and excess fatigue. The results obtained with the POMS and with the $\mathrm{BDI}$ suggest that it is excess fatigue or loss of vigour rather than depressed mood that characterizes a "state of vital exhaustion".

Acknowledgements-The assistance of Rutger Lulofs in the selection of subjects is gratefully acknowledged. Special thanks to Prof. Dr MW deVRIES for his stimulating discussion and suggestion to study vital exhaustion in a natural context.

\section{REFERENCES}

1. Appels A, Mendes de Leon CF. The association between vital exhaustion, unstable angina and future myocardial infarction. In Predisposing Conditions for Acute Ischemic Syndromes (Edited by von Arnim TH, Maseri A), pp. 51-58. Darmstadt: Steinkopf, 1989.

2. Falger PRJ. Life-span development and myocardial infarction: an epidemiological study. PhD Thesis, Limburg University, The Netherlands, 1989.

3. Appels A, Mulder P. Fatigue and heart disease. The association between 'vital exhaustion' and past, present and future coronary heart disease. J Psychosom Res 1989; 33: 727-738. 
4. Appels A. Loss of control, vital exhaustion and coronary heart disease. In Stress, Personal Control and Health (Edited by Steptoe A, Appels A), pp. 215-235. Brussels: Wiley and Sons, 1989.

5. Diagnostic and Statistical Manual of Mental Disorders (Third Edition-Revised). Washington DC: American Psychiatric Association, 1987.

6. Appels A. Mental Precursors of Myocardial Infarction. Br J Psychiatry 1990; 156: 465-471.

7. Crisp AH, Queenan M, d'Souza M. Myocardial infarction and the emotional climate. Lancet 1984; i: 616-619.

8. Booth-Kewley S, Friedman H. Psychological predictors of heart-disease: a quantitative review. Psychol Bull 1987; 101: 343-362.

9. Matthews K. Coronary heart disease and type A behavior: Update on and alternative to the Booth-Kewley and Friedman (1987) quantitative review. Psychol Bull 1988; 104: 373-380.

10. Bouman TK. The measurement of depression with questionnaires. PhD Thesis, Groningen, The Netherlands, 1987.

11. Roth D, Rehm LP, Rozensky RH. Selfreward, self-punishment and depression. Psychol Rep 1980; 47: 3-7.

12. Hamilton M. Symptoms and assessment of depression. In Handbook of Affective Disorders (Edited by Paykel ES), pp. 3-11. Edinburgh: Churchill Livingstone, 1982.

13. de Vries MW. Investigating mental disorders in their natural settings. J Nerv Ment Dis 1987; 175: 509-513.

14. Csikszentmihalyi M, Larson R. Validity and reliability of the Experience Sampling Method. J Nerv Ment Dis 1987; 175: 526-536.

15. Wald FDM, Mellenbergh GJ. The short version of the Dutch translation of the Profile of Mood States (POMS). Ned T Psychol 1990; 45: 86-90.

16. meNair DM, Lorr M, Droppleman LF. Manual for the Profile of Mood States. San Diego: Educational and Industrial Testing Service, 1971.

17. Lamiell J. Toward an idiothetic psychology of personality. Am Psychol 1981; 36: 276-289.

18. Nelson RO. Methodological issues in assessment via self-monitoring. In Behavioral Assessment: New Directions in Clinical Psychology (Edited by Cone JD, Hawkins RP), New York: Brunner/Mazel, 1977.

19. Hersen M, Barlow DH. Single-case experimental designs: strategies for studying behavior change. Oxford: Pergamon Press, 1982.

20. Beck AT, Rush AJ, Shaw BF, Emery G. Cognitive therapy of depression. New York: Wiley \& Sons, 1979.

21. van Riezen H, Segal M. Comparative evaluation of rating scales for clinical Psychopharmacology. Amsterdam: Elsevier, 1988.

22. Kearns NP, Cruickshank CA, mcGuigan KJ, Riley SA, Shaw SP, Snaith RP. A comparison of depression rating scales. Br J Psychiatry 1982; 141: 45-49. 
23. Steer RA, Beck AT, Garrison B. Applications of the Beck Depression Inventory. In Assessment of Depression (Edited by Sartorius N, Ban TA), Berlin: Springer Verlag, 1986.

24. van Diest $\mathbf{R}$. Subjective sleep characteristics as coronary risk factors, their association with Type A behaviour and vital exhaustion. J Psychosom Res 1990; 4: 415-426.

25. Appels A, Höppener P, Mulder P. A questionnaire to assess premonitory symptoms of myocardial infarction. Int J Cardiol 1987; 17: 15-24.

26. Bouman TK, Luteyn F, Albersnagel FA, van der Ploeg FAE. Enige ervaringen met de Beck Depression Inventory (BDI). Gedrag 1985; 13: 13-24.

27. o'Brien RG, Kister Kaiser M. MANOVA method for analyzing repeated measures designs: An extensive primer. Psychol Bull 1985; 97: 316-333.

28. Beck AT, Beamesderfer A. Assessment of depression: The depression inventory. In Psychological Measurements in Psychopharmacology, Modern Problems in Pharmacopsychiatry (Edited by Pichot P), vol. 7; pp 151-169. Basel: Karger, 1974.

29. Kop WJ, Appels APWM, Mendes de Leon CF. Relation between vital exhaustion and coronary artery disease. In: Proceedings of the First International Congress of Behavioral Medicine. Uppsala: Sweden, 1990.

30. Kop WJ, Appels APWM, Mendes de Leon CF, Bär FWHM. The relation between severity of coronary artery disease and exhaustion. In prep.

31. Costa e Silva JA, de Girolamo G. Neurasthenia: History of a concept. In Psychological Disorders in General Medical Settings (Edited by Sartorius N, Goldberg D, de Girolamo G, Costa e Silva JA, Lecrubier Y, Wittchen U), pp 69-81. Toronto: Hogrefe \& Huber Publishers, 1990.

32. Wessely S. Old wine in new bottles: neurasthenia and ME. Psychol Med 1990; 20: 35-53.

33. Wessely S. Chronic fatigue and myalgia syndromes. In Psychological Disorders in General Medical Settings (Edited by Sartorius N, Goldberg D, de Girolamo G, Costa e Silva JA, Lecrubier Y, Wittchen U), pp 82-97. Toronto: Hogrefe \& Huber Publishers, 1990.

34. Greenberg DB. Neurasthenia in the 1980s: Chronic mononucleosis, chronic fatigue syndrome, and anxiety and depressive disorders. Psychosomatics 1990; 31: 129-137

35. World Health Organization. Mental, behavioral and developmental disorders (draft chapter V (F)). In International Statistical Classification of Diseases, Injuries, and Causes of Death (10th revision). Geneva: World Health Organization, 1989. 
$-66-$ 


\title{
VITAL EXHAUSTION AND PERCEPTION OF SLEEP d
}

\author{
R. van Diest ${ }^{1}$ and A. Appels ${ }^{2}$
}

I Department of Clinical Psychiatry, Limburg University, Maastricht, The Netherlands. ${ }^{2}$ Department of Medical Psychology, Limburg University, Maastricht, The Netherlands.

Abstract-Sleep complaints and unusual sleep durations have been found to increase the risk for coronary heart disease. One explanation states that insomnia and excess fatigue on final waking are predictive for myocardial infarction because they are part of a state of "vital exhaustion". Sleep complaints and sleep durations, however, are usually assessed with retrospective self-report procedures. Such procedures must be interpreted with reserve because in insomniacs, a consistent disparity in the perception of habitual and current sleep has been observed. This caused us to question whether this phenomenon is present in exhausted subjects also. Two approaches were used. The first one consisted of a retrospective assessment of subjective sleep characteristics, the second one of selfmonitoring these sleep characteristics during 21 days. In the second week, subjects slept in a laboratory. No disparity was found in how exhausted subjects perceive their habitual and current sleep. It appeared that sleep quality is worse and sleep duration is shorter in exhausted subjects. They also feel more sleepy and take longer naps during the day, indicating that their daytime functioning is impaired. Sleeping in a laboratory reduced time asleep and midsleep wake. Sleep quality, however, was essentially the same as at home. These findings made us conclude that it is not the intrusion of nocturnal wake times per se but more likely the impaired daytime functioning which is the reason for exhausted subjects to complain about their sleep.

\section{INTRODUCTION}

Various studies have indicated that both short and long sleep durations and sleep complaints are potential risk factors for coronary heart disease (CHD) [1-10]. A direct comparison of these studies is difficult to draw, however, because most of them did not explore sleep complaints systematically nor did they make a distinction between transient and chronic sleep complaints [11]. Nevertheless, interesting explanations have been offered as to why sleep complaints may be predictive for myocardial infarction (MI). One came from a cross-sectional study in patients with a recent MI [10]. In this study, the prevalence of insomnia and

d Published in J Psychosom Res 1992; 36: 449-458. 
depression prior to MI was explored. The results suggest that many of these patients report insomnia (sleep onset, midsleep and early moming) prior to MI as part of a depressive episode they suffered from in the period prior to this cardiac event. Another explanation came from a prospective study among middle-aged males, initially free of CHD [7]. Insomnia (sleep onset and midsleep) and tiredness upon final waking were found to be predictive for MI because they are part of a state of "vital exhaustion". This observation was supported by a cross-sectional study, in which strong associations were found between chronic sleep complaints (sleep onset, midsleep, early morning, tiredness upon final waking, daytime sleepiness) and vital exhaustion (VE) [11]. The same study also revealed a strong association between habitual short sleep and VE, suggesting that short sleep can also be understood as a risk factor for MI by its association with VE. A state of vital exhaustion is characterized by excess fatigue, loss of energy, increased irritability, problems with sleep and feelings of demoralization. This state has been found to precede the occurrence of MI [12].

In all of these studies, sleep complaints and sleep durations were assessed with retrospective self-report questionnaires or interviews. Several studies have indicated, however, that subjects who suffer from insomnia differ significantly from controls in how they characterize their habitual sleep but do not differ from controls in how they describe their current nights of sleep in a sleep laboratory $[13,14]$. Although this can partly be explained by the fact that laboratory studies may induce sleep problems in controls and relieve them in insomniacs [15], these findings suggest that retrospective self-report procedures concerning sleep should be interpreted with reserve. The high prevalence of short sleep durations and of sleep complaints in exhausted subjects $[9,11]$ reflects the perception of habitual sleep by these subjects $[16,17]$. The disparity in how insomniacs perceive their habitual and current nights of sleep caused us to question whether this phenomenon is present in exhausted subjects also. To investigate such a disparity, we chose to use two approaches. The first approach consisted of a retrospective assessment of sleep complaints, habitual sleep duration, sleep quality, nocturnal wake times, daytime sleepiness and napping. The second approach consisted of the daily selfmonitoring of these sleep characteristics with a diary over a period of 21 days [18]. Self-monitoring circumvents retrospective recall bias [19], but does give rise to a possible "reactivity" effect [20] which causes subjects to change their reporting of sleep quality, nocturnal wake times, daytime sleepiness and napping during the course of monitoring. The design further included four nights of sleep in a sleep laboratory during the second week of this 21 day period. 
The aim of the present study was to explore in detail a possible discrepancy between subjective estimates of sleep quality, nocturnal wake times, daytime napping and daytime sleepiness in exhausted subjects, as obtained in retrospect and on a daily basis either at home or in a sleep laboratory.

\section{METHOD}

\section{Subjects}

Subjects were selected from 451 non-paid male volunteers (45-65 years) who participated in a study on the association between sleep characteristics, Type A behaviour and vital exhaustion [11]. The Maastricht Questionnaire (MQ) (Form B) was used to assess a state of exhaustion. A description of the MQ (range 0-42), is given elsewhere [21]. To increase the likelihood of selecting "true-positives" and "true-negatives", subjects with scores in the upper tertile (18-42) were designated "exhausted" $(\mathrm{N}=158)$ and those in the lower tertile (0-7) "non-exhausted" $(\mathrm{N}=161)$. Subjects in the intermediate tertile were excluded. Subsamples from both the "exhausted" and "non-exhausted" group were randomly invited by telephone to participate in a sleep physiological study. To further ensure "true-positives" or "true-negatives", these subjects were interviewed (interviews were stored on videotape) by a psychiatrist prior to the start of the study. Subjects were classified, using the video recordings, by two independent experts (who were blind as to whether subjects were assigned to either the "exhausted" or "non-exhausted" group) as either true positive (exhausted) or true negative (non-exhausted). They were classified as true-positives if their complaints had been present for a relatively short duration and reflected a breakdown in adaptation to stress. False-positives, which were excluded from the present study, may be caused by chronic psychiatric conditions or as a side effect of a somatic disease. After the interview, subjects were told that the present study comprised the completion of two questionnaires every morning on awaking and of a diary six times a day for a period of 21 days. Not all of the invited subjects were willing to sleep in the laboratory, but agreed to complete the diary study. These subjects will be used to explore a "reactivity to self-monitoring" effect (see Results). Informed consent was obtained from all participants. The study started within five weeks after returning the MQ. Prior to starting with the diary subjects were visited at home to discuss the questions and instructions involved in the measurement of current sleep. 


\section{Exclusion criteria}

The sleep physiological study further required that participants used no sleep medication, were not employed in shiftwork and were free of a medical history of MI.

\section{Measurements}

\section{Habitual sleep}

Sleep-Wake Experience List (SWEL). The SWEL was sent along with the MQ to assess problems in: initiating sleep; maintaining sleep; early termination of sleep; difficulty waking up; tiredness upon waking up; and daytime sleepiness. The answers are based on the past three months. The items and coding of the SWEL have been published elsewhere $[11,16,17]$. In addition to this, subjects were questioned about their sleep duration, nocturnal wake times, and taking naps for the past 3 months. Sleep duration: 'How many hours of sleep did you usually get?'. Possible answers ranged from 'less than 5 hr.' to 'more than 9 hr.' Nocturnal wake times: 'How long did it usually take you to fall asleep?' and 'If you woke up from your sleep, how long did you usually lie awake?'. Possible answers ranged from 'less than or equal to $5 \mathrm{~min}$ ' to 'more than $60 \mathrm{~min}$ '. Napping: 'How often did you have a nap?'. Possible answers ranged from 'less than once a month' to 'almost every day'.

Sleep quality. During the visit at home, the sleep quality for the past three months was assessed with the Groningen Sleep Quality Questionnaire (GSQ). The GSQ consists of 14 'yes' or 'no' items which have been shown to reliably measure a unidimensional construct [22]. The lower the score (range 0-14), the better the sleep quality. The items are as follows: Often, I do not close my eyes the whole night through; Often, I get up in the middle of the night; Often, after I get up in the morning, I feel tired; Often, I get up several times in the middle of the night; I feel that I mostly sleep badly; I feel that I often get only a few hours of sleep; I feel that I mostly sleep well at night; I feel that I do not get enough sleep; I fall asleep easily; I lie in bed for more than half an hour before I fall asleep; I toss and turn all night; I do not sleep longer than five hrs; Mostly, I feel well rested in the morning after I get up; If I wake up at night, it is difficult for me to fall asleep again. 


\section{Current sleep}

Nocturnal wake times and daytime napping. Every morning on rising, subjects were asked: 'At what time did you go to bed last night?', 'How long were you awake before you fell asleep?', 'When and how long were you awake last night?', 'At what time did you get up this moming?', 'How long were you awake before rising?', 'When and how long did you have a nap yesterday?'.

Sleep quality. Every morning on rising, the sleep quality of the previous night was assessed with the GSQ, described above. The items were, however, rephrased to refer to the previous night [22]. For instance, the item 'Often, I do not close my eyes the whole night through' is rephrased as 'Last night, I did not close my eyes once'. The lower the score (range 0-14), the better the sleep quality.

Stanford Sleepiness Scale. Daytime sleepiness was assessed with an adapted form of the Stanford Sleepiness Scale (SSS) [23]. In its adapted form, the SSS consists of four items, Fully alert, Dull, Sleepy and Almost falling asleep. They are answered on a 5-point adjective rating scale ranging from 'not at all' to 'extremely'. Subjects were urged to continue their habitual sleep-wake schedule. There was, therefore, no fixed time in answering the daily questions related to sleep quality, nocturnal wake times or daytime napping. Six times a day, subjects were alerted by a "beeping" wrist terminal to fill in the SSS. This procedure is likely to cause some loss of data. The average loss was five beeps (range $0-10$ ) out of 126. Details of this procedure of Experience Sampling have been published elsewhere $[24,25]$. Subjects were instructed to answer the SSS items according to how they felt at the moment of the beep. These were on average 149.0 minutes apart $(S D=30.0)$. All subjects, who participated in the sleep physiological part of the study, came to the sleep laboratory not later than 11.00 PM on the first night. All subsequent arrivals were made on an evening-to-evening basis for each subject, depending on his social and/or work activities. For the same reason, rise times were set on a morning-to-morning basis for each subject. Results of the sleep physiological part of the study will be presented elsewhere. 


\section{Data analysis}

\section{Habitual sleep}

Sleep duration. To estimate reported sleep durations, the midpoints of each sleep duration category were used; for example, subjects who reported sleeping less than $9 \mathrm{hr}$ were taken as sleeping $8.5 \mathrm{hr}$ and those who reported sleeping less than $5 \mathrm{hr}$ were taken as sleeping $4.5 \mathrm{hr}$ [3].

Nocturnal wake times. ('Less than or equal to $5 \mathrm{~min}$ ' and 'less than or equal to $20 \mathrm{~min}$ ') and ('less than or equal to $60 \mathrm{~min}$ ' and 'more than $60 \mathrm{~min}$ ') were combined into 'less than or equal to 20 minutes' and 'more than 20 minutes'.

Napping ('Less than once a month' and ' $1-4$ times a month') and ('1-4 times a week' and 'almost every day') were combined into 'less than once a week' and 'once or more than once a week'.

Sleep quality. Items were summed to obtain a final score for each subject.

\section{Current sleep}

Coding of the 21 day period. For each subject, the 21 day period started on a Monday morning and ended on a Sunday evening. To prevent possible changes in habitual sleep-wake schedules due to public holidays, these were circumvented in the planning of the study. For those subjects who slept in the laboratory (starting on Monday evening and ending on Friday morning in the second week), the 21 days can be divided into three periods: a prelaboratory (PRELAB), a laboratory (LAB) and a postlaboratory period (POSTLAB). To maximize comparability between these three periods, only those nights from the PRELAB and POSTLAB period were used which correspond to $\mathrm{LAB}$ nights, ie. nights starting on Monday evening and ending on Friday morning.

To examine a "reactivity to self-monitoring" effect, the same selection of nights starting on Monday and ending on Friday was made in those subjects who did not sleep in the laboratory. Their nights will also be referred to as the PRELAB, LAB and POSTLAB period.

Nocturnal wake times, napping. For each subject, time in bed, time asleep, total time awake, sleep onset awake, midsleep awake, early morning awake and napping 
were calculated in min for each night (or day). Furthermore, the number of days subjects took a nap during the PRELAB, LAB and POSTLAB period were determined.

Stanford Sleepiness Scale. For each item, 'not at all' was coded as '0' and 'extremely' as ' 4 '. The final SSS score at each beep for each subject was arrived at by subtracting the "fully alert" item score from the sum of the remaining three items. The range is therefore -4 (fully alert) to 12 (very sleepy).

\section{Statistics}

Habitual sleep. The Kruskal-Wallis one-way ANOVA was used to test for significant differences in habitual sleep characteristics between exhausted and nonexhausted subjects.

Current sleep. Data are collapsed into averages for the PRELAB, LAB and POSTLAB periods and are analyzed in a 2 (exhausted vs non-exhausted) by 3 (PRELAB, LAB, POSTLAB) MANOVA of repeated measures [26] to detect significant differences in current sleep characteristics between exhausted and nonexhausted subjects. A one-way MANOVA with three repeated measures (PRELAB, LAB, POSTLAB) was used to explore reactivity to self-monitoring. In case of a significant period effect (PRELAB, LAB, POSTLAB), orthogonal polynomial trend contrasts were used to search for the presence of significant linear and/or quadratic trends [26]. Because this is an exploratory study, we accepted a type I error of $10 \%$.

\section{RESULTS}

Based on their MQ scores, 25 "exhausted" and 10 "non-exhausted" males were invited to participate. The experts excluded five subjects who were all selected as "exhausted" by their MQ scores. In the case of one subject, the experts did not agree, two subjects were excluded because of a somatic disease (cancer of the prostate and hypothyroidism) and two subjects were excluded because their complaints had been present over an extended period of years. One man, selected as "exhausted" by his MQ score, was classified as non-exhausted by the two experts. After the interview, three subjects (selected and classified as exhausted (two) or non-exhausted (one), refused all further participation. The participants, therefore, were 17 exhausted subjects (mean age $=54.7$ years; $S D=2.8$ ) and 10 non- 
exhausted subjects (mean age $=53.3$ years; $S D=4.1$ ). In the exhausted group, nine subjects completed the study, including the sleep physiological part, eight subjects completed the study without sleep physiological monitoring. In the non-exhausted group, eight subjects completed the study, including the sleep physiological part, two subjects completed the study without sleep physiological monitoring. These two subjects are omitted from all further analyses. Table I shows demographic characteristics of these three groups.

Table I.-Demographic characteristics of exhausted and non-exhausted subjects with (physiology+) or without (physiology-) polysomnographic monitoring

\begin{tabular}{lccc}
\hline & $\begin{array}{c}\text { Exhausted } \\
\text { physiology+ } \\
(\mathrm{n}=9)\end{array}$ & $\begin{array}{c}\text { Exhausted } \\
\text { physiology- } \\
(\mathrm{n}=8)\end{array}$ & $\begin{array}{c}\text { Non-exhausted } \\
\text { physiology+ } \\
(\mathrm{n}=8)\end{array}$ \\
Age (SD) & $54.0(3.1)$ & $55.5(2.3)$ & $52.5(4.2)$ \\
Work (\% yes) & 77.8 & 75.0 & 100.0 \\
\hline
\end{tabular}

\section{Habitual sleep}

Habitual aspects of sleep are shown in Table II.

Table II.-Habitual aspects of sleep in exhausted and non-exhausted subjects with (physiology+) or without (physiology-) polysomnographic monitoring

\begin{tabular}{|c|c|c|c|c|}
\hline & & $\begin{array}{c}\text { Exhausted } \\
\text { physiology+ }\end{array}$ & $\begin{array}{l}\text { Exhausted } \\
\text { physiology- }\end{array}$ & $\begin{array}{c}\text { Non-exhausted } \\
\text { physiologyt }\end{array}$ \\
\hline Initiating sleep & $(\%)$ & 44.4 & 50.0 & 0 \\
\hline Maintaining sleep & $(\%)$ & 66.7 & 62.5 & 0 \\
\hline Early Morming awakening & $(\%)$ & 55.6 & 62.5 & 0 \\
\hline Difficulty waking up & (\%) & 0 & 0 & 0 \\
\hline Tiredness upon waking up & $(\%)$ & 33.3 & 37.5 & 0 \\
\hline Daytime sleepiness & $(\%)$ & 33.3 & 37.5 & 0 \\
\hline Sleep quality & (SD) & $6.56(3.5)$ & $7.38(4.1)$ & $2.38(1.3)$ \\
\hline Sleep duration & $(\mathrm{SD})$ & $6.9(0.7)$ & $6.6(0.6)$ & $7.5(0.8)$ \\
\hline Sleep Onset $\quad(\%>20$ & $\min )$ & 66.7 & 62.5 & 0 \\
\hline Sleep Maintenance $(\%>20$ & $\min )$ & 55.6 & 62.5 & 0 \\
\hline Napping $\quad(\%>$ once/ & week) & 55.6 & 50.0 & 0 \\
\hline
\end{tabular}


Sleep complaints were reported exclusively by exhausted subjects, except for difficulty waking up, which was reported by none of the subjects. Three of the 17 exhausted subjects (17.6\%) reported no sleep complaints. The sleep quality was significantly worse in exhausted subjects (Kruskal-Wallis $\mathrm{Chi}^{2} 8.79 ; \mathrm{p}=0.01$ ) than in non-exhausted subjects and sleep durations were significantly shorter $\left(\mathrm{Chi}^{2} 5.08\right.$; $\mathrm{p}=0.08$ ). More than $55 \%$ of exhausted subjects reported that it took them 20 minutes or more to fall (back) asleep. Finally, taking a nap more than once a week was reported by at least $50 \%$ of exhausted subjects.

\section{Current sleep}

Reactivity to self-monitoring. The one-way MANOVA with three repeated measures (PRELAB, LAB, POSTLAB) showed no significant period effect in any of the sleep characteristics under study. It may therefore be concluded that neither the reporting of sleep quality, time in bed, time asleep, or nocturnal wake times, nor the reporting of daytime napping, or daytime sleepiness, changes purely by selfmonitoring.

PRELAB, LAB and POSTLAB sleep. The means and SD of sleep quality, time in bed, time asleep, total time awake, sleep onset awake, midsleep awake, and early morning awake in exhausted and non-exhausted subjects with sleep physiological monitoring are shown in Fig. 1.

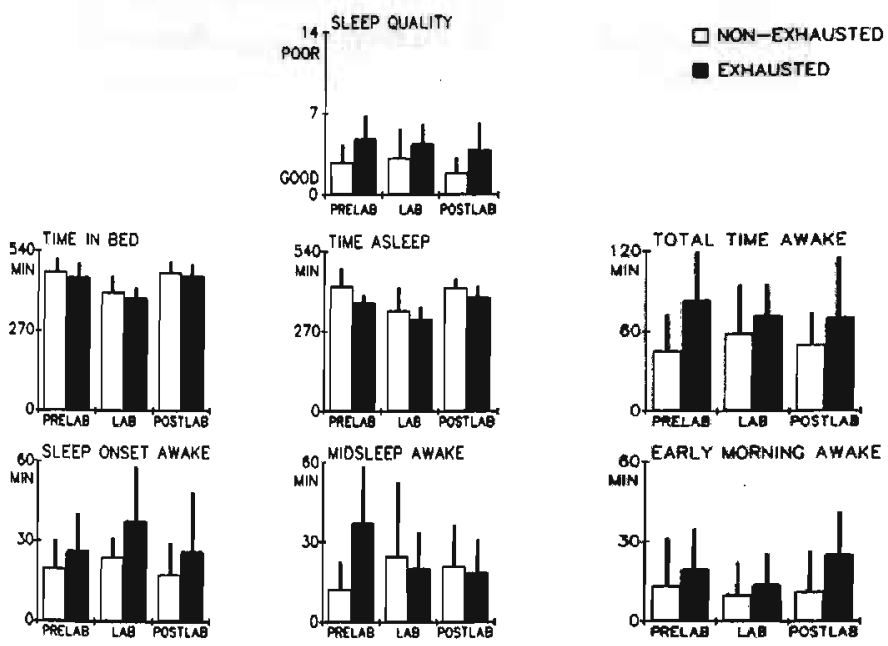

Fig. 1. Means and SD of sleep quality, time in bed, time asleep, and nocturnal wake times in exhausted and non-exhausted subjects with sleep physiological monitoring. 
The means and SD of daytime sleepiness, daytime napping, and number of daytime naps in exhausted and non-exhausted subjects with sleep physiological monitoring are shown in Fig. 2.

$\square$ NON-EXHAUSTEO

EXHAUSTED

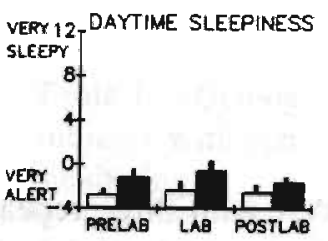

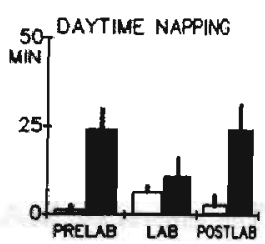

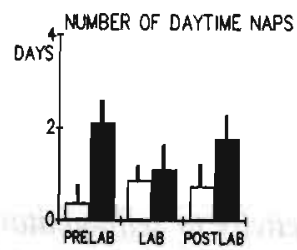

Fig. 2. Means and SD of daytime sleepiness, daytime napping, and number of daytime naps in exhausted and non-exhausted subjects with sleep physiological monitoring

A summary of a 2 (exhausted vs non-exhausted group) by 3 (PRELAB, LAB, POSTLAB period) MANOVA of repeated measures is shown in Table III.

Table III.-Summary of a 2 (exhausted vs non-exhausted: group) by 3 (PRELAB, LAB, POSTLAB: period) MANOVA of repeated measures

\begin{tabular}{|c|c|c|c|c|c|}
\hline \multirow[b]{2}{*}{ Sleep quality } & \multicolumn{2}{|c|}{$\begin{array}{l}\text { Group * period } \\
\text { Interaction } \\
\text { df } 2,14\end{array}$} & \multicolumn{2}{|c|}{ Period effect } & \multirow{2}{*}{$\begin{array}{c}\text { Between Groups } \\
\text { df } 1,15 \\
F=5.65 p=0.03\end{array}$} \\
\hline & $\mathrm{F}=0.42$ & NS & $F=2.67$ & NS & \\
\hline Time in bed & $F=0.05$ & NS & $F=26.19$ & $\mathrm{p}=0.00$ & $\mathrm{~F}=1.19 \quad \mathrm{NS}$ \\
\hline Time asleep & $\mathrm{F}=0.94$ & NS & $F=16.26$ & $\mathrm{p}=0.00$ & $F=5.53 \quad p=0.03$ \\
\hline Total time awake & $\mathrm{F}=1.26$ & NS & $\mathrm{F}=0.21$ & NS & $\mathrm{F}=2.62 \mathrm{NS}$ \\
\hline - Sleep onset & $F=0.41$ & NS & $F=2.17$ & NS & $F=3.18 p=0.09$ \\
\hline - Midsleep & $\mathrm{F}=4.26$ & $\mathrm{p}=0.04$ & $F=0.57$ & NS & $\mathrm{F}=0.65 \mathrm{NS}$ \\
\hline - Early morning & $F=0.85$ & NS & $\mathrm{F}=1.55$ & NS & $\mathrm{F}=1.79 \quad \mathrm{NS}$ \\
\hline Daytime sleepiness & $\mathrm{F}=2.96$ & NS & $\mathrm{F}=5.40$ & $\mathrm{p}=0.02$ & $F=9.19 p=0.01$ \\
\hline Daytime napping & $\mathrm{F}=3.42$ & NS & $F=0.76$ & NS & $F=7.17 p=0.02$ \\
\hline Number of naps & $F=3.26$ & NS & $F=0.40$ & NS & $F=3.29 p=0.09$ \\
\hline
\end{tabular}

Group $x$ period interaction. There is no significant group $\mathrm{x}$ period interaction for any of these sleep characteristics except for midsleep awake. Figure 1 shows that the period means of these sleep characteristics run almost parallel in both 
groups except for midsleep awake. The significant group $\mathrm{x}$ period interaction in midsleep awake was explored with a one-way MANOVA of repeated measures in exhausted and non-exhausted subjects separately. This revealed no significant period effect in midsleep awake in non-exhausted subjects ( $F=1.59 ; \mathrm{df} 2,6 ; \mathrm{NS})$ and a marginally significant period effect in exhausted subjects $(F=3.36$; df 2,7 ; $\mathrm{p}=0.10$ ). Orthogonal polynomial trend contrasts revealed a significant linear trend $(\mathrm{F}=7.39 ; \mathrm{df} 1,8 ; \mathrm{p}=0.03$ ) and no significant quadratic trend ( $\mathrm{F}=0.95 ; \mathrm{df} 1,8 ; \mathrm{NS})$ in this particular sleep characteristic in exhausted subjects. A post-hoc t-test further revealed a significant difference between exhausted and non-exhausted subjects in midsleep awake during the PRELAB period $(\mathrm{t}=2.44 ; \mathrm{df} 1,15 ; \mathrm{p}=0.03)$.

Period effect. There is also no significant period effect in any of these sleep characteristics, except for time in bed, time asleep and daytime sleepiness. Orthogonal polynomial trend contrasts revealed no significant linear trend in time in bed $(\mathrm{F}=0.02)$, time asleep $(\mathrm{F}=0.48)$ and daytime sleepiness ( $\mathrm{F}=0.32$ : df 1,15 ; all NS) but a quadratic trend was significant (time in bed $F=55.70$ : time asleep $F=33.81$ : daytime sleepiness $F=9.25$ : df 1,15 ; all $p<0.01$ ). Subjects in both groups therefore spent considerably less time in bed during the LAB period than in either the PRELAB or POSTLAB period ( 69 minutes less for non-exhausted subjects and 71.5 minutes less for exhausted subjects). Furthermore, subjects in both groups slept considerably less during the LAB period than during the PRELAB or POSTLAB period (79.5 minutes less for non-exhausted subjects and 67.5 minutes less for exhausted subjects). It also appeared that subjects in both groups were significantly more sleepy during the $\mathrm{LAB}$ period compared to either the PRELAB or POSTLAB period.

Between Groups. Finally, exhausted and non-exhausted subjects differ significantly with respect to sleep quality, time asleep (on average 38.7 minutes), daytime sleepiness, daytime napping, sleep onset and number of naps.

\section{DISCUSSION}

The main aim of the present study was to explore a possible discrepancy in subjective estimates of sleep quality, nocturnal wake times, daytime napping and daytime sleepiness in exhausted subjects, as obtained retrospectively and on a daily basis, either at home or in a sleep laboratory. 


\section{Reactivity to self-monitoring.}

The first point we considered in answering this question was whether the reporting of sleep quality, nocturnal wake times, daytime sleepiness, and napping changes as a result of self-monitoring. Because all these sleep characteristics remain essentially the same over a period of three weeks, it was concluded that the reporting of sleep quality, time in bed, time asleep, nocturnal wake times, daytime napping, or daytime sleepiness, does not change purely by self-monitoring.

\section{Sleeping in a sleep laboratory.}

The second point we considered was whether sleep quality, nocturnal wake times, daytime sleepiness, and napping change as a result of sleeping in a laboratory. In the absence of a "reactivity to self-monitoring" effect in all sleep characteristics under consideration, the results suggest that sleeping in a laboratory caused both exhausted and non-exhausted subjects to spend less time in bed, to sleep less, and to feel more sleepy during the day. The data further suggest that sleeping in a laboratory reduced the duration of midsleep awakening in exhausted subjects while it had no significant effect upon lying awake at the start of sleep or early in the morning. In view of the reduced time spent in bed or being asleep and the increased daytime sleepiness during the laboratory period, it is of interest to note that sleep quality at home and in the laboratory was essentially the same. Because almost all exhausted subjects reported suffering from one or more sleep complaints and non-exhausted subjects were in fact non-symptomatic with respect to their sleep, the results further suggest that sleeping in a laboratory did not induce sleep problems in non-exhausted subjects or relieve them in exhausted subjects.

\section{Self-monitoring vs Retrospective assessment.}

The main question to consider was a possible discrepancy in subjective estimates of sleep quality, nocturnal wake times, daytime napping, and daytime sleepiness in exhausted subjects, as assessed retrospectively or on a daily basis, at home or in a laboratory. It appeared that both self-monitored and retrospectively assessed sleep quality distinguished exhausted subjects from non-exhausted subjects. Furthermore, both habitual and self-monitored sleep duration (time spent asleep) was shorter in exhausted subjects. These findings are consistent with the fact that sleep complaints and sleep onset and midsleep wake times of more than 20 minutes were reported exclusively by exhausted subjects. It might be expected, therefore, that exhausted subjects report longer wake time than non-exhausted 
subjects during self-monitoring. The results indicate that this was true for sleep onset awake but not for early morning or midsleep awake. As noted before, however, sleeping in a laboratory reduced the duration of midsleep awakening in exhausted subjects and it could be shown that they did report a longer midsleep waking time during the PRELAB period than non-exhausted subjects. Retrospective assessment of daytime sleepiness revealed that one third of exhausted subjects reported this complaint. Retrospective assessment of daytime napping further revealed that at least $50 \%$ of exhausted subjects took a nap more than once a week. These findings are consistent with the fact that self- monitoring of these sleep characteristics also discriminated exhausted subjects from non-exhausted subjects.

Although exhausted subjects report a worse sleep quality than non-exhausted subjects, they apparently do not base their self-monitored sleep quality entirely upon time spent asleep. This is deduced from the fact that a substantial reduction in sleeptime during polygraphical monitoring of sleep is not reflected in a worsening of their sleep quality. Exhausted subjects also do not appear to base their selfmonitored sleep quality entirely upon the length of nocturnal wake times. Early morning awake times were essentially the same in exhausted and non-exhausted subjects and midsleep awake times even decreased in exhausted subjects. Sleep onset awake times, however, were longer in exhausted subjects, so part of their poor sleep quality may be explained by their difficulty in falling asleep.

The question arises why exhausted subjects report a worse sleep quality or report more sleep complaints than non-exhausted subjects. Somatic conditions, associated with pain for instance, are not likely to be involved. Screening of the health status of these exhausted and non-exhausted subjects for the past 12 months (with additional information from general practitioners or specialists, if necessary) yielded no evidence for the presence of physical complaints or a disease which could account for disturbed sleep. Depression, which is closely tied to disturbed sleep (DSM-III-R, 1987) and encompasses a complex of feelings quite similar to that reported by exhausted subjects, is also not likely to be involved. In a previous study, it could be demonstrated that a depressed mood does not distinguish exhausted subjects from non-exhausted subjects [27]. A more likely reason for exhausted subjects to report a poor sleep quality is the fact that they suffer from an impaired daytime functioning. Firstly, they feel more sleepy during the day than non-exhausted subjects. Secondly, they are more tired and less vigorous throughout 
the day than non-exhausted subjects [27]. This would also explain the longer and more frequent daytime napping of exhausted subjects. It is not unlikely that exhausted subjects attribute their impaired daytime functioning to a nonrecuperative sleep which causes them to complain more about sleep than nonexhausted subjects. This does not contradict the association of sleep complaints with the coronary risk factor vital exhaustion [11], but suggests that hindrance of lying awake is not the main reason for exhausted subjects to complain about their sleep. To clarify this issue, a polysomnographic study of sleep was conducted. The results of that study are in progress.

\section{REFERENCES}

1. Thiel H, Parker D, Bruce T. Stress factors and the risk of myocardial infarction. J Psychosom Res 1973; 17: 43-45.

2. Kuller L. Prodomata of sudden death and myocardial infarction. Adv Cardiol 1978; 25: 61- 72 .

3. Kripke DF, Simons RN, Garfinkel L, Hammond EC. Short and long sleep and sleeping pills: Is increased mortality associated. Arch Gen Psychiatry 1979; 36: 103116.

4. Partinen M, Putkonen PT, Kaprio J, Koskenvuo M, Hilakivi I. Sleep disorders in relation to coronary heart disease. Acta Med Scand (Suppl) 1982; 660: 69-83.

5. Wingard DL, Berkman LF. Mortality risk associated with sleeping patterns among adults. Sleep 1983; 6: 102-107.

6. Koskenvuo M, Kaprio J, Partinen M, Langinvainio H, Sarna S, Rita H, Heikkilä K. Poor sleep quality, emotional stress and morbidity: a six year follow-up of 10778 persons aged 35-59 years. In Stress and Psychosomatics (Edited by Achte K, Pakaslahti A), pp. 115-120. Helsinki: Psychiat Fennica (Suppl), 1986.

7. Appels A, de Vos Y, van Diest R, Höppener P, Mulder P, de Groen J. Are sleep complaints predictive of future myocardial infarction? Act Nerv Sup (Praha), 1987; 29: 147-151.

8. Siegrist J. Impaired quality of life as a risk factor in cardiovascular disease. J Chronic Dis 1987; 40: 571-578.

9. Falger PRJ, Schouten EGW, Appels AWPM, de Vos YCM. Sleep complaints, behavioral characteristics and vital exhaustion in myocardial infarction cases. Psychology and Health 1988; 2: 231-258.

10. Carney RM, Freedland KE, Jaffe AS. Insomnia and depression prior to myocardial infarction. Psychosom Med 1990; 52: 603-609.

11. van Diest R. Subjective sleep characteristics as coronary risk factors, their association with Type A behaviour and vital exhaustion. J Psychosom Res 1990; 4: 415-426.

12. Appels A, Mulder P. Fatigue and heart disease. The association between "vital exhaustion' and past, present and future coronary heart disease. J Psychosom Res 1989; 33: 727-738. 
13. Mendelson WB, Garnett D, Gillin JC, Weingartner $\mathbf{H}$. The experience of insomnia and daytime and nighttime functioning. Psychiat Res 1984; 12: 235-250.

14. Mendelson WB, James SP, Garnett D, Sack DA, Rosenthal NE. A psychophysiological study of insomnia. Psychiat Res 1986; 19: 267-284.

15. Kales A, Kales JD. Evaluation and treatment of insomnia. New York; Oxford University Press, 1984.

16. van Diest R, Milius H, Markusse R, Snel J. De Slaap-Waak Ervaring Lijst. T Soc Gezondheidsz 1989: 10: 343-347.

17. van Diest R, Snel J. The sleep-wake experience list. In Proceedings of the 10th Congress of the European Sleep Research Society, Strasbourg, France, 1990.

18. Csikszentmihalyi M, Larson R. Validity and reliability of the Experience Sampling Method. J Nerv Ment Dis 1987; 175: 526-536.

19. Lamiell J. Toward an idiothetic psychology of personality. Am Psychol 1981; 36: 276-289.

20. Nelson RO. Methodological issues in assessment via self-monitoring. In Behavioral Assessment: New Directions in Clinical Psychology (Edited by Cone JD, Hawkins RP), New York: Brunner/Mazel, 1977.

21. Appels A, Höppener P, Mulder P. A questionnaire to assess premonitory symptoms of myocardial infarction. Int J Cardiol 1987; 17: 15-24.

22. Mulder-Hajonides van der Meulen WREH. Measurement of subjective sleep quality. In Proceedings of the 5th European Sleep Congress of the European Sleep Research Society, Amsterdam, The Netherlands, 1980.

23. Hoddes E, Dement WC, Zarcone V. The history and use of the Stanford Sleepiness Scale. (Abstract) Psychophysiology 1972; 9: 150.

24. de Vries MW. Investigating mental disorders in their natural settings. J Nerv Ment Dis 1987; 175: 509-513.

25. van Diest R. Vital Exhaustion or Depression: a study of daily mood in exhausted males at risk for myocardial infarction. In The Experience of Psychopathology (Edited by de Vries MW), pp. 233-239. Cambridge: Cambridge University Press, 1992.

26. 0'Brien RG, Kister Kaiser M. MANOVA method for analyzing repeated measures designs: An extensive primer. Psychol Bull 1985; 97: 316-333.

27. van Diest R, Appels A. Vital exhaustion and depression: A conceptual study, J Psychosom Res 1991; 35: 535-544. 
$-82$. 


\title{
SLEEP PHYSIOLOGICAL CHARACTERISTICS OF EXHAUSTED MALES $\mathrm{e}$
}

\author{
R. van Diest ${ }^{1}$ and A. Appels ${ }^{2}$
}

I Department of Clinical Psychiatry, Limburg University, Maastricht, The Netherlands.
${ }^{2}$ Department of Medical Psychology, Limburg University, Maastricht, The Netherlands.

Abstract-Problems initiating and maintaining sleep, and waking up exhausted have been implicated as precursors of a first, non-fatal myocardial infarction. These sleep problems are part of an array of complaints that we have labelled as reflecting a state of "vital exhaustion". Excess fatigue, loss of vigour, increased irritability, and feelings of demoralization are also characteristic of this state of vital exhaustion, which has been found to constitute a risk indicator for future myocardial infarction. In the present study, we tested the hypothesis that the sleep of exhausted subjects is characterized by a relative absence of slow wave sleep. To test this hypothesis, all-night recordings of the EEG, EOG, and submental EMG of nine exhausted and eight non-exhausted subjects were made for four nights. Sleep stages were rated according to standard criteria. Because these stages do not adequately reflect the essentially continuous aspect of slow wave sleep (SWS), a more detailed analysis of changes in frequencies of the EEG during sleep was also made, using spectral analysis. It appeared that SWS was significantly diminished in exhausted subjects. This suggests that the normal restoration processes that take place during sleep are impaired in exhausted subjects. Additional studies are required to determine the significance of this finding with respect to cardiovascular control during sleep.

\section{INTRODUCTION}

Problems initiating and maintaining sleep have been implicated as potential risk indicators for coronary artery disease [1-12]. Among the explanations as to why these complaints are predictive for myocardial infarction (MI) is one from a prospective study (the Rotterdam Civil Servant Study (RCSS)) among 3877 middle-aged males. At the start of that study, subjects were screened for cardiovascular risk factors and different manifestations of a state of vital exhaustion (VE). This latter concept was derived from interviews with coronary patients who often indicated that they had suffered from excess fatigue, loss of

$\mathrm{e}_{\text {accepted for publication in Psychosom Med }}$ 
vigour, increased irritability, and feelings of demoralization in the months prior to their MI. Many of these patients attributed these feelings to prolonged overwork or long-standing problems that could not be solved. Our working hypothesis was that these feelings reflect a state of exhaustion at which subjects arrive when their resources for adapting to stress have broken down. The average follow-up period for the RCSS was 4.2 years. Exhausted subjects had a significantly elevated risk (2.28 times the normal risk) for non-fatal MI at follow-up [12]. It also appeared that problems falling asleep and, in particular, feeling exhausted upon waking up in the morning are predictive for a first, non-fatal MI because they are elements of VE $[7,11]$.

The RCSS, however, was not designed to systematically explore sleep complaints as risk indicators for MI. It also lacked data on how long sleep problems had been present. This prompted us to investigate sleep problems $[13,14]$ in exhausted subjects in more detail [15]. The latter study indicated a high prevalence of chronic complaints (i.e., present for more than three weeks) regarding initiating and maintaining sleep in exhausted subjects. This observation supports the notion that these complaints may be risk indicators for MI by their association with VE.

The question then arose as to why exhausted subjects report more sleep complaints than non-exhausted subjects. To explore this issue, both the habitual sleep from the past three months and self-monitored sleep over a period of 21 days were assessed in exhausted subjects [16]. It appeared that exhausted subjects describe both their habitual and self-monitored sleep as more disturbed than controls. The two groups, however, did not differ significantly in their subjective estimates of lying awake. The study further revealed that somatic conditions were not a major reason for exhausted subjects to complain about their sleep. However, something that might have caused exhausted subjects to complain about their sleep was the possibility that they suffer from depression, a condition that is closely tied to a disturbed sleep and that shares a number of symptoms with exhaustion [17]. In order to rule out this possibility, a detailed assessment of symptoms of depression was made in exhausted subjects [18]. The study showed that a depressed mood is not among the major characteristics of VE and thus, depression is not a likely reason for exhausted subjects to complain about their sleep either. However, the latter study did convincingly demonstrate that undue fatigue and loss of vigour, which are well known sequelae of at least some types of insomnia [19], are major characteristics of exhausted subjects.

Our results, therefore, indicate that problems initiating and/or maintaining sleep are frequently reported by exhausted subjects. Various studies [20] have provided evidence that these same problems are associated with a deficiency in slow wave 
sleep (SWS). We therefore hypothesized that the sleep of exhausted subjects is also characterized by a relative absence of SWS. To test this hypothesis, the sleep of nine exhausted and eight non-exhausted subjects was monitored polygraphically for four nights.

\section{METHOD}

\section{Subjects}

Subjects were selected from 451 non-paid male volunteers (45-65 years) who participated in a study on the association between sleep problems, Type $A$ behaviour and vital exhaustion in the general population [15]. In that study, complaints of exhaustion were assessed using Form B of the Maastricht Questionnaire (MQ). This self-administered questionnaire consists of 21 items that have been found to predict future MI [12]. Higher scores on the MQ (range 0-42) indicate more exhaustion. A complete description of this questionnaire has been given elsewhere [21]. For the present study, we invited 25 randomly selected exhausted subjects (MQ scores between 18 and 42 ) and 10 randomly selected nonexhausted subjects (MQ scores between 0 and 7 ) by telephone to participate in a sleep physiological study. Ten exhausted subjects and three non-exhausted subjects were no longer willing to participate, after they were informed that the study was comprised of four consecutive nights of sleep in a laboratory.

To avoid the inclusion of 'false-positives' or 'false-negatives' with respect to $\mathrm{VE}$, subjects were interviewed by a psychiatrist prior to the start of the present study. Interviews were stored on videotape. The psychiatrist was unaware of all details of this selection procedure, including the subjects' answers on the MQ. During the interview, using the 21 items of the $\mathrm{MQ}$, complaints of exhaustion were reassessed and possible causes and durations of these complaints were explored. The psychiatrist also screened the mental health status to exclude subjects who were suffering from a psychiatric disorder (e.g., depression, drug or alcohol addiction, or other conditions) and screened the general health status for the past 12 months to exclude subjects who were suffering from a somatic disease (e.g., cancer, diabetes, chronic infectious diseases, MI or other cardiovascular disorders). If necessary, additional information was gathered from general practitioners or specialists. As a result, two exhausted subjects were excluded because of a somatic disease (i.e., cancer of the prostate and hypothyroidism). Subjects were also to be excluded if: (1) they were on any medication, including sleep medication; or (2) they were employed in shiftwork. Since no subjects were excluded because of these criteria, 13 exhausted and 7 non-exhausted subjects were eligible. 
Using video recordings, two independent experts (blind to the subjects' MQ score) rated whether these complaints of exhaustion reflected a breakdown in adaptation to chronic psychological stress. A subject was considered to be exhausted when his excess fatigue, increased irritability, and feelings of demoralization resulted from prolonged overwork or long-standing problems that could not be solved and were of relatively recent onset (i.e., no longer than 1.5 years). The experts used three categories to rate the psychiatric interview: (1) exhausted, (2) non-exhausted, (3) not representative (i.e., complaints lasted longer than 1.5 years). Of the 13 eligible exhausted subjects, three did not meet the criteria of VE and were excluded as being unrepresentative. One subject was classified as non-exhausted and was added to the seven eligible non-exhausted subjects who were all classified as such. This raised the number of non-exhausted subjects to eight. Finally, subjects suffering from sleep apnoeas (visually rated from an impedance plethysmographic recording of respiration during the adaptation night) with a duration of more than $10 \mathrm{sec}$ and a frequency of more than 10 per hour, were also to be excluded. Because those sleep apnoeas were not observed, results will be presented of nine exhausted and eight non-exhausted participants. Coffee consumption of these participants was less than 10 cups per day. The present study started within five weeks after returning the MQ. Informed consent was obtained from all participants. Demographic characteristics of the participants are shown in Table I.

Table 1.-Demographic characteristics of exhausted and non-exhausted subjects

\begin{tabular}{lcc} 
& Exhausted $(\mathrm{n}=9)$ & Non-exhausted $(\mathrm{n}=8)$ \\
Age (SD) & $54.0(3.1)$ & $52.5(4.2)$ \\
Work (Yes) & 7 & 8 \\
Married (Yes) & 7 & 8 \\
Non-smokers & 3 & 3 \\
Smokers (cigarettes/day) & $20.0(3.6)$ & $20.0(3.8)$ \\
\hline
\end{tabular}

\section{Measurements}

Habitual sleep characteristics. Sleep complaints (sleep onset, midsleep awakening, early morning awakening, difficulty waking up, fatigue upon waking in the morning, daytime sleepiness) were assessed with the Sleep-Wake Experience List (SWEL). The items and coding of this list have been published elsewhere [1315]. Sleep quality was assessed using the Groningen Sleep Quality Questionnaire (GSQ). The GSQ consists of 14 'yes' or 'no' items that have been shown to reliably measure a unidimensional construct [22]. The lower the score (range 0-14), 
the better the sleep quality. Questions about habitual sleep duration, nocturnal wake times, and taking naps were also included. Details of these last three questions and their coding are discussed elsewhere [15]. Subjects were instructed to base their answers on the past three months.

Sleep physiology. The study always started on a Monday evening and ended on a Friday morning. Public holidays, which may affect habitual sleep-wake schedules, were avoided. Subjects were instructed to avoid ingestion of caffeine after 6:00 PM on the nights of study. The arrival time on the first night (the adaptation night) was not later than 11:00 PM. All subsequent arrivals and times that subjects actually got out of bed were set on a night-to-night basis, depending on social and/or work activities. Two electroencephalographic (EEG) signals (derivation C3-A2; C4-A1), two elecro-oculographic (EOG) signals, and a submental electromyographic (EMG) signal were recorded continuously on paper (speed $10 \mathrm{~mm} / \mathrm{sec}$ ). The pre-amplified EEGs and EOGs (time constant $0.3 \mathrm{sec}$ ) were recorded simultaneously on magnetic tape. A $50 \mu \mathrm{V}$ calibration and a time code were also recorded. Good quality EEG recordings were obtained from the C3A2 derivation and were used in all later analyses. During the adaptation night, respiration was monitored with impedance plethysmography and recorded on paper. Sleep apnoeas were visually rated from this recording.

\section{Data analysis}

Sleep stages were scored per 30-sec epoch from paper according to standard criteria [23] by the first author and by an automatic system (The Sleep Analyzer f). This system clusters frequency and amplitude characteristics of the EEG into sleep stages NREM 1-4 and the wake stage. It also counts rapid eye movements, detected from two EOG signals, for the classification of the REM stage [24]. The average agreement between this system and visual rating of almost 18000 epochs of sleep was $71 \%$ [25]. All EEG epochs for which there was disagreement between the system and visual scoring were rescored in the present study by the first author. The detection of artifacts and of alpha activity duration (to be discussed below) are additional characteristics of this system.

The essentially continuous aspect of SWS, however, is only poorly reflected by the NREM stages 2-4 [26-28]. This is due to the fact that the scoring criteria for human sleep stages subdivide the human NREM sleep into discrete NREM stages

${ }^{f}$ Copyright by Medcare Automation, Amsterdam, The Netherlands 
2-4 [27,29]. An EEG epoch containing less than 20\% of SWS, for instance, is rated as NREM stage 2, and epochs containing from $20 \%$ to $50 \%$ or from $50 \%$ to $100 \%$ of SWS are rated as NREM stage 3 or 4, respectively. Any variation in the amount of SWS within these percentages is not accommodated for by these criteria. To complement the information, obtained from classical sleep stage scoring, a detailed analysis of changes in frequencies of the EEG during sleep was also made, using spectral analysis (see below).

NREM, REM, and wake measures. Sleep stages were used to obtain the following [30];

1. Recording period: time between 'lights off' and 'lights on' (lights off was determined by subjects themselves and lights on equals the times that subjects actually got out of bed). Both were set on a night-to-night basis, depending on social and/or work activities)

2. Sleep period: time between sleep onset and end of sleep (sleep onset was defined as the first epoch of NREM stages 2-4 or REM followed by at least ten minutes of sleep interrupted by no more than two minutes of NREM stage 1 , wakefulness, or movement time; end of sleep was defined as the last epoch of NREM stages 2-4 or REM preceded by at least ten minutes of sleep interrupted by no more than two minutes of NREM stage 1, wakefulness, or movement time)

3. Sleep latency: time between 'lights off' and sleep onset

4. Time awake: time awake between onset and end of sleep

5. Early morning awake: time between end of sleep and 'lights on'

6. Sleep stages: time spent in NREM stage 1, NREM stage 2, NREM stages $3+4$ (SWS), and REM between onset and end of sleep

7. REM latency: time between sleep onset and the onset of the first REM period (the first REM period has to last at least three minutes).

Alpha activity. Alpha activity is considered to be intracortical activity with a central frequency of $10 \mathrm{~Hz}$ and a modulation band width of $4 \mathrm{~Hz}$ [31]. Both the duration and the amount of power/energy of activity in the alpha band can be quantified. The measurement of alpha activity duration was based on a complex demodulation method. With this method, the EEG is demodulated in the alpha band to obtain an envelope of alpha activity. Subsequently, alpha activity duration in each $30-\mathrm{sec}$ epoch was measured (resolution $0.125 \mathrm{sec}$ ) as the time that the 
envelope exceeded $15 \mu \mathrm{V}$ [32]. Measurement of the power in the alpha band was accomplished using spectral analysis (see below).

Artifact detection. The EEG was high-pass filtered with a cut-off frequency of $20 \mathrm{~Hz}(3 \mathrm{~dB})$ for the detection of high-frequency artifacts. Artifact duration in each 30 -sec epoch was measured (resolution $0.125 \mathrm{sec}$ ) as the time that the root-meansquare value of the filtered EEG signal exceeded a value equivalent to $15 \mu \mathrm{V}$ EEG amplitude [33]. The presence of artifacts was confirmed by visual inspection of the EEG as recorded on paper.

Spectral analysis. The EEG was calibrated, low-pass filtered $(35 \mathrm{~Hz}$; $24 \mathrm{~dB} /$ octave), and analog-to-digital (A/D) converted (64 samples/sec) by a data acquisition board on a 80386 PC. 'Lights off' and 'lights on' determined the start and end of $A / D$ conversion. Spectral analysis was performed on consecutive 4-sec of digitized EEG data using a Fast Fourier Transform (FFT). For each $4 \mathrm{sec}$, power values (expressed as $\mu \mathrm{V} 2$ ) in the range of $0.75-16 \mathrm{~Hz}$ (resolution $0.25 \mathrm{~Hz}$ ) were used for further analysis. To obtain a $1-\mathrm{Hz}$ resolution in the range of $1.25-16 \mathrm{~Hz}$, power values of four consecutive frequencies were added. Power values of the 0.75 and $1.0 \mathrm{~Hz}$ bin were also added. To obtain a resolution of $30-\mathrm{sec}$, power values of 7.5 adjacent 4 -sec epochs were summed for each frequency bin thus calculated. Per 30-sec epoch, sleep stages, alpha activity and artifacts of each night were synchronized with the FFT data for further analysis.

To maximize the comparison between exhausted and non-exhausted subjects with respect to power densities and alpha activity, this comparison was restricted to the minimum duration of artifact-free NREM stages 2-4 sleep encountered across all available nights. This minimum duration appeared to be 128.5 minutes and was the duration used for all nights. On the average, it made up $37.9 \%$ (SD 3.9) of the sleep period of exhausted subjects and $38.0 \%$ (SD 3.7) of the sleep period of nonexhausted subjects. An example of how these 128.5 minutes were obtained for one night in a non-exhausted subject is shown in Fig. 1.

Alpha activity duration. For each night, the total percentage of alpha activity duration during this minimum NREM duration was calculated.

Spectral analysis. For each night, power densities during this minimum NREM duration were condensed into four frequency bands: delta $(0.75-4 \mathrm{~Hz})$; theta $(4.25-8 \mathrm{~Hz})$; alpha $(8.25-12 \mathrm{~Hz})$, and sigma $(12.25-16 \mathrm{~Hz})$ [34]. 


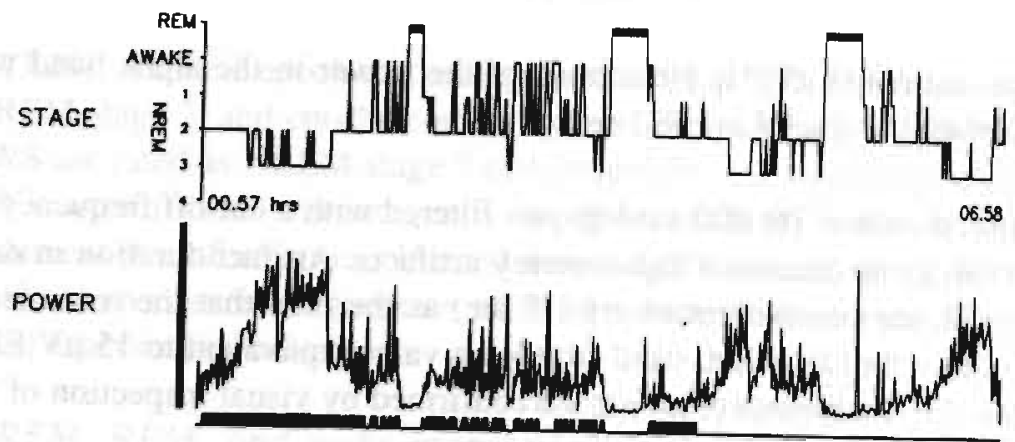

ARTIFACT

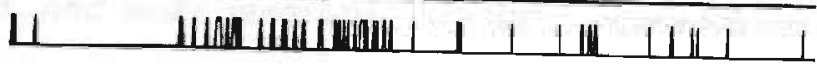

Fig. 1. Example of the distribution of 128.5 minutes of artifact-free NREM stages $2-4$ sleep for one night in a non-exhausted subject. From top to bottom: Hypnogram (plotted from sleep onset to end of sleep). Course of power (integrated from 0.75 to $16 \mathrm{~Hz}$ ) during the sleep period. Artifacts as they occurred during this sleep period. The interrupted thick bar just below the power course marks the 128.5 minutes of artifact-free NREM stages 2-4 sleep that were selected from this night of sleep for further analysis. The thick bar to the left of the power course represents $50 \mu \mathrm{V} 2 / \mathrm{Hz}$.

\section{Statistics}

Apart from the visual check of sleep apnoeas, the adaptation night was excluded from all further analysis. For all sleep measures described, the average of the remaining three nights of each subject was calculated (e.g., the average of the three sleep latencies of each subject was used for further analysis). Differences in the reporting of habitual sleep complaints between the exhausted and non-exhausted group were evaluated with a test for significant differences between two proportions. The Mann-Whitney U-test was used to test for significant differences with respect to habitual sleep duration, habitual sleep quality, sleep measures derived from sleep stage scoring, and alpha activity duration. A multivariate ANOVA [35] was applied to absolute power values to test for significant differences between exhausted and non-exhausted subjects in sleep measures derived from spectral analysis.

\section{RESULTS}

Habitual sleep. Habitual aspects of sleep are shown in Table II. Sleep complaints were reported exclusively by exhausted subjects. More than $55 \%$ of these subjects reported being awake for at least 20 minutes before falling (back) asleep and napping at least once a week. Furthermore, the self-reported habitual 
Table II.-Habitual aspects of sleep in exhausted and non-exhausted subjects

\begin{tabular}{|c|c|c|c|c|c|c|}
\hline \multicolumn{3}{|l|}{ Sleep measure } & $\begin{array}{l}\text { Exhausted } \\
n=9\end{array}$ & $\begin{array}{l}\text { Non-exhausted } \\
\quad \mathrm{n}=8\end{array}$ & $\mathrm{z}$ & $\mathrm{p}$ \\
\hline \multicolumn{2}{|l|}{ Initiating sleep } & $(\%)$ & 44.4 & 0 & 2.2 & $\mathrm{p}<0.04$ \\
\hline \multicolumn{2}{|l|}{ Maintaining sleep } & $(\%)$ & 66.7 & 0 & 2.9 & $\mathrm{p}<0.01$ \\
\hline \multicolumn{2}{|c|}{ Early morning awakening } & $(\%)$ & 55.6 & 0 & 2.5 & $p<0.02$ \\
\hline \multicolumn{2}{|c|}{ Difficulty waking up } & $(\%)$ & 0 & 0 & - & \\
\hline \multicolumn{2}{|c|}{ Tiredness upon waking up ( } & $(\%)$ & 33.3 & 0 & 1.8 & $p<0.07$ \\
\hline \multicolumn{2}{|c|}{ Daytime sleepiness } & $(\%)$ & 33.3 & 0 & 1.8 & $\mathrm{p}<0.07$ \\
\hline \multirow{2}{*}{\multicolumn{3}{|c|}{$\begin{array}{l}\text { Sleep onset } \quad(\%>20 \mathrm{~min}) \\
\text { Sleep maintenance }(\%>20 \mathrm{~min})\end{array}$}} & 66.7 & 0 & 2.9 & $\mathrm{p}<0.01$ \\
\hline & & & 55.6 & 0 & 2.9 & $\mathrm{p}<0.01$ \\
\hline \multirow[t]{2}{*}{ Napping } & \multicolumn{2}{|c|}{ (\% >once/week) } & 55.6 & 0 & 2.9 & $\mathrm{p}<0.01$ \\
\hline & \multirow{3}{*}{\multicolumn{2}{|c|}{ (mean) (SD) }} & & & $\mathrm{U}$ & p \\
\hline Sleep quality & & & $6.6(3.5)$ & $2.4(1.3)$ & 8.0 & $p<0.01$ \\
\hline Sleep duration & & & $6.9(0.7)$ & $7.5(0.8)$ & 23.0 & $0 \quad$ NS \\
\hline
\end{tabular}

NS, not significant

sleep quality score of exhausted subjects was significantly higher, indicating that their habitual sleep quality is poor. Habitual sleep durations were not significantly different. The results further suggest that non-exhausted subjects are asymptomatic with respect to their sleep.

NREM, REM, wake measures, and alpha activity duration. Results of the visual rating of sleep and of alpha activity duration are shown in Table III.

Most of the NREM, REM, or wake measures did not differentiate exhausted subjects from non-exhausted subjects, with the exception of time spent in stages NREM 3+4 (SWS). This was significantly less in exhausted subjects. Alpha activity duration also did not differentiate the two groups.

Spectral analysis. The means and SD of power values in the delta, theta, alpha, and sigma bands in exhausted and non-exhausted subjects are shown in Table IV.

The MANOVA revealed a significant overall difference in power densities (Hotelling's $\mathrm{T}^{2}=1.20$; df 4,$12 ; \mathrm{p}=0.04$ ) between the two groups. This could be attributed to a significant lower power in the delta band ( $F=5.53$; df 1,$15 ; \mathrm{p}=0.03$ ) in exhausted subjects. 
Table III.-NREM, REM, Wake measures and alpha activity duration in exhausted and non-exhausted subjects

\begin{tabular}{|c|c|c|c|c|c|c|c|}
\hline Sleep measure & & $\begin{array}{l}\text { Exha } \\
n=\end{array}$ & $\begin{array}{l}\text { austed } \\
=9\end{array}$ & $\begin{array}{r}\text { Non-ex } \\
n\end{array}$ & $\begin{array}{l}\text { lausted } \\
=8\end{array}$ & U & $\mathrm{p}$ \\
\hline & & mean & (SD) & mean & (SD) & & \\
\hline Recording period & $(\min )$ & 371.2 & $(26.8)$ & 368.6 & (32.7) & 34 & NS \\
\hline Sleep period & $(\min )$ & 340.8 & $(33.3)$ & 341.6 & $(35.2)$ & 35 & NS \\
\hline Sleep latency & $(\min )$ & 19.5 & $(9.5)$ & 17.7 & (10.1) & 31 & NS \\
\hline Time awake & $(\min )$ & 18.0 & $(9.8)$ & 20.3 & (13.7) & 35 & NS \\
\hline $\begin{array}{l}\text { Early morning } \\
\text { awakening }\end{array}$ & $(\min )$ & 10.9 & $(7.7)$ & 9.3 & (6.2) & 31 & NS \\
\hline NREM stage 1 & (min) & 37.3 & (15.4) & 34.7 & (7.8) & 35 & NS \\
\hline $\begin{array}{l}\text { NREM stage } 2 \\
\text { NREM stages }\end{array}$ & $(\min )$ & 209.0 & $(29.2)$ & 201.0 & $(19.5)$ & 30 & NS \\
\hline $\begin{array}{l}\text { NREM stages } \\
3+4 \text { (SWS) }\end{array}$ & $(\min )$ & 9.5 & $(6.0)$ & 23.3 & (8.1) & & \\
\hline $\begin{array}{l}3+4 \text { (SWS) } \\
\text { REM }\end{array}$ & (min) & 67.0 & $\begin{array}{r}(0.0) \\
(11.1)\end{array}$ & 62.3 & $\begin{array}{r}(0.1) \\
(16.0)\end{array}$ & $\begin{array}{l}14 \\
29\end{array}$ & $\begin{array}{l}\mathrm{p}=.04 \\
\mathrm{NS}\end{array}$ \\
\hline REM latency & $(\min )$ & 56.4 & $(15.0)$ & 64.8 & $(24.2)$ & 28 & NS \\
\hline Alpha duration & $(\%)$ & 15.0 & (11.3) & 15.8 & $(14.4)$ & 35 & NS \\
\hline
\end{tabular}

NS, not significant

Table IV.-Average power in four frequency bands in exhausted and nonexhausted subjects

\begin{tabular}{lrrrr}
\hline Sleep measure & \multicolumn{2}{c}{ Exhausted } & \multicolumn{2}{c}{ Non-exhausted } \\
& mean & (SD) & mean & $\mathrm{n}=8$ \\
Delta & 527.96 & 144.79 & 801.12 & 213.70 \\
Theta & 56.74 & 34.49 & 74.66 & 40.81 \\
Alpha & 23.16 & 23.10 & 22.52 & 15.85 \\
Sigma & 4.38 & 3.75 & 3.73 & 2.98 \\
\hline
\end{tabular}

\section{DISCUSSION}

In a carefully selected sample of subjects suffering from symptoms frequently observed in near-future MI patients (the exhausted group) and a sample of subjects not suffering from these symptoms (the non-exhausted group), the hypothesis was tested that the sleep of exhausted subjects is characterized by a reduced SWS. First, habitual aspects of the subjective experience of sleep were considered. The results 
support previous findings $[7,9,11,15]$ that sleep complaints are highly prevalent in subjects suffering from vital exhaustion. Although they frequently report problems initiating or maintaining sleep, their EEG-derived awake times (sleep latency, time awake during the sleep period, and early morning awakening) were not significantly different from those of non-exhausted subjects. For instance, the difference between exhausted and non-exhausted subjects with respect to time awake during the sleep period was less than 3 minutes. The difference with respect to REM latency was slightly more than 8 minutes. These differences were always around $0.3 \mathrm{SD}$ and would have required a large sample size to reach statistical significance [36]. We accepted the possibility of making a type II error because, in our opinion, small differences in either time awake or in other sleep physiological characteristics between these highly selected groups would only be of minor importance. Therefore, the absence of significant differences in EEG-derived awake times is considered as further support for the notion, made in a previous study [16], that the duration of lying awake is not a major reason for exhausted subjects to complain about their sleep.

The results with respect to SWS (as reflected in NREM stages $3+4$ and in power in the delta band) support our hypothesis that the sleep of exhausted subjects is characterized by a relative absence of SWS. Although the functional significance of SWS is not known, it has been suggested that SWS marks a time during which a restorative process, following the wear and tear of wakefulness, takes place [27,3739]. Increasing amounts of SWS are assumed to reflect higher rates of this recovery process. Based upon these assumptions, our observation of a relative absence of SWS in exhausted subjects suggests that this recovery process is impaired in these subjects. The comparison between exhausted and non-exhausted subjects with respect to power densities in the various frequency bands was restricted to the minimum duration of artifact-free NREM stages 2-4 sleep encountered across all available nights. Notwithstanding the fact that this approach was chosen to maximize the comparison between these two groups, it can be argued that intervening NREM 1, REM or awake stages during this minimum NREM duration were present to a greater extent in exhausted subjects, thus providing a larger 'disturbance' of their minimum NREM duration. The average amounts of these intervening stages, however, did not significantly differentiate the two groups. This suggests that the reduced SWS in exhausted subjects is not due to a larger disturbance of their minimum NREM duration.

A reduced SWS is a relatively nonspecific sleep abnormality associated with, for instance, a depressive disorder or a medical illness [40]. However, we do not think that the reduced SWS is due to a higher prevalence of depression in the exhausted group. First, none of the exhausted subjects was diagnosed as suffering 
from a major or minor depression by the psychiatrist. Second, the average duration of the REM latency that has been reported as a characteristic of the sleep of depressed subjects [30], is almost twice as short as the REM latency we have observed in exhausted subjects of comparable age. In fact, the REM latencies that were found in the present study are within the limits reported for normal subjects and insomniacs of comparable age groups $[41,42]$.

The difference in SWS cannot be attributed to a current medical illness either because subjects, suffering from a disease, were excluded from the present study. It cannot be excluded, however, that the reduced SWS has been caused by a subclinical disease not yet detectable in a routine medical examination. This issue is important because we consider VE to be a prodromal state of MI. Although it is beyond the scope of the present paper to discuss this issue in detail, the following remarks make us think that VE does not reflect early, as yet undetected heart disease. First, the essential finding of the prospective Rotterdam Civil Servant Study was that VE is predictive of MI after excluding subjects with angina pectoris and/or manifestations of heart disease that are visible on a resting electrocardiogram [12]. Second, in a study of coronary patients whose bloodflow was successfully restored by coronary angioplasty, feelings of exhaustion were not related to cardiac output as measured by the left ventricular ejection fraction and only marginally related to severity of atherosclerosis of the coronary vessels [43]. The results of that study also showed that restoration of the perfusion by angioplasty did not result in a meaningful decrease in the number of exhausted patients after two weeks. Most importantly, however, is the observation that feelings of exhaustion after angioplasty are predictive of new cardiac events during a follow-up of 1.5-years, when the severity of atherosclerosis and other clinical characteristics were controlled for [44]. These findings suggest that feelings of exhaustion are not predictive of future MI simply because they are the physical sequelae of manifest heart disease, left ventricular impairment, or severe atherosclerosis.

Exhausted and non-exhausted subjects did not differ significantly with respect to alpha activity during NREM sleep. In fact, the percentage of alpha duration during sleep in both groups was well within the limits reported for normal subjects and chronic insomniacs [45]. These findings seem to be ad odds with those of Moldofsky [45]. He observed anomalous amounts of alpha during the NREM sleep of subjects suffering from fybromyalgia, an illness that was recently subsumed under the heading of the chronic fatigue syndrome (CFS) [46]. This syndrome shares a number of symptoms with VE, in particular the severe and unexplained fatigue and the frequently reported sleep problems. Most CFS patients ascribe their fatigue to a physical cause, although abnormalities on conventional medical 
investigations are usually absent. They further report a rapid onset of their symptoms and a length of illness ranging from 1.5 to 13 years [46]. Exhausted subjects, however, usually have no rapid onset of their symptoms, and they ascribe their complaints to one or more stressful life events. Furthermore, the duration of a state of vital exhaustion is relatively short (on the average, 1.5 years) while a somatic disease is, by definition, excluded. This suggests that at least part of the difference between the observation of Moldofsky and our finding is due to the difference in the chronicity of both conditions.

One may wonder why SWS is reduced in exhausted subjects. A possible explanation for a reduced SWS is given by the two-process model for the regulation of human sleep [47]. According to this model, the alternation between sleep and wakefulness results from an interaction between a circadian process (C) and a sleep-dependent process, formalized as process $\mathrm{S}$. The model postulates that process $S$ rises during wakefulness and declines during sleep. It further postulates that a deficiency in the build-up of process $S$ during the day will result in a reduced SWS during the sleep period that follows. One of the predictions of this model, therefore, is that the build-up of process $S$ is disrupted by a daytime nap because process $S$ will also decline during this daytime sleep [48]. The prediction that daytime napping reduces SWS of the night that follows has been confirmed in a number of studies $[27,49,50]$. The results of the present and previous studies $[9,15]$ indicate that daytime napping is more prevalent among near future coronary victims than among controls. This suggests that this sleep characteristic is a plausible reason for the reduced SWS that was found in subjects suffering from vital exhaustion.

In sum, the major finding of the present study is a relative absence of SWS in subjects suffering from feelings identified as precursors of MI. This observation, however, leaves unanswered the question of the relevance of a reduced SWS with respect to cardiovascular control during the sleep of these subjects. In a review of the effects of sleep on cardiovascular disorders in humans [51], it was concluded that: 'SWS appears to result in a moderate antiarrhythmic effect in some subjects'. One might speculate, therefore, that the relative absence of SWS in exhausted subjects makes them more vulnerable to these arrhythmias. It is also conceivable that the reduced SWS, as observed in exhausted subjects, reflects increased arousal during sleep. Because arousal from sleep has been associated with the incidence of ischemic events [52], this too may be the underlying mechanism for the association of disturbed sleep, vital exhaustion, and future myocardial infarction. 
Acknowledgements-The authors thank Henk Milius for his psychiatric expertise during the interviews. Special thanks to Leon Bemelmans and coworkers of Beltech Co (Eindhoven, The Netherlands) for the writing and testing of AVD conversion and FFT computer programs in ASYST 3.0 (copyright of MacMillan Software) and to Anand Kumar of Medcare Automation (Amsterdam, The Netherlands) for the implementation of the sleep stage analyzer system.

\section{REFERENCES}

1. Thiel H, Parker D, Bruce T. Stress factors and the risk of myocardial infarction. J Psychosom Res 1973; 17: 43-45.

2. Kuller L. Prodomata of sudden death and myocardial infarction. Adv Cardiol 1978; 25: 61-72.

3. Kripke DF, Simons RN, Garfinkel L, Hammond EC. Short and long sleep and sleeping pills: Is increased mortality associated?. Arch Gen Psychiatry 1979; 36: 103116.

4. Partinen M, Putkonen PT, Kaprio J, Koskenvuo M, Hilakivi I. Sleep duration in relation to coronary heart disease. Acta Med Scand (Suppl) 1982; 660: 69-83.

5. Wingard DL, Berkman LF. Mortality risk associated with sleeping patterns among adults. Sleep 1983; 6: 102-107.

6. Koskenvuo M, Kaprio J, Partinen M, Langinvainio H, Sarna S, Rita H, Heikkilä K. Poor sleep quality, emotional stress and morbidity: a six year follow-up of 10778 persons aged 35-59 years. In Stress and Psychosomatics (Edited by Achte K, Pakaslahti A), pp. 115-120. Helsinki: Psychiat Fennica (Suppl), 1986.

7. Appels A, de Vos Y, van Diest R, Höppener P, Mulder P, de Groen J. Are sleep complaints predictive of future myocardial infarction? Act Nerv Sup (Praha) 1987; 29: 147-151.

8. Siegrist J. Impaired quality of life as a risk factor in cardiovascular disease. J Chronic Dis 1987; 40: 571-578.

9. Falger PRJ, Schouten EGW, Appels AWPM, de Vos YCM. Sleep complaints, behavioral characteristics and vital exhaustion in myocardial infarction cases. Psychology and Health 1988; 2: 231-258.

10. Carney RM, Freedland KE, Jaffe AS. Insomnia and depression prior to myocardial infarction. Psychosom Med 1990; 52: 603-609.

11. Appels A, Schouten E. Waking up exhausted as risk indicator of myocardial infarction. American J Cardiol 1991; 68: 395-398.

12. Appels A, Mulder P. Fatigue and heart disease. The association between 'vital exhaustion' and past, present and future coronary heart disease. J Psychosom Res 1989; 33: 727-738.

13. van Diest $\mathbf{R}$, Milius H, Markusse R, Snel J. De slaap-waak ervaring lijst. T Soc Gezondheidsz 1989; 10: 343-347.

14. van Diest R, Snel J. The sleep-wake experience list. In: Proceedings of the 10th Congress of the European Sleep Research Society. Strasbourg: France, 1990. 
15. van Diest $\mathbf{R}$. Subjective sleep characteristics as coronary risk factors, their association with Type A behaviour and vital exhaustion. J Psychosom Res 1990; 34: 415-426.

16. van Diest R, Appels A. Vital exhaustion and perception of sleep. J Psychosom Res 1992; 36: 449-458.

17. van Diest $\mathbf{R}$. Vital exhaustion or depression: a study of daily mood in exhausted male subjects at risk for myocardial infarction. In The Experience of Psychopathology (Edited by deVries MW), pp. 233-239. Cambridge: Cambridge University Press, 1992.

18. van Diest R, Appels A. Vital exhaustion and depression: A conceptual study. J Psychosom Res 1991; 35: 535-544.

19. Sugerman JL, Stern JA, Walsh JK. Daytime alertness in subjective and objective insomnia: Some preliminary findings. Biol Psychiatry 1985; 20: 741-750.

20. Sewitch DE. Slow wave sleep deficiency insomnia: A problem in thermodownregulation at sleep onset. Psychophysiol 1987; 24: 200-215.

21. Appels A, Höppener P, Mulder P. A questionnaire to assess premonitory symptoms of myocardial infarction. Int J Cardiol 1987; 17: 15-24.

22. Mulder-Hajonides van der Meulen WREH, van den Hoofdakker RH. The Groningen sleep quality scale. In: Proceedings of the 14th CINP congress. Florence: Italy, 1984.

23. Rechtschaffen A, Kales A. A manual of standardized terminology, techniques, and scoring system for sleep stages of human subjects. Washington DC, Public Health Service, US Government Printing Office, 1968.

24. Kumar A. A real-time system for pattern recognition of human sleep stages by fuzzy system analysis. Pattern Recognition 1977; 9: 43-46.

25. Kumar A, Hofman W, Jurriens A, van Diest $\mathbf{R}$, Campbell K, Vallet $\mathbf{M}$. Evaluation and validation of an automatic method of sleep stage classification of human sleep recordings done in the homes. In: Proceedings of the International Conference on Cybernetics and Society. Atlanta: USA, 1981.

26. Borbély AA, Bauman F, Brandeis D, Strauch I, Lehman D. Sleep deprivation: Effect on sleep stages and EEG power density in man. Electroencephalogr Clin Neurophysiol 1981; 51: 483-493.

27. Feinberg I, March JD, Floyd TC, Jimison R, Bossom-Demitrack L, Katz PH. Homeostatic changes during post-nap sleep maintain baseline levels of delta EEG. Electroencephalogr Clin Neurophysiol 1985; 61: 134-137.

28. Dijk DJ, Beersma DGM, van den Hoofdakker RH. All night spectral analysis of EEG sleep in young adults and middle-aged male subjects. Neurobiology of Aging 1989; 10: 677-682.

29. Borbély AA. Sleep regulation: Circadian rhythm and homeostasis. In Current Topics in Neuroendocrinology, Vol. 1: Sleep. Clinical and experimental aspects (Edited by Ganten D, Pfaff D), pp 83-103. Berlin: Springer Verlag, 1982. 
30. Reynolds II ChF, Coble PA, Kupfer DJ, Shaw DH. Depressive patients and the sleep laboratory. In Sleeping and Waking Disorders; Indications and Techniques (Edited by Guilleminault CH), pp 245-263. Menlo Park: Addison-Wesley Publ. Co., 1982.

31. Markand ON. Alpha rhythms. J Clin Neurophysiol 1990; 7: 163-189.

32. Kumar A. A complex demodulation method for detection of alpha waves and sleep spindles of the human EEG in real time. In: Proceedings of the International Conference on Advanced Signal Processing Techniques. Lausanne: Switzerland, 1975.

33. Kumar A, Hofman W, van Diest R. An automatic procedure for detecting artifacts in the sleep EEG. In: Proceedings of the 5th European Sleep Congress of the European Sleep Research Society. Amsterdam: The Netherlands, 1980.

34. Armitage R, Roffwarg HP, Rush J, Scott Calhoun J, Purdy DG, Giles DE. Digital period analysis of sleep EEG in depression. Biol Psychiat 1992; 31: 52-68.

35. O'Brien RG, Kister Kaiser M. MANOVA Method for analyzing repeated measures designs: An extensive primer. Psychol Bull 1985; 97: 316-333.

36. Fleiss JM. The design and analysis of clinical experiments. Brussels: Wiley and Sons, 1986.

37. Feinberg I. Changes in sleep cycle patterns with age. J Psychiat Res 1974; 10: 283306.

38. Spiegel R, Köberle S, Allen SR. Significance of slow wave sleep: Considerations from a clinical viewpoint. Sleep 1986; 9: 66-79.

39. Horne JA. Functional aspects of human slow wave sleep (hSWS). In Slow wave sleep: Physiological, pathophysiological and functional aspects (Edited by Wauquier A, Dugovic C, Radulavacki M), pp 109-118. New York: Raven Press, Lid., 1989.

40. Mendelson WB. Pharmacology of slow wave sleep in illnesses and health. In Slow wave sleep: Physiological, pathophysiological and functional aspects (Edited by Wauquier A, Dugovic C, Radulavacki M), pp 155-165. New York: Raven Press, Ltd., 1989.

41. Reynolds III ChF, Kupfer DJ, Taska LS, Hoch CC, Sewitch DE, Spiker DG. Sleep of healthy seniors: a revisit. Sleep $1985 ; 8: 20-29$.

42. Frankel BL, Coursey RD, Buchbinder R, Snyder F. Recorded and reported sleep in chronic primary insomnia. Arch Gen Psychiat 1976; 33: 615-623.

43. Kop WJ, Appels APWM, Mendes de Leon CF. The effect of coronary angioplasty on exhaustion (abs). Psychosom Med 1991; 53: 213.

44. Kop WJ, Appels APWM, Mendes de Leon CF, de Swart H, Bär FW. Vital exhaustion predicts new cardiac events after successful coronary angioplasty. (submitted).

45. Moldofsky H. Sleep and fibrositis syndrome. Rheumatic Disease Clinics of North America 1989; 15: 91-103. 
46. Wessely S. Chronic fatigue and myalgia syndromes. In Psychological disorders in general medical settings (Edited by Sartorius N, Goldberg D, de Girolamo G, Costa e Silva JA, Lecrubier Y, Wittchen U), pp 82-97. Toronto: Hogrefe \& Huber Publishers, 1990.

47. Borbély AA. A two process model of sleep regulation. Hum Neurobiol 1982; 1: 195204.

48. Borbély AA, Acherman P. Concepts and models of sleep regulation: an overview. J Sleep Res 1992; 1: 63-79.

49. Karacan I, Williams RL, Finley WW, Hursch CJ. The effects of naps on nocturnal sleep: influence on the need for stage 1 REM and stage 4 sleep. Biol Psychiat 1970; 2: 391-399.

50. Knowles JB, MacLean AW, Brunet D, Coulter M. Nap-induced changes in the time course of process $\mathrm{S}$. Effects on nocturnal slow wave activity. In Sleep ' 90 (Edited by Horne JA ), pp 68-70. Bochum, Pontenagel Press, 1990.

51. Verrier RL. Behavioral state and cardiac arrhythmias. In Clinical physiology of sleep (Edited by Lydic R, Biebuyck JF), pp 31-51. Bethesda: American Physiological Society, 1988.

52. Verrier RL, Dickerson LW. Autonomic nervous system and coronary blood flow changes related to emotional activation and sleep. In Mental stress as a trigger of cardiovascular events (Edited by Tavazi L, Shabetai R, Dimsdale J), Circulation (Suppl) 1991; 83: 81-89. 
$-100-$ 


\section{GENERAL DISCUSSION}

The central theme of the studies, presented in this thesis has been an investigation of the sleep of subjects suffering from a state of vital exhaustion (VE). This concept originated from the descriptions given by myocardial infarction (MI) patients of their feelings in the months prior to their MI. A study aimed at testing the predictive validity of this state for future MI revealed that exhausted subjects ran a significantly greater risk of having a first MI at follow-up than nonexhausted subjects. Of particular interest was the observation, derived from that study, that problems falling asleep and feeling exhausted upon waking up in the morning were predictive for a first, non-fatal MI because they are elements of VE. The study, however, was not designed to systematically explore sleep complaints as risk indicators for MI. This criticism also applies to other studies that have explored associations between sleep problems and future MI. What these studies, taken together, suggest is that a vast number of sleep problems, such as difficulty initiating and/or maintaining sleep, fatigue on waking up in the morning, heavy snoring, unusual sleep durations, and daytime naps, can all be conceived of as potential risk indicators for future MI. What is lacking, however, is a unifying concept that relates these various subjective sleep characteristics to future MI. In the current thesis, the conjecture is made that VE is this unifying concept. At the outset of the thesis, however, no empirical data were available to substantiate this conjecture. For this reason, a study was needed that explored whether VE is associated with these sleep characteristics. As has been discussed in the general introduction, the Type A coronary-prone behaviour pattern (TABP) was also included in this study. However, to explore this issue, a questionnaire is needed that systematically assesses sleep complaints, and such a questionnaire was not available at the outset of the current thesis.

\section{The Sleep-Wake Experience List.}

In chapter two, a questionnaire is presented for the assessment of six types of sleep complaints as they occur within a 24-hour period. The final form of this questionnaire -the Sleep-Wake Experience List (SWEL)- consists of 15 items to assess either the severity or the occurrence of a sleep complaint within a specified period of time. These items were combined to assess problems initiating and/or maintaining sleep, as well as problems with early morning awakening, difficulty waking up, tiredness upon waking up, and daytime sleepiness. For daytime sleepiness, items only assess the occurrence of the complaint. These item combina- 
tions were validated against a clinical diagnosis of chronic sleep complaints, a diagnosis arrived at by "blind" raters from videotaped interviews. Their chancecorrected agreement ranged from $71 \%$ to $95 \%$ for the various sleep complaints. To determine the quality of the SWEL as a screening, diagnostic, and prognostic instrument for these complaints, a "weighted" chance-corrected measure (Kappa) was used. The results showed that the SWEL is a moderate to good screening instrument, with a Kappa ranging from $52.3 \%$ to $90.3 \%$ for the various sleep complaints. It is also moderate with respect to diagnosis and prognosis, with Kappa ranging from $51.1 \%$ to $78.0 \%$. These results set the stage for a study that explored whether VE is associated with these sleep characteristics.

Subjective sleep characteristics as coronary risk factors, their association with Type A behaviour and vital exhaustion.

In chapter three, the question was raised as to whether an association of VE with chronic sleep complaints, habitual sleep durations, napping, and habitual snoring is confounded by TABP, and vice versa. Sleep durations, napping, and snoring were assessed with items not included in the SWEL. The results suggest that, with the exception of difficulty maintaining sleep, these sleep characteristics are not likely risk indicators for MI because of an association with TABP. Exhausted subjects, however, reported problems initiating and/or maintaining sleep, and problems with early morning awakening, tiredness upon waking up, a short habitual sleep, frequent napping, and daytime sleepiness significantly more often than non-exhausted subjects. TABP did not confound these associations. These results support the assumption that VE is the unifying concept that relates these various sleep characteristics to future MI. The fact that daytime sleepiness is frequently observed in exhausted subjects further suggests that sleep apnoea is a potential confounder in the association of VE with future MI.

However, the assumption that VE is the unifying concept that relates these various sleep characteristics to future MI cannot be made without also taken into account the fact that VE shares a number of symptoms with depression, a condition that is closely tied to a disturbed sleep. It is not unlikely, therefore, that exhausted subjects complain about their sleep because they in fact suffer from depression. This conceptual overlap of VE and depression has been investigated in the study that is presented in chapter 4 . 
Vital exhaustion and depression: a conceptual study.

This study explored whether VE is characterized more by a depressed mood than by a loss of vigour and excess fatigue. Two approaches were used. The first approach employed the Profile of Mood States to assess depressed mood, vigour and fatigue on a day-to-day basis for 21 days, using the method of experience sampling. The second approach employed the Beck Depression Inventory to assess affective, cognitive, motivational, and somatic symptoms of depression for the prior two weeks. The results of both approaches led to the conclusion that depression is not a likely reason for exhausted subjects to complain about their sleep because the key symptom for depressive disorders, a depressed mood, is not among the major characteristics of VE. The study also demonstrated that excess fatigue and a loss of vigour are major characteristics of VE. These results provide the first evidence to suggest that what we term a state of vital exhaustion is distinct from depression and support the assumption that it is VE that relates problems initiating and/or maintaining sleep, and problems with early morning awakening, tiredness upon waking up, a short habitual sleep, frequent napping, and daytime sleepiness to future MI.

Taken together, these results indicate that a polysomnographic study in exhausted subjects is a valid approach to search for underlying mechanisms that link these subjective sleep characteristics to future MI. One final problem, however, is the fact that this high prevalence of sleep complaints and short sleep in exhausted subjects reflects the way these subjects perceive their habitual sleep. There is, however, ample evidence that subjects suffering from insomnia describe their habitual, but not their current, sleep as different from that of controls. This discrepancy in the perception of habitual and current sleep was the focus of the study that is presented in chapter 5 .

\section{Vital exhaustion and perception of sleep.}

In this study, the question was raised as to whether a discrepancy in the perception of habitual and current sleep is also characteristic for exhausted subjects. Two approaches were used. With the first approach, sleep problems during the prior three months were assessed using the SWEL. Habitual sleep durations, nocturnal wake times, and napping were assessed with items not included on the SWEL. Sleep quality for the prior three months was assessed using the Groningen Sleep Quality Questionnaire (GSQ; general version). The second approach consisted of the daily self-monitoring of these sleep characteristics for three weeks. Sleep quality, in this case, was assessed with the specific version of 
the GSQ, daytime sleepiness with the Stanford Sleepiness Scale, using the method of experience sampling. During the second week, subjects slept in a laboratory for four consecutive nights. Both approaches led to the conclusion that exhausted subjects perceive their habitual and their current quality of sleep as more disturbed than non-exhausted subjects. The results further suggested that exhausted subjects do not base their sleep quality entirely upon time spent asleep. This was deduced from the fact that the substantial reduction in time spent sleeping, that occurred while these subjects slept in the laboratory, did not result in a worsening of their sleep quality. They also do not appear to base their sleep quality entirely upon the number of minutes they were awake. The minutes awake early in the morning were essentially the same in both groups, and minutes awake during the sleep period even decreased in exhausted subjects. Minutes awake prior to sleep onset, however, were somewhat longer in exhausted subjects, suggesting that part of their poor sleep quality may be explained by their difficulty falling asleep. The fact that both habitual and current sleep are perceived as disturbed by exhausted subjects set the stage for a study, described in chapter 6, in which the sleep of exhausted subjects was polygraphically monitored.

\section{Sleep physiological characteristics of exhausted males.}

Our results indicate that sleep problems are frequently reported by exhausted subjects. Sleep problems have frequently been associated with a deficiency in slow wave sleep (SWS). In this study, therefore, we hypothesized that the sleep of exhausted subjects is also characterized by a relative absence of SWS. To test this hypothesis, all-night sleep recordings of exhausted and non-exhausted subjects were visually analyzed according to standard criteria. The sleep recordings were also analyzed by an automated sleep stage analyzing system. For the quantification of the essentially continuous aspect of SWS, an analysis of changes in frequencies of the sleep EEG, using spectral analysis, was also made. Although the results indicate that disturbed sleep is a major problem in exhausted subjects, their EEGderived number of minutes awake were not significantly different from those of non-exhausted subjects. This is further support for the notion that the duration of lying awake is not a major reason for exhausted subjects to complain about their sleep. It is quite interesting, therefore, that both visual and spectral analysis of sleep led to the conclusion that the sleep of exhausted subjects is characterized by a reduced SWS. Although the functional significance of this particular aspect of sleep is still unknown, it has been suggested that SWS reflects a recovery of the daily "wear and tear" that takes place during sleep. If this is a valid assumption, one might conclude that this recovery process is impaired in exhausted subjects. 
Daytime napping is the likely reason for the reduced SWS in exhausted subjects. First, daytime napping reduces SWS of the night that follows. Second, exhausted subjects frequently nap. It is, therefore, not unlikely that exhausted subjects are trapped in a vicious circle in which their excess fatigue, daytime napping, and a reduced SWS interact to maintain a state of vital exhaustion. Following this reasoning, one may conclude that any treatment aimed at relieving feelings of exhaustion (a stress management course, for instance), should also take into account daytime napping, as this may maintain the very state of vital exhaustion one is trying to eliminate.

\section{Concluding remarks}

The studies presented in this thesis leave unanswered the question of the relevance of a reduced SWS to cardiovascular control during sleep. It is well established, however, that heart rate (HR) and blood pressure (BP) of normal, healthy subjects decrease during the transition from wakefulness to sleep to reach their lowest levels during SWS. The REM stages of sleep do not induce any further decrease in HR and BP. The decrease in HR and BP during sleep has been found to occur both at night and during day sleep [1], but is absent under the condition of sleep deprivation [2]. This makes it unlikely that these sleep-related decreases in $\mathrm{HR}$ or BP are due to a circadian rhythm. One of the most noticeable effects of REM sleep on cardiovascular control is the increase in variability of HR and BP that clearly contrasts with their reduced variability throughout the NREM stages of sleep [1]. In one study in healthy subjects, however, the effects of sleep on HR variability (defined as the standard deviation of $H R$ ) and respiratory arrhythmia (identified as the peak in the HR power spectrum that corresponds to respiration rate) were found to depend upon the HR level prior to the onset of sleep [3]. For instance, HR variability and respiratory arrhythmia decreased during the transition from wakefulness to sleep in subjects with a slow HR during wakefulness (average $H R=52.2$ beats/min). However, HR variability and respiratory arrhythmia increased during this transition from wakefulness to sleep in subjects with a normal HR during wakefulness (average $H R=63.8$ beats $/ \mathrm{min}$ ). The same study also investigated the effects of blocking either the sympathetic (by propanolol) or parasympathetic (by atropine) input on HR during sleep. The results, derived from these two drug conditions, suggest that the progressive decrease in HR, as observed during the transition from wakefulness to SWS, is associated with an increased parasympathetic input. The increase in HR during the REM stage was thought to be due to a reduction in the parasympathetic input. The results further suggest that the sympathetic control of HR remains relatively constant throughout all sleep stages, 
except for a decrease in NREM stage 1. A study in cats on the effects of sleep on ventricular refractoriness indicated that the effective refractory period was significantly increased during sleep. This effect was independent of HR changes because HR was held constant. The effect was not influenced by bilateral stellectomy but was abolished after administration of atropine [4]. These findings support the notion that cardiac electrophysiological changes associated with sleep are mediated by fluctuations in vagal tone. It is quite interesting, therefore, that distinct HR patterns can be observed during the sleep of subjects suffering from coronary heart disease [5]. The first HR pattern (the "typical" pattern) was characterized by HR changes typical of those observed during the sleep of healthy subjects. The second pattern (the "paradoxical" pattern) was characterized by a decrease in HR during NREM stages 1 and 2 and by a paradoxical increase in HR during SWS. In this group, HR during REM sleep decreased with respect to HR observed during SWS. The final HR pattern (the "reduced" pattern) was characterized by a relatively constant HR throughout all sleep stages. Based upon a detailed analysis of HR, HR variability, and respiratory arrhythmia, it was concluded that the reduced and paradoxical HR patterns were primarily due to a decreased parasympathetic input during sleep. No attempt was made to relate these different HR patterns to possible differences in sleep physiological characteristics (i.e., differences in amounts of the various sleep stages). Nevertheless, the possible involvement of a reduced vagal tone in these deviant HR patterns is of interest because an increased vagal tone has been shown to reduce the probability of dangerous dysrhythmias [6].

Finally, in a review of the effects of sleep on cardiovascular disorders in humans, it was concluded that "SWS appears to result in a moderate antiarrhythmic effect in some subjects" [7]. This is likely to be due to the increased parasympathetic tone during this stage of sleep. Because a relative absence of SWS is likely to reflect a reduced parasympathetic tone, one might speculate that subjects suffering from vital exhaustion are more vulnerable to arrhythmias during sleep. It is also likely that the relative absence of SWS in these subjects is associated with a relative constancy of their HR during sleep. Preliminary support for this latter assumption comes from a study that indicated a constancy of HR during the transition from wakefulness to sleep in a subject suffering from disturbed sleep, increased irritability, and feelings of helplessness, quite similar to what we have termed a state of vital exhaustion [8].

There is reason to believe that a reduced SWS may result not only from daytime naps but also from increased physiological arousal during sleep [9]. The importance of this concept as the underlying mechanism for the association of 
disturbed sleep, vital exhaustion, and future MI can be deduced from the observation that arousal from sleep, either at night or in the morning, is highly associated with the occurrence of transient myocardial ischemia in patients suffering from coronary heart disease (CHD) [10]. In that study, evidence is reviewed that indicates that waking and rising in the morning is associated with increases in heart rate, blood pressure, platelet aggregation, and coronary artery tone, while fibrinolytic activity in the blood decreases. With respect to this latter finding, it should be noted that decreased fibrinolytic activity has been found to be one of the potential mechanisms that mediates the association between a state of vital exhaustion and MI [11]. What this evidence indicates, at least in patients suffering from CHD, is a possible imbalance in coronary blood supply and myocardial demand in the first 2-4 waking hours that could lower the threshold to ischemia [10]. Particularly germane in this context is that excess fatigue upon waking up (as part of a state of vital exhaustion) has been found to be a precursor of a first, non-fatal MI. Additional studies are required to determine whether this excess fatigue in the morning is associated with a relative absence of SWS, as might be deduced from the current thesis, or with a possible imbalance in coronary blood supply and myocardial demand in the first 2-4 waking hours. In any event, it is clear that sleep is associated with distinct patterns of autonomic nervous system activity [12] that produce characteristic changes in cardiovascular control in normal and CHD subjects. In addition, the empirical data from the current thesis indicate that the concept of vital exhaustion could well bring about important advances in our understanding of what underlying mechanisms link subjective sleep characteristics to future MI.

\section{REFERENCES}

1. Mancia G, Zanchetti A. Cardiovascular regulation during sleep. In Physiology in Sleep (Edited by Orem J, Barnes ChD), pp. 2-55. New York: Academic Press, 1980.

2. Ahnve S, Theorell T, Åkerstedt T, Fröberg JE, Hallberg F. Circadian variation in cardiovascular parameters during sleep deprivation. Eur J Appl Physiol 1981; 46: 919.

3. Zemaityte D, Varoneckas G, Sokolov E. Heart rhythm control during sleep. Psychophysiol 1984; 21: 279-289.

4. Francis GC, Hagestad EL, Verrier RL. Influence of sleep stage on ventricular refractoriness (abstract). Physiologist 1986; 29: 163. 
5. Zemaityte D, Varoneckas G, Sokolov E. Heart rhythm during sleep in ischemic heart disease. Psychophysiol 1984; 21: 290-298.

6. Yoon MS, Han J, Tse WW, Rogers R. Effects of vagal stimulation, atropine, and propanolol on fibrillation threshold of normal and ischemic ventricles. Am Heart $\mathbf{J}$ 1977; 93: 60-65.

7. Verrier RL. Behavioral state and cardiac arrhythmias. In Clinical physiology of sleep (Edited by Lydic R, Biebuyck JF), pp 31-51. Bethesda: American Physiological Society, 1988.

8. Siegrist J, Peter JH. Schlafstörungen und kardiovaskuläres Risiko. Med Klin 1986; 81: $429-432$.

9. Sewitch DE. Slow wave sleep deficiency insomnia: A problem in thermodownregulation at sleep onset. Psychophysiol 1987; 24: 200-215.

10. Barry JB, Campbell S, Yeung AC, Raby KE, Selwyn AP. Waking and rising at night as a trigger of myocardial ischemia. Am J Cardiol 1991; 67: 1067-1072.

11. Kop W, Hamulyak K, Appels A. Chronic psychological stress and vital exhaustion as related to coagulation and fibrinolysis (in prep).

12. Mancia G. Autonomic modulation of the cardiovascular system during sleep. N Engl J Med 1993; 328: 347-349. 
$-109-$ 
$-110-$ 


\section{Appendix I: The Sleep-Wake Experience List (SWEL) (Dutch version)}

De vragen die $U$ in deze lijst aantreft gaan over hoe $U$ de afgelopen drie maanden geslapen heeft en over hoe $U$ zich de afgelopen drie maanden overdag voelde.

Indien U onregelmatige werktijden heeft, wordt met 'overdag' bedoeld de tijd waarin U werkt of wakker bent en met 's nachts' de tijd waarin U slaapt.

01 Is het voor u een probleem om in slaap te vallen?

$\begin{array}{cccc}\begin{array}{c}\text { helemaal een nogal erg heel } \\ \text { niet beetje }\end{array} & \begin{array}{c}\text { erg } \\ \text { be }\end{array}\end{array}$

02 Is het voor u een probleem als $u$ 's nachts wakker wordt? ...... O

0

$0 \quad 0$

0

03 Als u 's nachts wakker word, is het dan een probleem

weer in slaap te vallen?

$\mathrm{O}$

O

o

O

o

04 Heeft u problemen met 's ochtends

te vroeg wakker worden?

o

o

o $\quad 0$

$\mathrm{O}$

05 Heeft u problemen met 's ochtends

moeilijk wakker worden en opstaan?

o

o

O

o

06 Heeft u last van vermoeidheid bij het opstaan,

ook al heeft u voldoende geslapen?

o

0

o

o

07 Als u wilde gaan slapen, viel u dan snel in slaap?

nooit

zelden

soms

vaak altijd

08 Kon u meestal weer snel inslapen als

u uit uw slaap wakker was geworden?

o

o

$\mathrm{O}$

o

o

09 Hoe vaak werd u vroeger wakker dan u wenselijk vond?

$\mathrm{O}$

o

0

0

0

10 Indien u te vroeg wakker werd,

kon $u$ dan weer gemakkelijk inslapen?

$\mathrm{O}$

O

$\mathrm{O}$

0

0

11 Hoe vaak merkte u dat u erg

moeilijk wakker kon worden?

o

o

0

0

12 Hoe vaak voelde u zich te moe on op te staan?

o

0

o

0

13 Viel u overdag regelmatig in slaap

zonder dat $u$ dat wilde?

o

o

o

0

o

14 Hoe vaak had u tijdens uw dagelijkse

bezigheden last van slaperigheid?

o

o

0

O

o

15 Hoe vaak had u tijdens uw dagelijkse

bezigheden moeite om wakker te blijven?

o

0

O

$\mathrm{O}$

o 


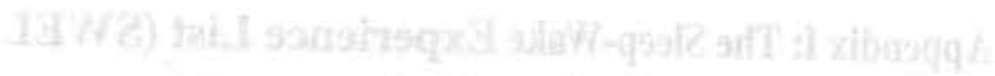

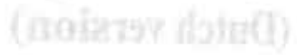

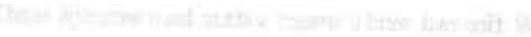

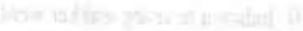

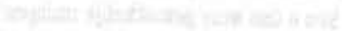

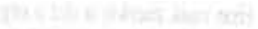

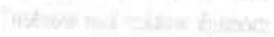

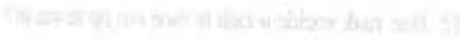

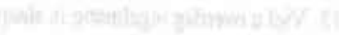

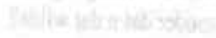

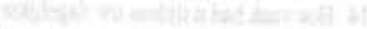

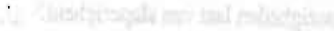

The

$-112-$ 


\section{Appendix II: Maastricht Questionnaire (MQ) (Dutch version)}

Wilt $\mathrm{U}$ bij elke vraag met een cirkeltje aangeven welk antwoord op $\mathrm{U}$ van toepassing is.

01 Voelt U zich vaak moe?

$\begin{array}{ccc}\text { Ja } & ? & \text { Nee } \\ \text { Ja } & ? & \text { Nee } \\ \text { Ja } & ? & \text { Nee } \\ \text { Ja } & ? & \text { Nee }\end{array}$

05 Hebt $U$ het gevoel dat $U$ de laatste tijd weinig presteert?

Ja

Nee

O6 Hebt U het gevoel dat het allemaal wat teveel word?

Ja ? Nee

07 Hebt $U$ het gevoel dat $U$ in een impasse (in het slop) zit?

Ja ? Nee

08 Voelt U zich de laatste tijd lustelozer dan vroeger?

Ja ? Nee

$09 \mathrm{Ik}$ heb net zoveel plezier in het sexuele als vroeger

Ja ?

Nee

10 Hebt U de laatste tijd weleens een gevoel van hopeloosheid gehad?

Ja

Nee

11 Doet $U$ er nu langer over om een moeilijk probleem te begrijpen

dan een jaar geleden?

Ja

Nee

12 Is het zo dat allerlei kleine dingen U meer ergeren dan vroeger?

Ja ? Nee

13 Hebt $U$ de laatste tijd weleens het verlangen voelen opkomen het bijltje er bij neer te willen leggen?

$\begin{array}{ccc}\text { Ja } & ? & \text { Nee } \\ \mathrm{Ja} & ? & \text { Nee }\end{array}$

14 Ik voel mij prima

15 Hebt $U$ weleens het gevoel dat uw lichaam een batterij is

waarvan de kracht of het vermogen aan het opraken is?

$\begin{array}{ccc}\text { Ja } & ? & \text { Nee } \\ \text { Ja } & ? & \text { Nee } \\ \text { Ja } & ? & \text { Nee } \\ \text { Ja } & ? & \text { Nee } \\ \text { Ja } & ? & \text { Nee } \\ \text { Ja } & ? & \text { Nee } \\ \text { Ja } & ? & \text { Nee }\end{array}$

16 Zou U soms weleens dood willen zijn?

17 Hebt $U$ de laatste tijd het gevoel dat U niet meer zoveel waard bent als vroeger? ...

18 Voelt U zich moedeloos?

19 Hebt U weleens huilbuien?

20 Wordt $\mathrm{U}$ weleens wakker met een gevoel van uitputting en vermoeidheid?

21 Is het moeilijk voor $U$ geworden om $U$ lang op een ding te concentreren?

Nee 


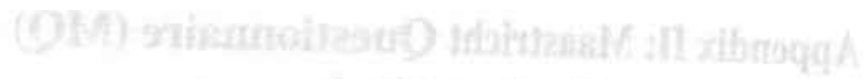

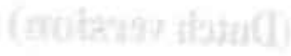




\section{Appendix III: Diary (Profile of Mood Scales (POMS)) (Stanford Sleepiness Scale (SSS))}

Hieronder vindt $U$ een lijst met woorden. Deze woorden beschrijven stemmingen of gevoelstoestanden. Kruis bij elk woord het antwoord aan, welke het best weergeeft HOE U ZICH VOELDE toen het horloge afging. Elk antwoord is goed, als het maar uw eigen stemming weergeeft. Sla geen woord over.

\begin{tabular}{|c|c|c|c|c|c|}
\hline & $\begin{array}{c}\text { helemaal } \\
\text { niet }\end{array}$ & $\begin{array}{l}\text { een } \\
\text { beetje }\end{array}$ & enigszins & nogal & $\begin{array}{r}\text { heel } \\
\text { erg }\end{array}$ \\
\hline Actief & 0 & 0 & 0 & 0 & 0 \\
\hline Aan het eind van mijn krachten & 0 & $\mathrm{O}$ & $\mathrm{O}$ & 0 & 0 \\
\hline Slaperig & $\mathrm{O}$ & $\mathrm{O}$ & 0 & 0 & $\mathrm{O}$ \\
\hline Eenzaam & 0 & $\mathrm{O}$ & 0 & 0 & 0 \\
\hline 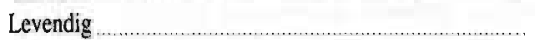 & 0 & o & $\mathrm{O}$ & 0 & 0 \\
\hline Vermoeid & $\mathrm{O}$ & $\mathrm{O}$ & $\mathrm{O}$ & $\mathrm{O}$ & 0 \\
\hline Lusteloos & $\mathrm{O}$ & 0 & 0 & $\mathrm{O}$ & D \\
\hline Volledig wakker.. & $\mathrm{O}$ & 0 & 0 & 0 & 0 \\
\hline Neerslachtig........ & $\mathrm{O}$ & 0 & 0 & 0 & $\mathrm{O}$ \\
\hline Vol energie & 0 & 0 & 0 & 0 & 0 \\
\hline Droevig & $\mathrm{O}$ & 0 & 0 & $\mathrm{O}$ & 0 \\
\hline Wanhopig & $\mathrm{O}$ & 0 & $\mathrm{O}$ & 0 & 0 \\
\hline Zo, dat $U$ bijna in slaap valt & $\mathrm{O}$ & $\mathrm{O}$ & 0 & 0 & 0 \\
\hline Ongelukkig & $\mathrm{O}$ & 0 & 0 & 0 & 0 \\
\hline Helder & 0 & 0 & $\mathrm{O}$ & 0 & 0 \\
\hline Hulpeloos & 0 & 0 & 0 & 0 & 0 \\
\hline Opgeruind. & $\mathrm{O}$ & $\mathrm{O}$ & 0 & 0 & 0 \\
\hline Onwaardig.. & 0 & $\mathrm{O}$ & 0 & 0 & 0 \\
\hline Doodop .......... & 0 & $\mathrm{O}$ & 0 & 0 & $\mathrm{O}$ \\
\hline Droefgeestig... & $\mathrm{O}$ & 0 & 0 & 0 & 0 \\
\hline Afgemat & 0 & 0 & 0 & 0 & 0 \\
\hline Duf & $\mathrm{O}$ & $\mathrm{O}$ & 0 & 0 & 0 \\
\hline Uitgeput & 0 & 0 & 0 & 0 & $\mathrm{O}$ \\
\hline
\end{tabular}




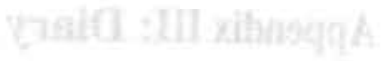

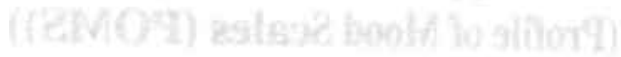

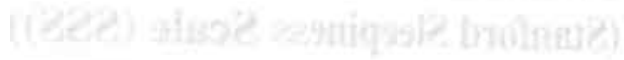

$-116-$ 


\section{Appendix IV: Groningen Sleep Quality Scale (GSQ) (General version: Dutch)}

Hieronder volgen 14 uitspraken over hoe $\mathrm{U}$ uw slaap de afgelopen drie maanden gevonden hebt. Als $\mathrm{U}$ het met een uisspraak EENS bent, dan zet $U$ achter deze uitspraak een kruisje onder de kolom EENS. Als $U$ het met een uitspraak ONEENS bent zet U achter deze uitspraak een kruisje onder de kolom ONEENS. U wordt verzocht geen enkele uitspraak over te slaan.

\begin{tabular}{|c|c|c|}
\hline & EENS & ONEENS \\
\hline Ilk heb 's ochtends, nadat ik ben opgestaan, vaal & 0 & 0 \\
\hline Ik slaap meestal gemakkelijk in .................. & 0 & o \\
\hline Ik vind dat ik meestal heel slecht slaap .... & 0 & o \\
\hline Ik doe vaak's nachts geen oog dicht & 0 & 0 \\
\hline 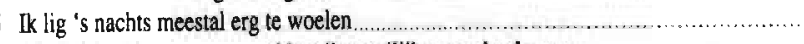 & 0 & 0 \\
\hline Als ik 's nachts wakker word kan ik moeilijk weer inslapen ....... & $\mathrm{o}$ & 0 \\
\hline Ik slaap naar mijn gevoel vaak maar een paar uur. & 0 & 0 \\
\hline Ik lig vaak langer dan een half uur in bed voordat ik inslaap & 0 & o \\
\hline Ik kom naar mijn gevoel meestal slaap tekort & $\mathrm{O}$ & 0 \\
\hline Ik word 's nachts vaak meerdere malen wakker & $\mathrm{O}$ & 0 \\
\hline Ik vind dat ik 's nachts meestal goed slaap............ & $\mathrm{O}$ & 0 \\
\hline Ik sta 's nachts vaak op & 0 & 0 \\
\hline Ik voel mij 's ochtend, nadat ik ben opgestaan, meestal goed uitgerust & 0 & 0 \\
\hline Ik slaap niet langer dan vijf uur & 0 & 0 \\
\hline
\end{tabular}




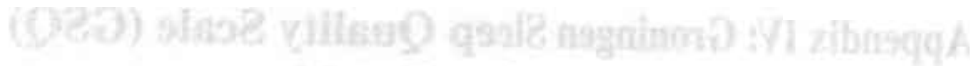 (flotud : aroicior fanns?)}

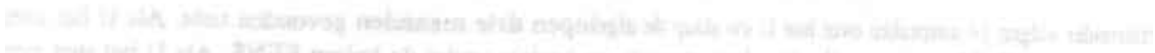

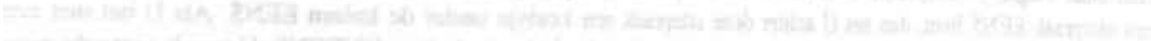

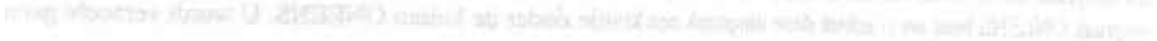

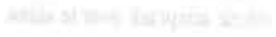

27x




\section{Appendix V: Groningen Sleep Quality Scale (GSQ) (Specific version: Dutch)}

Wilt U deze vragen telkens 's ochtends NA HET OPSTAAN invullen.

Hieronder volgen 14 uitspraken over hoe $U$ uw slaap de afgelopen nacht gevonden hebt. Als $U$ het met een uitspraak EENS bent, dan zet $U$ achter deze uitspraak een kruisje onder de kolom EENS. Als $U$ het met een uitspraak ONEENS bent zet $U$ achter deze uitspraak een kruisje onder de kolom ONEENS. $U$ wordt verzocht geen enkele uitspraak over te slaan.

\begin{tabular}{|c|c|}
\hline & 0 \\
\hline g gisteravond langer dan een half uur wakker voordat ik insliep... & o \\
\hline Ik ben vannacht meerdere malen wakker geworden & $\mathrm{o}$ \\
\hline Ik had vanochtend, nadat ik was opgestaan, een moe gevoel ... & 0 \\
\hline Ik ben vannacht naar mijn gevoel slaap tekort gekomen .......... & 0 \\
\hline Ik ben vannacht opgestaan & 0 \\
\hline Ik voelde me vanochtend, nadat ik was opgestaan, goed uitgerust & $\mathrm{O}$ \\
\hline Ik heb naar mijn gevoel vannacht maar een paar uur geslapen & 0 \\
\hline Ik vind dat ik vannacht goed geslapen heb & 0 \\
\hline Ik heb vannacht geen oog dicht gedaan ......... & 0 \\
\hline Ik sliep gisteravond gemakkelijk in ......... & 0 \\
\hline Ik had vannacht, nadat ik wakker geworden was, moeite weer in slaap te vallen *... & 0 \\
\hline lag vannacht erg te woelen & 0 \\
\hline sliep vannacht niet langer dan & $\mathrm{O}$ \\
\hline
\end{tabular}

* Als U vannacht niet wakker geworden bent, dient $U$ deze vraag met ONEENS te beantwoorden 


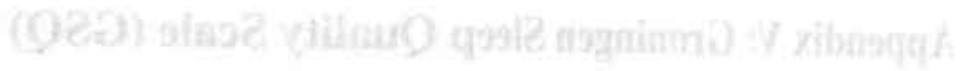

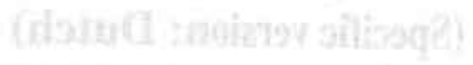

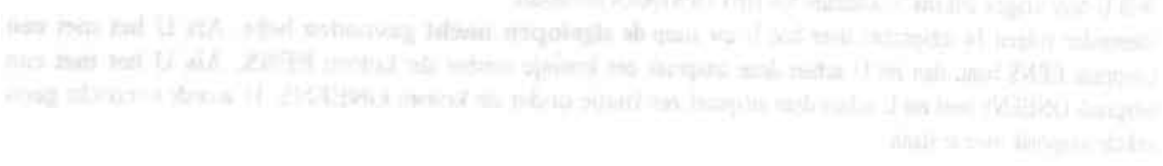

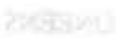

$-120$ 


\section{Appendix VI: Diary (Sleep \& Wake times)}

Wilt U deze vragen telkens 's ochtends NA HET OPSTAAN invullen.

01 Hoe laat bent $U$ gisteravond naar bed gegaan?

02 Hoe lang lag U nog wakker voor $U$ insliep?

03 Kunt $U$ aangeven wanneer $U$ vannacht wakker bent geweest?

O Niet wakker geweest (aankruisen indien van toepassing)

Wakker geweest van

tot

Wakker geweest van

tot

Wakker geweest van

tot

Wakker geweest van

tot

04 Hoe laat bent $U$ vanochtend opgestaan?

05 Hoe lang lag U wakker voordat U opstond?

06 Kunt $\mathrm{U}$ aangeven wanneer $\mathrm{U}$ gisteren overdag geslapen heeft?

O Niet geslapen (aankruisen indien van toepassing)

Geslapen van

tot

Geslapen van

tot 


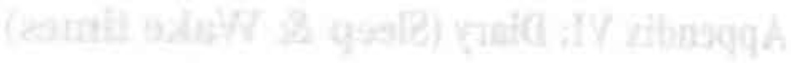

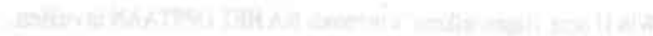

$-122-$ 


\section{Appendix VII: Health Questionnaire}

01 Bent $U$ de afgelopen 12 maanden onder behandeling van een huisarts geweest?

Ja Nee

Zo ja, kunt U toelichten waarvoor?

02 Bent $U$ de afgelopen 12 maanden onder behandeling van een medisch specialist geweest?

Ja Nee

Zo ja, kunt U toelichten waarvoor?

03 Bent $\mathrm{U}$ de afgelopen 12 maanden één of meerdere keren in een ziekenhuis opgenomen geweest in verband met een operatie?

Zo ja, kunt U toelichten waarvoor?

04 Bent U de afgelopen 12 maanden één of meerdere keren in een ziekenhuis opgenomen

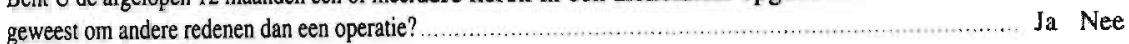

Zo ja, kunt U toelichten waarvoor?..

05 Stond U de afgelopen 12 maanden onder controle van een consultatiebureau?

Zo ja, kunt U toelichten waarvoor?

06 Bent $U$ de afgelopen 12 maanden onder behandeling van een psychiater of psycholoog geweest? Ja Nee

Zo ja, kunt U toelichten waarvoor?

07 Heeft $U$ de afgelopen 12 maanden lichamelijke en/of psychische klachten gehad waarvoor U geen behandeling hebt gezocht bij een huisarts, een medisch specialist (waaronder psychiater)

of een psycholoog?

Zo ja, kunt U toelichten waarvoor?

08 Heeft $\mathrm{U}$ de afgelopen drie maanden weleens pijn of een onaangenaam, drukkend, zwaar gevoel in de borst gehad?

09 Heeft $U$ de afgelopen drie maanden weleens aanvallen van beklemmende pijn in de borst gehad? .... Ja Nee (Indien vragen 8 of 9 met NEE zijn beantwoord, door naar vraag 13)

10 Kreeg $U$ deze pijn of druk in rust (bv als $U$ zit of in bed ligt)?

11 Kreeg U deze pijn als U in uw eigen tempo liep?

12 Kreeg $U$ deze pijn als $U$ zich moest inspannen (traplopen, $U$ voorthaasten, tegen de wind fietsen)

13 Heeft $U$ de afgelopen drie maanden last gehad van kortademigheid? (Indien vraag 13 met NEE is beantwoord, door naar vraag 17)

14 Kreeg $U$ deze kortademigheid in rust (bv als $U$ zit of in bed ligt)?

15 Kreeg $U$ deze kortademigheid als $U$ in uw eigen tempo liep?

16 Kreeg $U$ deze kortademigheid als $U$ zich moest inspannen (traplopen, U voorthaasten)?

Ja Nee

Ja Nee

Ja Nee

17 Heeft U de afgelopen drie maanden last gehad van hartkloppingen? .......................................... Ja Nee

18 Heeft $U$ de afgelopen drie maanden last gehad van een onregelmatige hartslag? ............................ Ja Nee

19 Heeft $U$ de afgelopen drie maanden last gehad van pijn in de benen als $U$ een eindje liep? ............. Ja Nee

20 Laat naar uw gevoel uw gezondheid op dit moment te wensen over? ............................................ Ja Nee Zo ja, in welk opzicht?

21 Gebruikt U medicijnen?

Zo ja, kunt $U$ aangeven welke?

22 Rookt U?

Ja Nee (Indien vraag 22 met NEE is beantwoord, door naar vraag 25)

23 Kunt $U$ aangeven wat $U$ rookt?

shag; vaste sigaretten; sigaren/cigarillos; pijptabak

24 Kunt $U$ aangeven hoeveel $U$ de afgelopen drie maanden per dag rookte?

sigaretten

sigaren pijpen

25 Sloeg $U$ zo nu en dan maaltijden over als $U$ alcohol aan het drinken was

26 Bent $U$ weleens wakker geworden, de dag nadat $U$ alcohol gedronken had, en wist $U$ toen niet meer wat $\mathrm{U}$ tijdens het drinken gedaan had?.

Ja Nee

27 Als U eenmal begonnen was te drinken, was het dan moeilijk voor $\mathrm{U}$ te stoppen?....

Ja Nee

28 Begon U 's ochtends al te drinken, meteen nadat U opgestaan was?

Ja Nec

29 Had U de ochtend, nadat U gedronken had, trillende handen?

Ja Nee

30 Ging U soms door met drinken, terwijl U uzelf beloofd had dit niet te doen? 


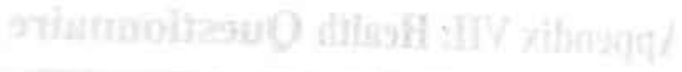

$-124$ 


\section{Appendix VIII: Visual analysis of sleep}

Sleep recordings were obtained from standard leads with a Beckman eight-channel electroencephalograph.

Standard leads include:

- left and right electro-oculogram (EOG),

- Electroencephalogram (EEG) (C3/A2; C4/A1)

- Submental electromyogram (EMG).

- Electrode impedances less than 5,000 ohms.

- Calibration $50 \mu \mathrm{V}$ equals $8 \mathrm{~mm}$ pen deflection.

- Time Constant 〈EOG and EEG〉 $0.3 \mathrm{sec}(0.5 \mathrm{~Hz})(-3 \mathrm{~dB})$.

- High Frequency <paper recording> $\quad(35.0 \mathrm{~Hz})(-3 \mathrm{~dB})$.

- BCD time code recorded on paper.

- Paper speed was $10 \mathrm{~mm} / \mathrm{sec}$.

- EEG's, EOG's and BCD time code tape were also recorded on an instrumentation recorder (RACAL 14DS) for automated analysis.

Sleep recordings were visually analyzed in successive 30-sec epochs according to Rechtschaffen and Kales to arrive at the following sleep parameters:

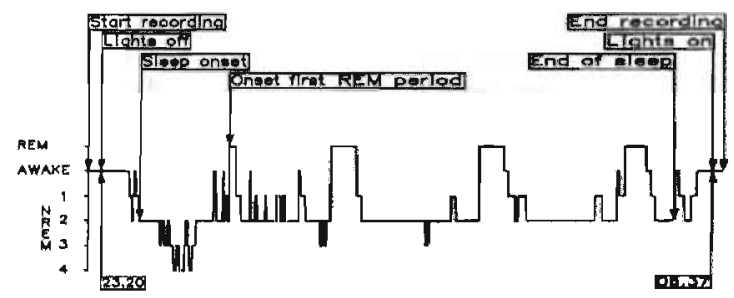

Sleep onset was defined as the first epoch of NREM stages 2-4 or REM followed by at least ten minutes of sleep interrupted by no more than two minutes of NREM stage 1, wakefulness or movement time

End of sleep onset was defined as the last epoch of NREM stages 2-4 or REM preceded by at least ten minutes of sleep interrupted by no more than two minutes of NREM stage 1, wakefulness or movement time

The first REM period had to last at least three minutes

- Sleep latency

- Time awake

- Eearly morning awake

- Sleep stages

- REM latency
Time between 'lights off' and sleep onset.

Time awake between onset and end of sleep.

Time between end of sleep and 'lights on'.

Time spent in each sleepstage between onset and end of sleep.

Time between sleep onset and the onset of the first REM period. 


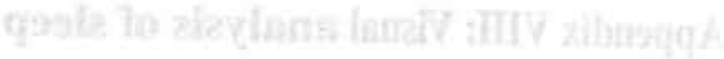

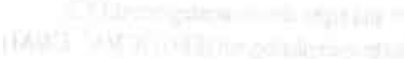

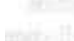

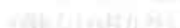

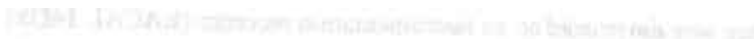




\section{Appendix IX: Spectral analysis of sleep}

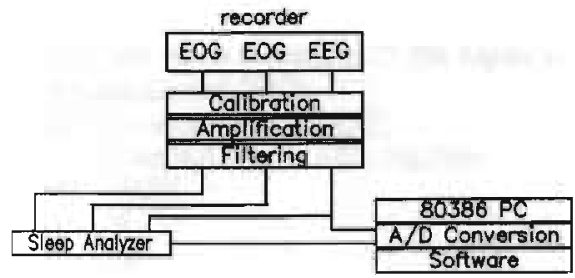

Sampling of digital output from SLEEPANALYZER

- Calibration EOGs

- Calibration EEG

- Filtering

- Sample frequency

Sampling of analog EEG for FFT

- EEG (visual check)

- Filtering

Input range $\mathrm{ADC}$

Sample frequency

\section{$: 50$ microVolt \\ 50 microVolt \\ : TC $<$ EOG/EEG $>$ \\ $\mathrm{HF}$ \\ $: 8$ samples/sec}

$: 50$ microVolt

: TC $<$ EEG >

$\mathrm{HF}$

$:-2.51+2.5$ Volt bipolar

: 64 samples/sec
$=500$ millivolt.

$=1500$ milliVolt.

$=0.3 \mathrm{~s}(0.5 \mathrm{~Hz})(3 \mathrm{~dB})$.

$=(35.0 \mathrm{~Hz})(3 \mathrm{~dB})$.

$=1000$ milliVolt.

$=0.3 \mathrm{~s}(0.5 \mathrm{~Hz})(3 \mathrm{~dB})$.

$=(35.0 \mathrm{~Hz})(24 \mathrm{~dB})$.

- FFT is performed over consecutive series of 256 datapoints (256 datapoints equal $4 \mathrm{sec}$ EEG).

- Given $4 \mathrm{sec}$ duration, the lowest frequency is $0,25 \mathrm{~Hz}$.

- Given 64 samples/sec, the highest frequency is $32.00 \mathrm{~Hz}$.

This allows computation of Fourier coefficients $\mathrm{A}$ and $\mathrm{B}$ for the following frequencies.

\begin{tabular}{|c|c|c|c|c|}
\hline $\mathrm{Hz}$ & FFT & cont & & \\
\hline & A B & $10 \mathrm{~m}$ & power & \\
\hline 00.00 mean & $\mathrm{R}=\mathrm{A}$ & $\mathbf{R}^{2}$ & & exclude \\
\hline 00.251 st harmonic & $R=2 \sqrt{ }\left(A^{2}+B^{2}\right)$ & $2 \mathrm{R}^{2}$ & & exclude \\
\hline 00.50 2nd harmonic & $R=2 \sqrt{ }\left(A^{2}+B^{2}\right)$ & $2 \mathrm{R}^{2}$ & & store \\
\hline $00.75 \mathrm{etc}$ & $R=2 \sqrt{ }\left(A^{2}+B^{2}\right)$ & $2 \mathrm{R}^{2}$ & & add and \\
\hline 01.00 & $R=2 \sqrt{ }\left(A^{2}+B^{2}\right)$ & $2 \mathrm{R}^{2}$ & - & store \\
\hline 01.25 & & $2 \mathrm{R}^{2}$ & — & add \\
\hline 01.50 & & $2 R^{2}$ & $\ldots$ & and \\
\hline 01.75 & & $2 \mathbf{R}^{2}$ & $\ldots$ & store \\
\hline 02.00 & & $2 \mathbf{R}^{2}$ & $\longrightarrow$ & \\
\hline 15.25 & & $2 R^{2}$ & - & add \\
\hline 15.50 & & $2 R^{2}$ & + & and \\
\hline 15.75 & & $2 R^{2}$ & $\longrightarrow$ & store \\
\hline 16.00 & End & $2 \mathbf{R}^{2}$ & $\longrightarrow$ & exclude \\
\hline
\end{tabular}

This yields a file with a $1-\mathrm{Hz}$ resolution (Lights off for example at $23.20 \mathrm{~h}$; Lights on for example $06.37 \mathrm{~h}$ ).

$\mathrm{Hz}$

$\begin{array}{llllll} & 0.5 & (0.75-1.00) & (1.25-2.00) & . . & (15.25-16.00) \\ 23.2001(1 \mathrm{st} 4 \mathrm{sec}) & 2 \mathrm{R}^{2} & 4 \mathrm{R}^{2} & 8 \mathbf{R}^{2} & & 8 \mathrm{R}^{2} \\ 23.2002(2 \mathrm{nd} 4 \mathrm{sec}) & 2 \mathrm{R}^{2} & 4 \mathrm{R}^{2} & 8 \mathrm{R}^{2} & 8 \mathrm{R}^{2} \\ .06 .3615(15 \mathrm{th} 4 \mathrm{sec}) & 2 \mathrm{R}^{2} & 4 \mathrm{R}^{2} & 8 \mathbf{R}^{2} & & 8 \mathrm{R}^{2}\end{array}$




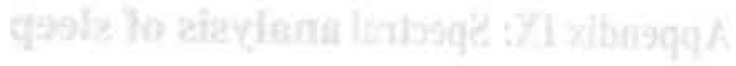

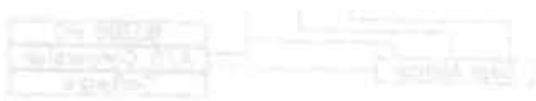

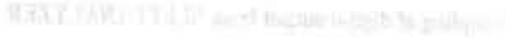




\section{Spectral analysis (continued)}

The analyzer yields the following output (Lights off for example at 23.20h; Lights on for example 06.37h).

Moss probable stage decided (STG)

\section{Time in 0.1 sec of artefacts (ART)}

\section{Time in 0.1 sec of alpha (ALPH)}

HrMin Epoch STG ART ALPH

23:20 $\quad 1 \quad 0 \quad 000$

$\begin{array}{llll}23: 20 & 2 & 0 & 7\end{array}$

06:36 $\quad 2 \quad 0 \quad 5 \quad 14$

Visual analysis yields the following output (Lights off for example at $23.20 \mathrm{~h}$; Lights on for example $06.37 \mathrm{~h}$ ). HrMin Epoch STG

23:20 $\quad 1 \quad 0$

$23: 20 \quad 2 \quad 0$

$06: 36 \quad 2 \quad 0$

Program flow for analysis of one night

\begin{tabular}{|c|c|c|}
\hline $\begin{array}{l}\text { FFT } \\
\text { content }\end{array}$ & $\begin{array}{l}\text { Visual analysis } \\
\text { content }\end{array}$ & $\begin{array}{l}\text { Sleep Analyzer } \\
\text { content }\end{array}$ \\
\hline Time code & Time code & Time code \\
\hline $\begin{array}{l}\text { Powers } .50 \mathrm{t} / \mathrm{m} 29.75 \mathrm{~Hz} \text {. } \\
\text { Artefact/Alpha } \\
\text { per } 04 \mathrm{sec}\end{array}$ & $\begin{array}{l}\text { Sleepstages } \\
\text { per } 30 \mathrm{sec}\end{array}$ & $\begin{array}{l}\text { Sleepstages } \\
\text { per } 30 \text { sec }\end{array}$ \\
\hline Aggregate to $30 \mathrm{sec}$ & $\begin{array}{l}\text { Combine on time code } \\
\text { Visual correction of } \\
\text { analyzer stages }\end{array}$ & \\
\hline
\end{tabular}

Match the three files on time code

Select between 'onset of sleep' and 'end of sleep'

Select NREM stages 234

Select artifact free epochs

Make total epochs equal to minimum NREM sleep across subjects.

Repeat for second and third night

For each subject, aggregate three nights into mean power for each frequency

$(0.75-1.00)(1.25-2.00)$ etc

For each subject, condense mean power into combined frequency band of

Delta $0.75-4 \mathrm{~Hz}$

Theta $4.25-8 \mathrm{~Hz}$

Alpha $8.25 \cdot 12 \mathrm{~Hz}$

Sigma $12.25-16 \mathrm{~Hz}$

Apply MANOVA to these absolute power values 


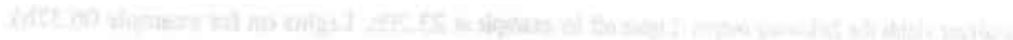

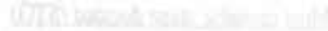

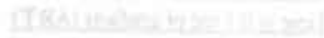

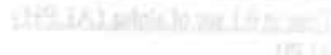

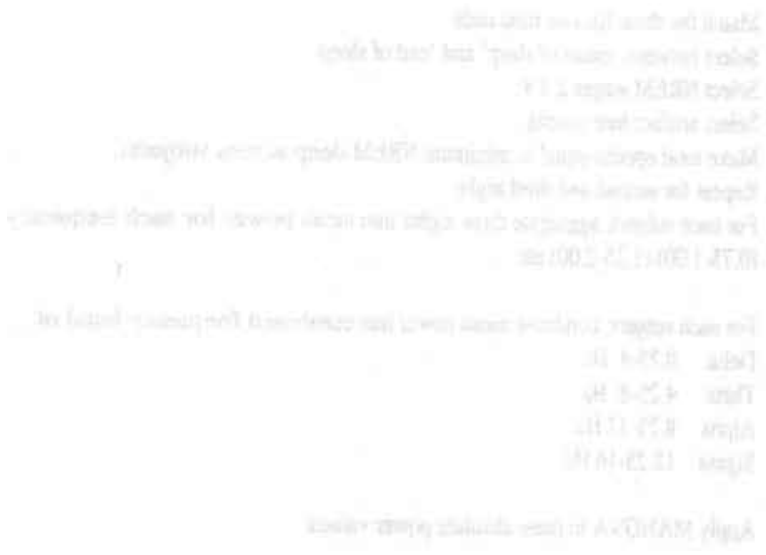

$-130$ 


\section{DANKWOORD}

Het zal niet voor veel promovendi zijn weggelegd dat zij kunnen aantonen dat het maken van hun proefschrift tot slapeloze nachten aanleiding heeft gegeven. Tussen het opzetten van dit onderzoek en het schrijven van dit dankwoord liggen er in ieder geval 68, die de auteur al wakende heeft doorgebracht met al die Maastrichtse mannen die bereid waren huis en haard te verlaten om, geheel belangeloos, hun kostbare nachtelijke uren te spenderen op het voormalige Gedragslaboratorium van het Biomedisch Centrum. Mijn dank gaat dan ook in de eerste plaats naar hen uit, want zonder hun medewerking was dit proefschrift niet tot stand gekomen. Meerdere mensen hebben daarnaast een bijdrage geleverd aan het tot stand komen van één of meerdere hoofdstukken van dit proefschrift. Enkele daarvan wil ik in het bijzonder noemen.

Yolande de Vos, Rida Markusse, Hans Stauder, Jan Snel en Henk Milius zijn de collega's geweest die betrokken waren bij het ontwikkelen van de in het tweede hoofdstuk beschreven slaapklachten vragenlijst. Zonder hun inzet zou deze vragenlijst niet die vorm hebben gekregen die uiteindelijk bereikt is. Jan Snel wil ik verder nog bedanken voor de creatieve naamgeving van deze vragenlijst en Henk Milius voor het feit dat hij, gezeten voor de video, de slaapproblematiek van de Maastrichtse mannen heeft willen beoordelen. Jolanda Koch wil ik bedanken voor de vele uren die zij, samen met mij, achter de computer terminal heeft doorgebracht voor het invoeren en nakijken van de gegevens welke de basis vormden voor het derde hoofdstuk. Henk Milius heeft ook een bijzondere rol gespeeld bij het tot stand komen van het vierde hoofdstuk. Ondanks zijn toen al overbezette agenda wist hij toch tijd vrij te maken om zijn psychiatrische expertise in te zetten bij het verzamelen van de gegevens voor dit hoofdstuk. Daarnaast heeft hij een onmiskenbare rol gespeeld in mijn nadenken over de overeenkomsten en verschillen tussen vitale uitputting en depressie. Ook Rutger Lulofs wil ik hier bedanken voor zijn bijdrage in de selectie van de Maastrichtse mannen op basis waarvan het vierde tot en met het zesde hoofdstuk tot stand zijn gekomen. Annie Ledoux ben ik erkentelijk voor het invoeren en nakijken van de vele "Experience Sampling" gegevens die de basis vormden voor het vierde en vijfde hoofdstuk. Anand Kumar, Winni Hofman en Jan Janssen zijjn door de jaren heen mijn Amsterdamse vrienden geweest met wie $i k$ heb mogen discussiëren over de verschillende facetten van geautomatiseerde slaapstadia analyse. Hun kritische benadering van deze materie en grondige signaalanalytische kennis die bij een dergelijke benadering onontbeerlijk is hebben mij zeer geholpen bij het slaapfysiologische deel van dit proefschrift. Ook Domien Beersma, die bij de Groningse slaapgroep de basis heeft gelegd voor de spectraalanalytische 
benadering van slaapfysiologisch onderzoek, ben ik zeer erkentelijk voor zijn hulp bij de implementatie van deze techniek ten behoeve van dit proefschrift. Op deze plaats past ook een uitdrukkelijk woord van dank aan mijn Maastrichtse collega en vriend Lex van Bemmel. Met hem heb ik niet alleen vele discussies mogen voeren over het brede terrein van slaapfysiologisch onderzoek, maar ook over de aloude 'Amsterdam-Rotterdam' controverse. De gegevensverwerking voor het zesde hoofdstuk is voor een belangrijk deel mogelijk geworden door zijn inzet te komen tot een 'slaap laboratorium' in het PMS Vijverdal. Een woord van dank gaat ook uit naar Paul Falger, Cor Meesters, Ferdy Otten, Hans Bosma en Wijo Kop die op de maandelijkse vergadering van divisie VIII bereid waren kritisch naar mij te luisteren en me te stimuleren om een nieuw onderdeel van dit proefschrift tot een afronding te brengen. Erik Schouten heb ik met opzet daar niet genoemd want hem wil ik apart bedanken voor het nauwgezet doornemen van alle door mij gehanteerde statistiek in de diverse hoofdstukken. Pamela Falger en Alan Ralston ben ik erkentelijk voor de vele suggesties en verbeteringen met betrekking tot mijn Engelse taalgebruik.

Mijn wetenschappelijke belangstelling voor slaaponderzoek heb ik te danken aan Piet Visser, emeritus hoogleraar van de Universiteit van Amsterdam. Beste Piet, vooral in de beginfase van dit onderzoek ben je, meer dan je waarschijnlijk beseft, voor mij een steun en mijn toeverlaat geweest. Daarvoor nogmaals mijn uitdrukkelijke dank.

Hooggeleerde Appels, beste Ad, onze goede samenwerking moge blijken uit het feit dat we ons beider naam hebben verbonden aan een aantal artikelen die uit dit proefschrift naar voren zijn gekomen. Vooral jij hebt mij er steeds op gewezen om hoofdzaken en bijzaken van elkaar gescheiden te houden. Het feit dat aan elk van deze artikelen meerdere versies zijn voorafgegaan geeft wel aan dat dit voor mij geen eenvoudige opgave is geweest.

Hooggeleerde Richartz, beste Mark, door de jaren heen ben je er van overtuigd gebleven dat het "psychosomatisch georiënteerde" onderzoek, waar ik mee bezig ben, ook voor de Psychiatrie van belang is. Daar ben ik je dankbaar voor, want het is vanuit deze overtuiging dat je mij altijd de mogelijkheden hebt gegeven om, als medewerker van de vakgroep Klinische Psychiatrie, met dit onderzoek te kunnen blijven doorgaan.

Mijn persoonlijk leven is gedurende deze periode ook veranderd. Nog in het begin van dit onderzoek is mijn vader overleden, het verlies van zijn vrouw enkele jaren voor zijn eigen overlijden had hem het plezier in leven ontnomen.

Mijn deelname aan de divisie "Psychosociale factoren van hart-vaatziekten" heeft verder niet alleen geleid tot de afronding van dit proefschrift, ik heb daar ook de vrouw leren kennen met wie ik nu getrouwd ben. 
Anneke, het feit dat we elkaar altijd weer weten te vinden op de vele terreinen van gemeenschappelijke interesses heeft er toe geleid dat ik, als ik weer eens 'vast' zat, door jouw steun en begrip wist door te gaan. 
$-134-$ 


\section{CURRICULUM VITAE}

De auteur van dit proefschrift is 1 januari 1951 te Haarlem geboren. In 1967 behaalde hij het eindexamen MULO-B en in 1969 het eindexamen HBS-B. Van 1969 tot 1980 studeerde hij Psychologie aan de Gemeente Universiteit van Amsterdam (hoofdrichting Psychofysiologie). Gedurende de laatste vijf jaar van zijn studie is de auteur van dit proefschrift werkzaam geweest als kandidaatsassistent/wetenschappelijk medewerker bij de (toenmalige) vakgroep Psychofysiologie. Van maart 1981 tot mei 1982 is hij verbonden geweest aan de vakgroep Medische Psychologie van de Rijksuniversiteit Limburg. Van mei 1982 tot heden is de auteur als universitair docent bij deze universiteit verbonden aan de vakgroep Klinische Psychiatrie.

Het onderzoek, waarover in dit proefschrift verslag wordt gedaan, werd uitgevoerd binnen divisie VIII "Psychosociale factoren van hart-vaatziekten" (leider; Prof. Dr. A.P.W.M. Appels) van de onderzoeksschool CARIM (Cardiovascular Research Institute Maastricht). 
ISBN nr 90-9006293-9 